\title{
Discovery of thieno[2,3-d]pyrimidine based hydroxamic acid derivatives as bromodomain-containing protein 4/histone deacetylases dual inhibitors induce autophagic cell death in colorectal carcinoma cells
}

Zhaoping Pan,†† Xiang Li, †† Yujia Wang, $†$ Qinglin Jiang,\#* Li Jiang, \# Min Zhang, \# Nan Zhang, $\dagger$ Fengbo Wu, $\uparrow$ Bo Liu, $\dagger^{*}$ and Gu He $\dagger^{*}$

$\uparrow$ State Key Laboratory of Biotherapy and Department of Urology, West China Hospital, Sichuan University and Collaborative Innovation Center of Biotherapy, Chengdu, Sichuan 610041, PR China

\# School of Pharmacy and Sichuan Province College Key Laboratory of Structure-Specific Small Molecule Drugs, Chengdu Medical College, Chengdu 610500, PR China

† These authors contributed equally to this work. 


\section{Table of contents}

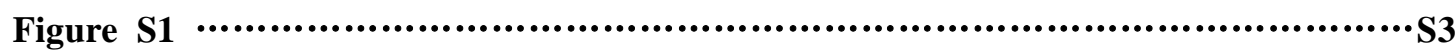

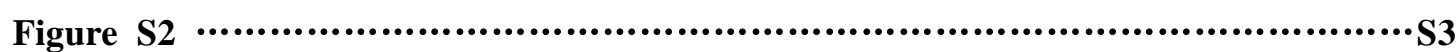

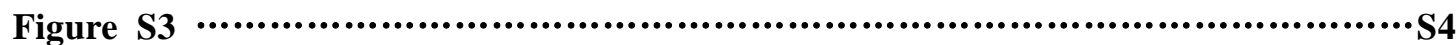

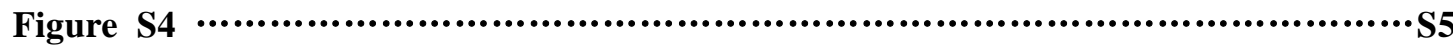

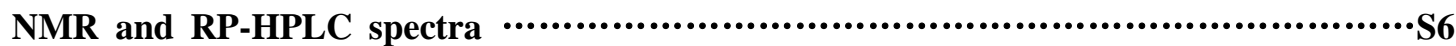



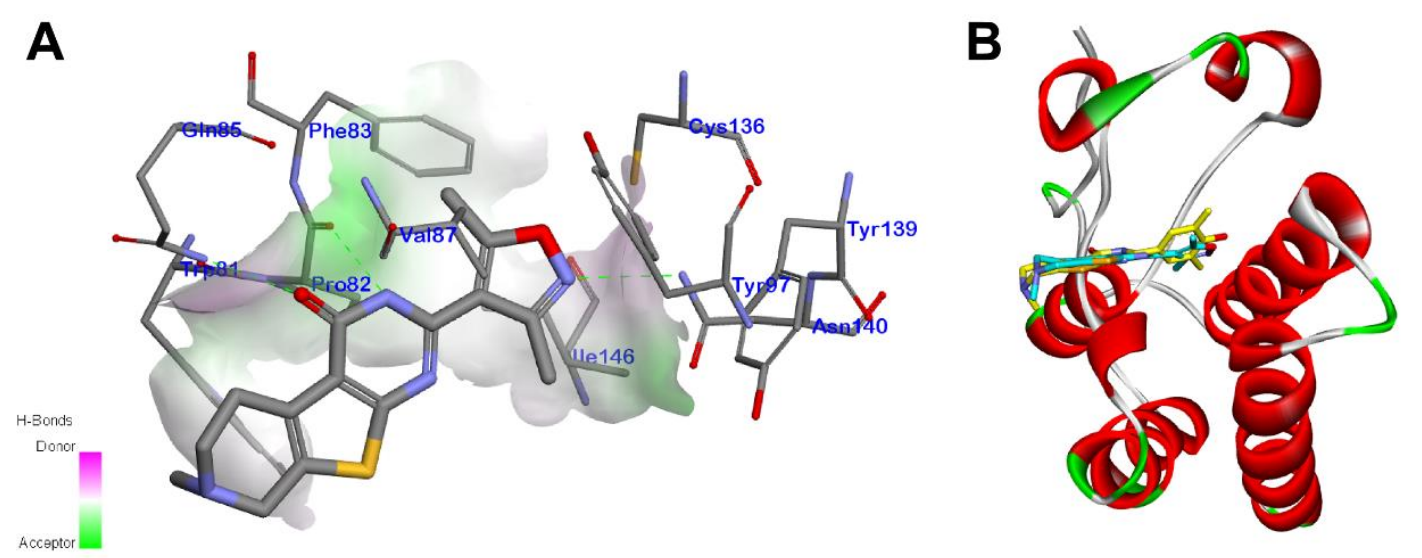

Figure S1. (A) The docked confirmation of 9a to BRD4; (B) Alignment of compound 9a and 41 in the binding site of BRD4 (PDB ID:4ZW1).

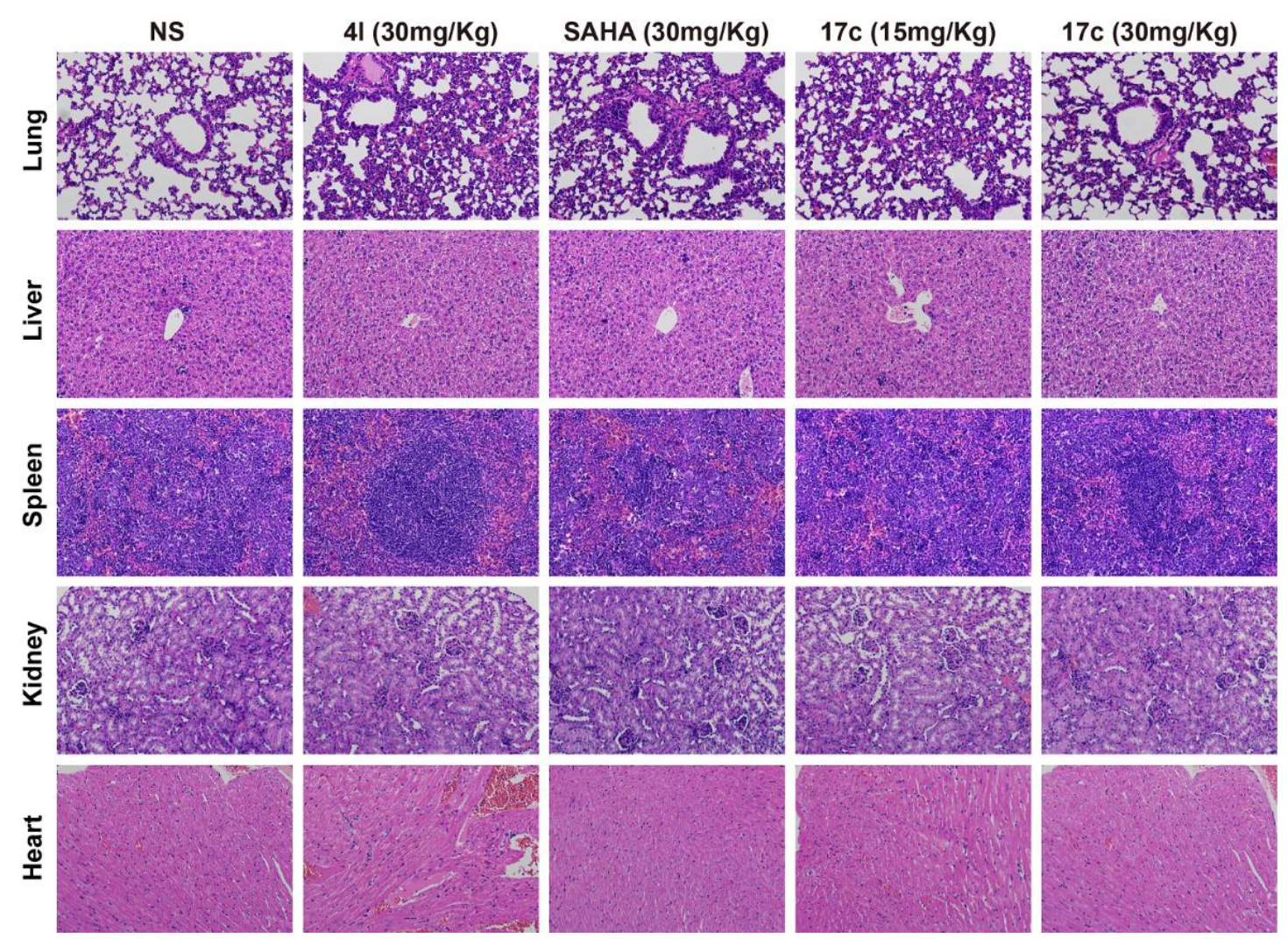

Figure S2. Representative images of main organ tissues after staining with hematoxylin-eosin $(\mathrm{H} \& \mathrm{E})$ in each group. 


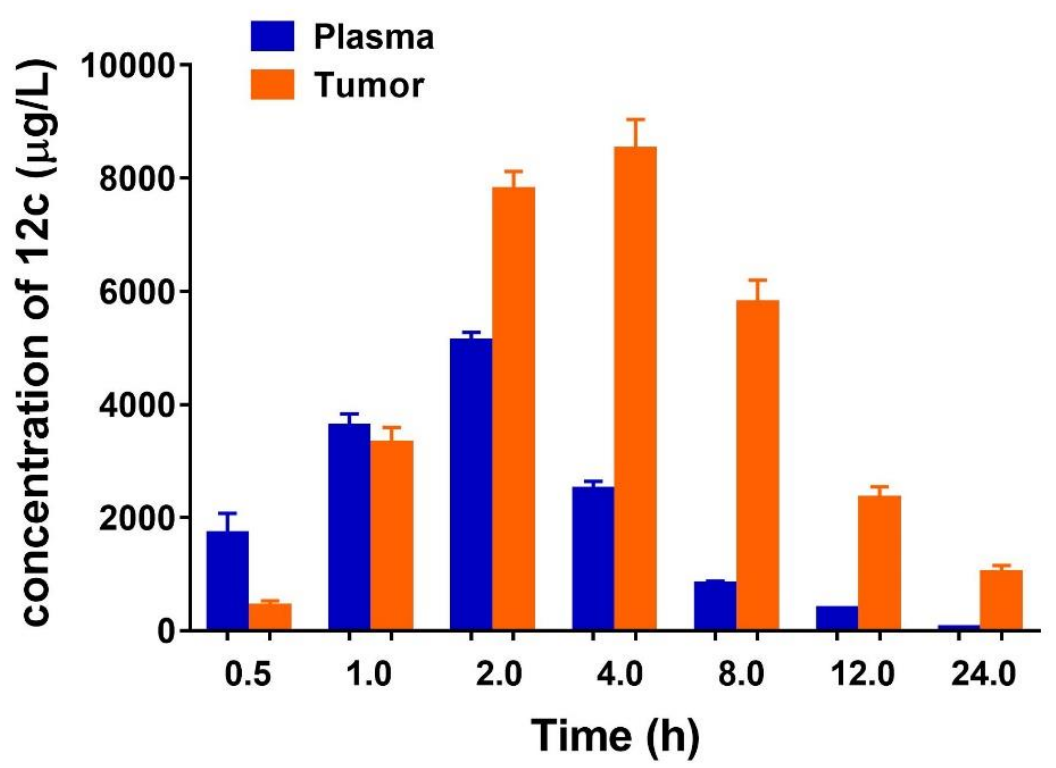

Figure S3. The concentrations of 17c in plasma or tumor tissues in subcutaneous HCT-116 xenograft models after oral administration $30 \mathrm{mg} / \mathrm{Kg}$ compound $17 \mathrm{c}$.

It is obviously that the concentrations of $17 \mathrm{c}$ in tumor tissues are higher than in the plasma. The maximum concentration of $17 \mathrm{c}$ in plasma and tumor tissues are 5123.57 and $8511.69 \mu \mathrm{g} / \mathrm{L}$, respectively. And the Tmax in in plasma and tumor tissues are about $1.5-2 \mathrm{~h}$ and $4 \mathrm{~h}$, respectively. These results suggested that compound $17 \mathrm{c}$ could enriched in the tumor tissues and prolong its antitumor effects.

Experimental procedure: The concentrations of $17 \mathrm{c}$ in plasma or tumors were determined in the HCT-116 subcutaneous xenograft tumor model. At the 10 days after tumor cell inoculation, mice were oral administrated with $0.5 \%$ sodium carboxyl methyl cellulose (CMC-Na) aqueous solution of $17 \mathrm{c}(30 \mathrm{mg} / \mathrm{kg}$ body weight). At specific time points, five mice in each group were sacrificed, the plasma were collected and separated and the tumors were collected. The concentrations of $17 \mathrm{c}$ in plasma were determined according to the experimental procedures in pharmacokinetics section. Tumor samples were weighed and homogenized in $0.25 \mathrm{~mL}$ normal saline. $100 \mu \mathrm{L}$ of tumor homogenate samples were mixed with $300 \mu \mathrm{L}$ of ethyl acetate and then vortex mixed for $5 \mathrm{~min}$. Subsequently, the organic layer was collected and evaporated to dryness under a flow of nitrogen gas. The extracted residue was reconstituted and analyzed by HPLC. 


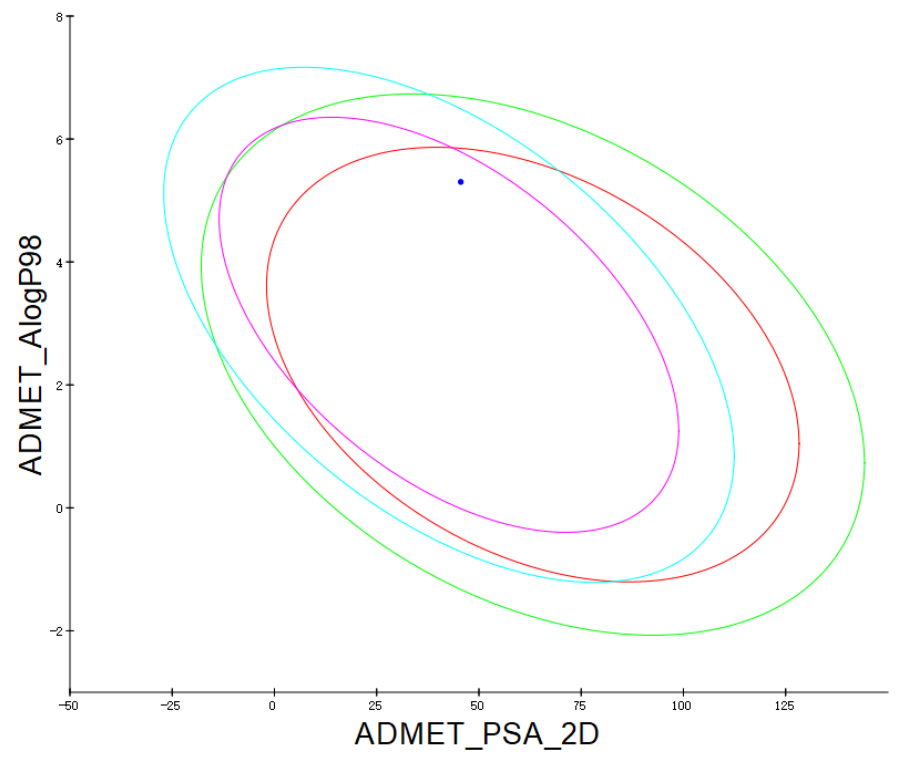

Figure S4. The predicted ADMET descriptor of 17c, contoured by ALogP98 and PSA_2D. 


\section{NMR and RP-HPLC spectra}
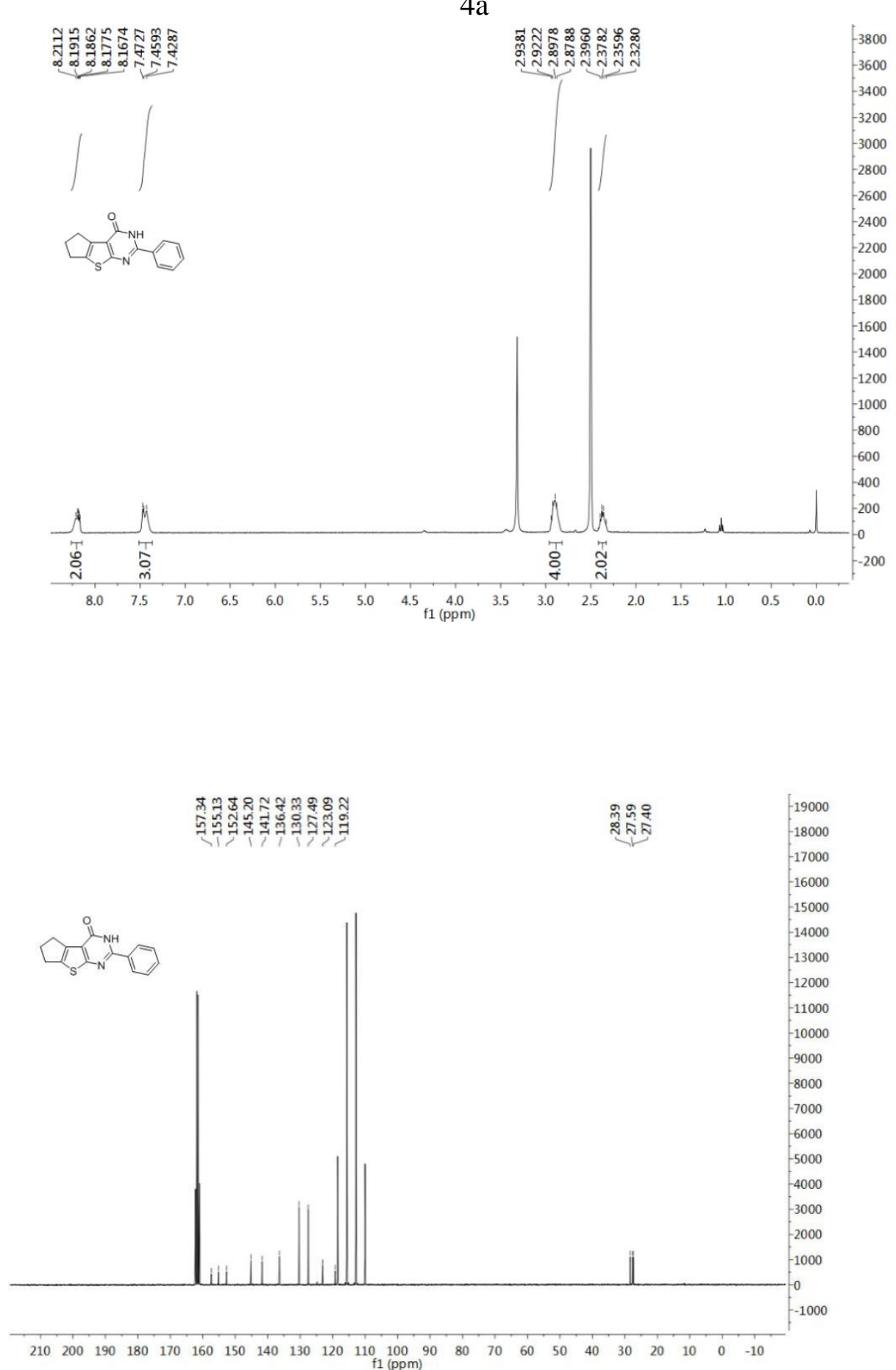
HPLC

Methanol $/$ water $(\mathrm{v} / \mathrm{v})=80: 20,1 \mathrm{ml} / \mathrm{min}$

$\mathrm{mAC}$

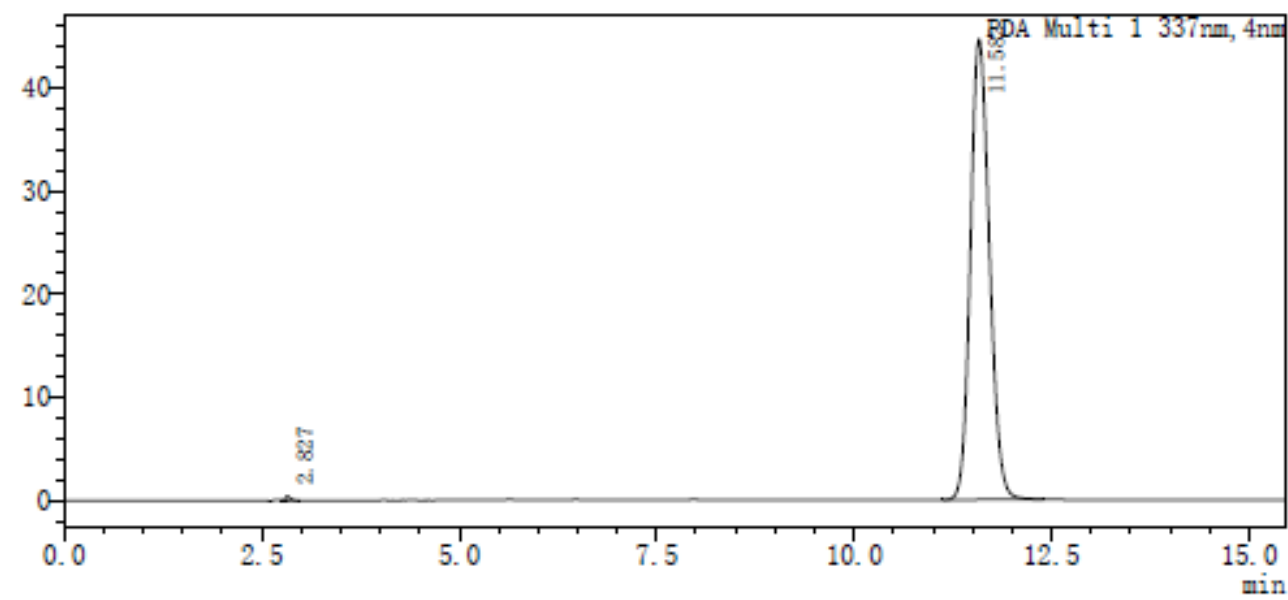

〈峰表〉

\begin{tabular}{|r|r|r|r|r|r|r|l|}
\hline 峰号 & 保留时间 & \multicolumn{1}{c|}{ 面积 } & \multicolumn{1}{c|}{ 高度 } & \multicolumn{1}{c|}{ 㳖度 } & 浓度单位 & 标记 & 化合物名 \\
\hline 1 & 2.827 & 2239 & 461 & 0.299 & & V & \\
\hline 2 & 11.582 & 747593 & 44572 & 99.701 & & & \\
\hline 总计 & & 749832 & 45032 & & & & \\
\hline
\end{tabular}

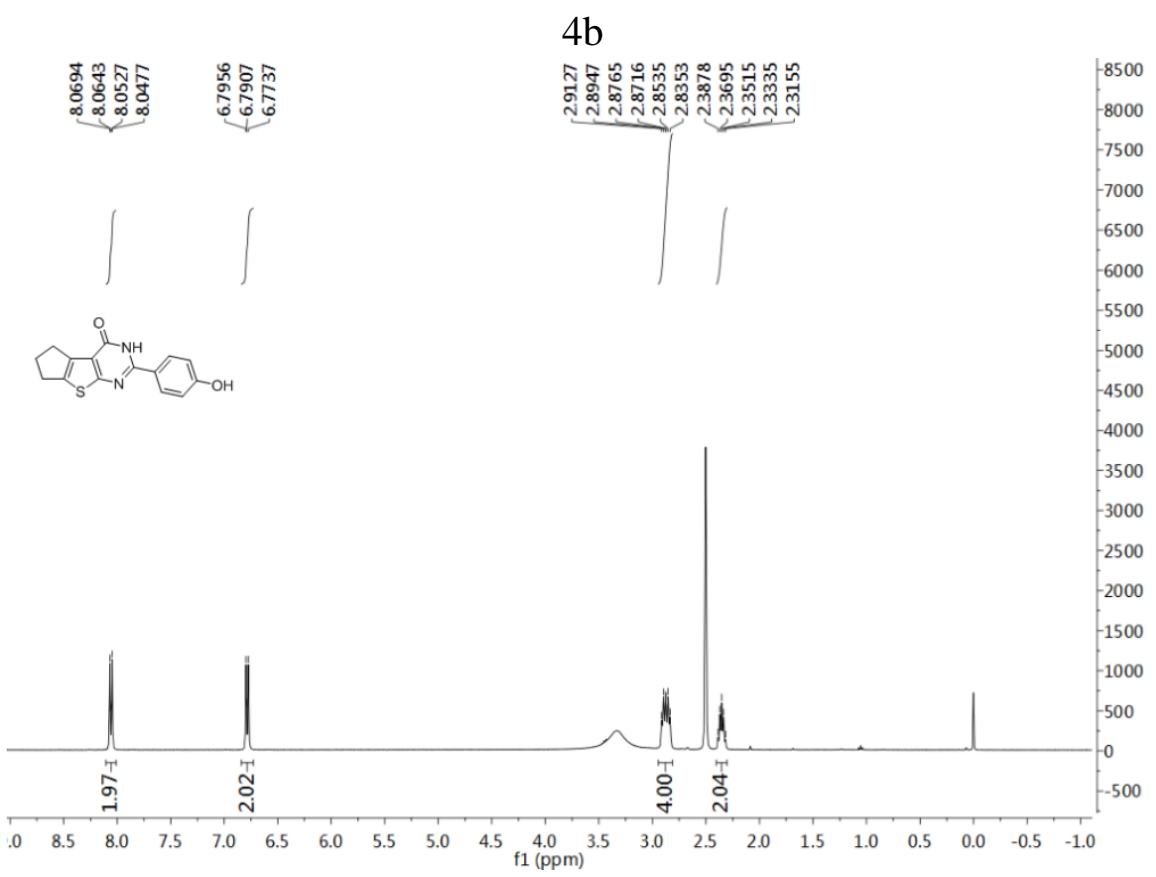




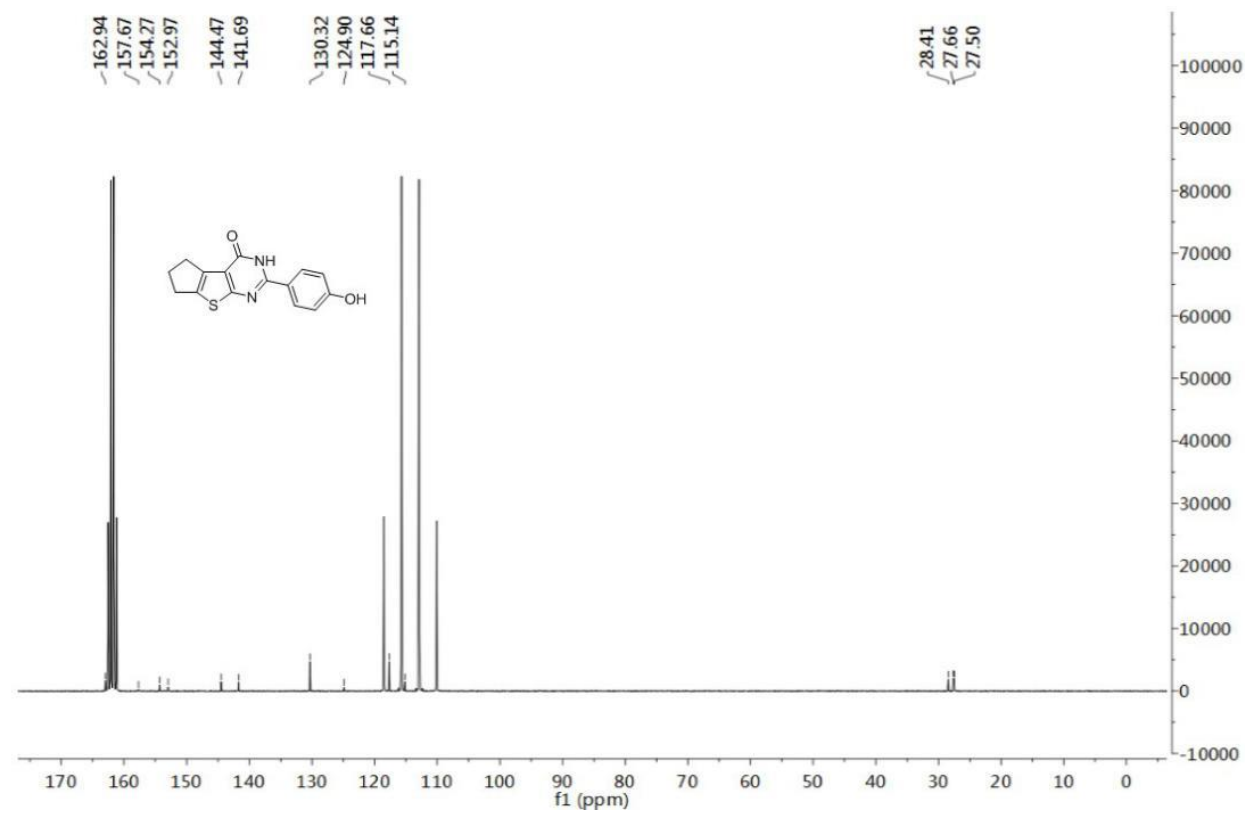

HPLC

Methanol $/$ water $(\mathrm{v} / \mathrm{v})=80: 20,1 \mathrm{ml} / \mathrm{min}$

$\mathrm{mAU}$

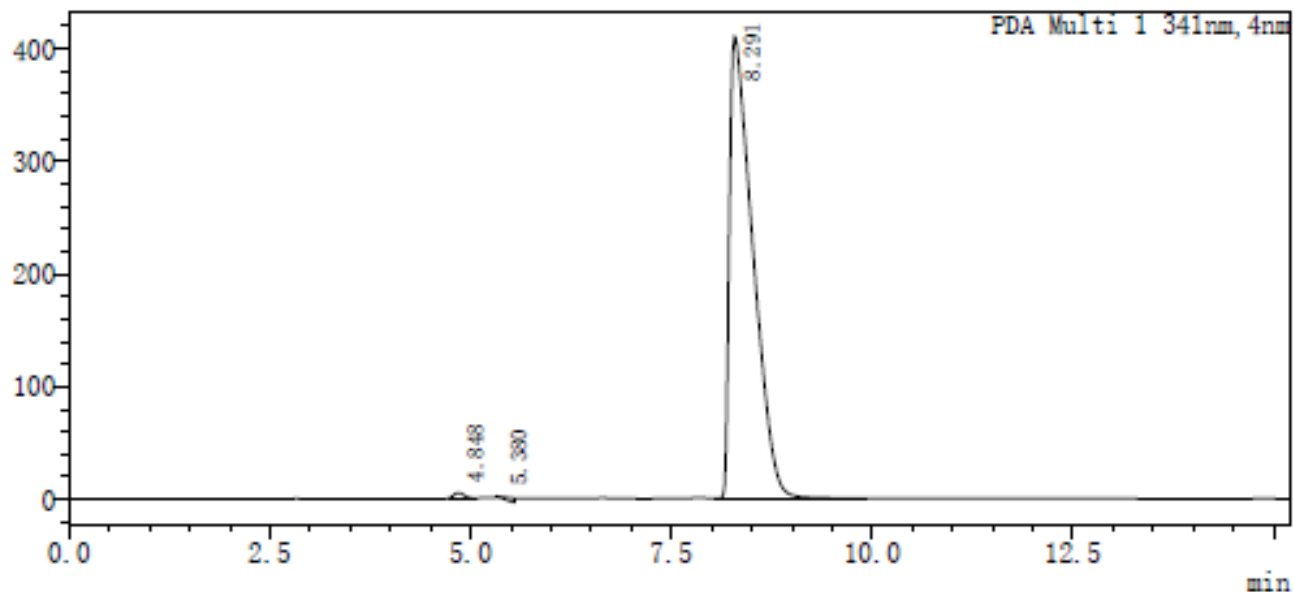

〈峰表〉

\begin{tabular}{|c|c|c|c|c|c|c|c|}
\hline 峰䒓 & 保留时间 & 面积 & 高度 & 浓度 & 浓度单倍 & 标记 & 化合物名 \\
\hline & 4.848 & 61480 & 5842 & 0.732 & & M & \\
\hline & 5. 380 & $\frac{22844}{319096}$ & $\begin{array}{r}758 \\
440197\end{array}$ & $\frac{0.272}{98997}$ & & M & \\
\hline 总语 & & $\frac{05919206}{8403530}$ & $\frac{410197}{416798}$ & & & & \\
\hline
\end{tabular}


$4 c$
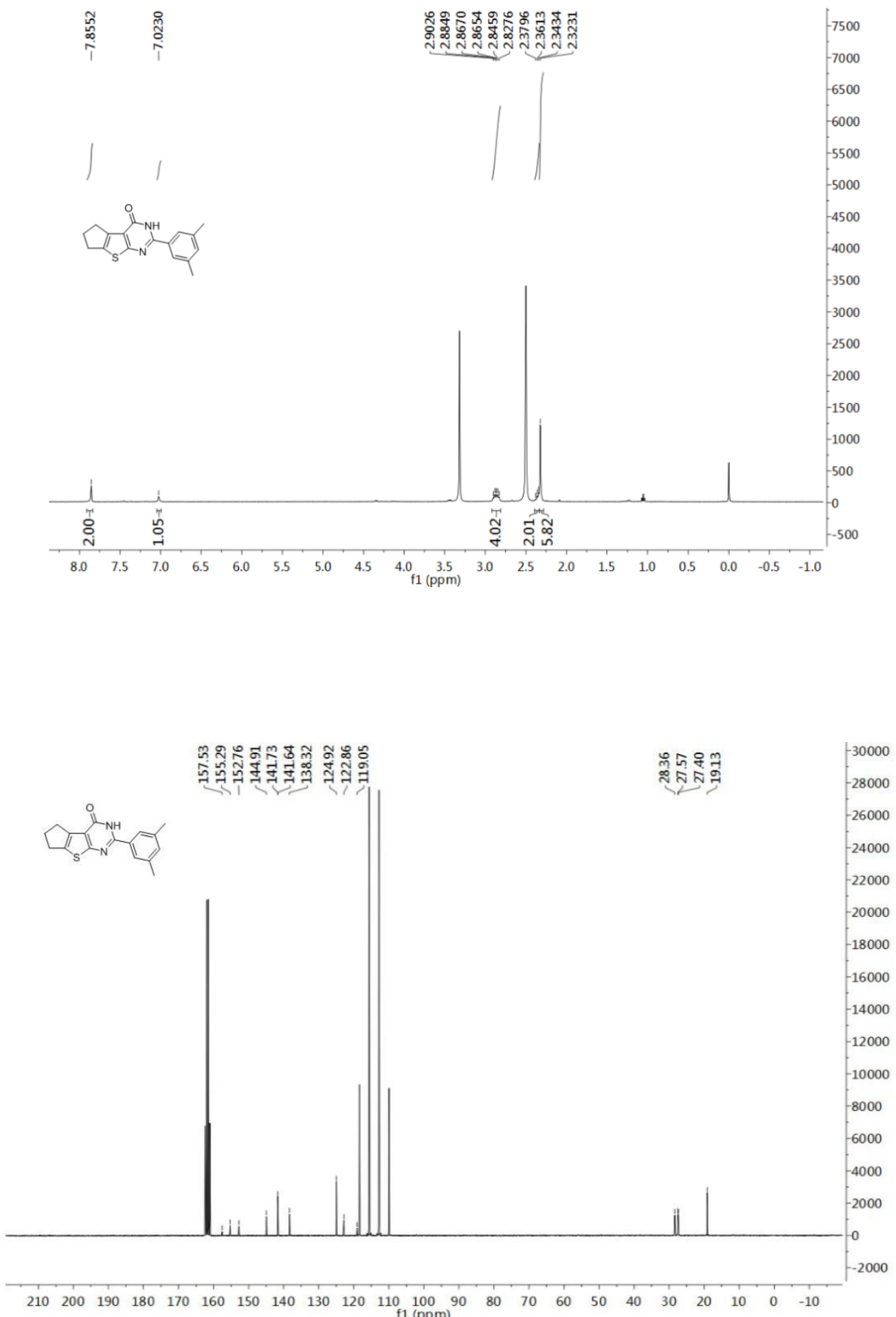
HPLC

Methanol/water $(\mathrm{v} / \mathrm{v})=80: 20,1 \mathrm{ml} / \mathrm{min}$

MAU

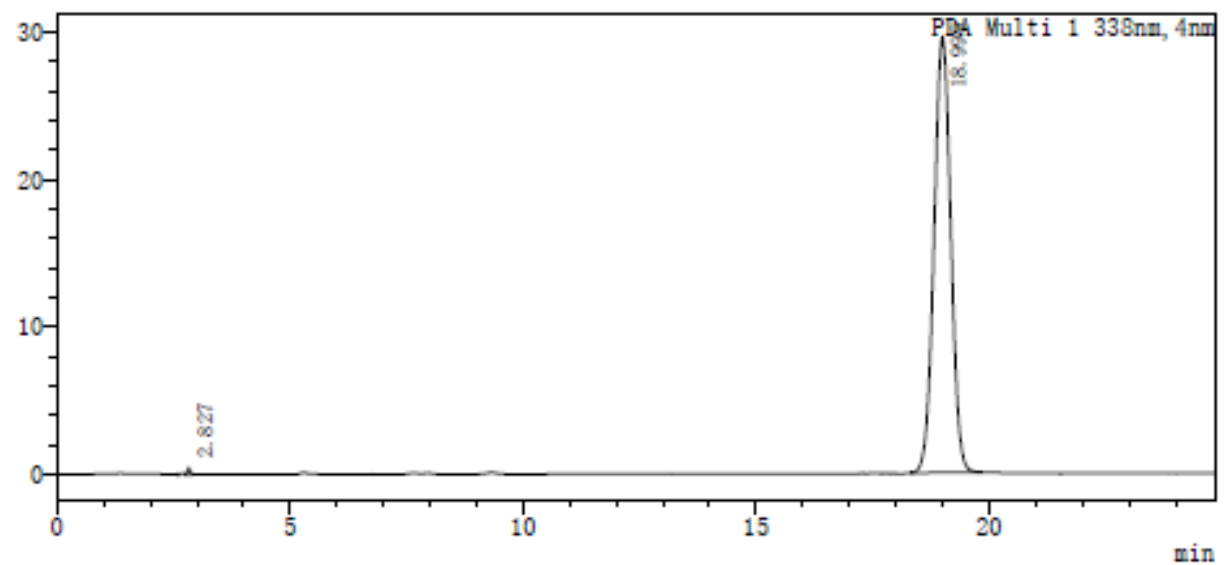

〈峰表〉

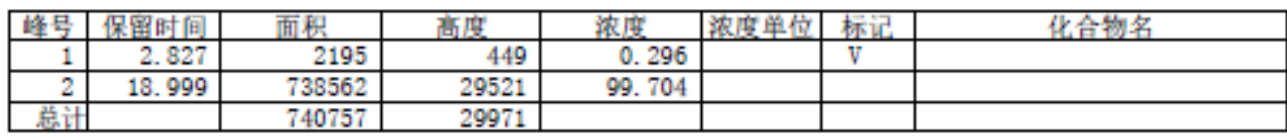

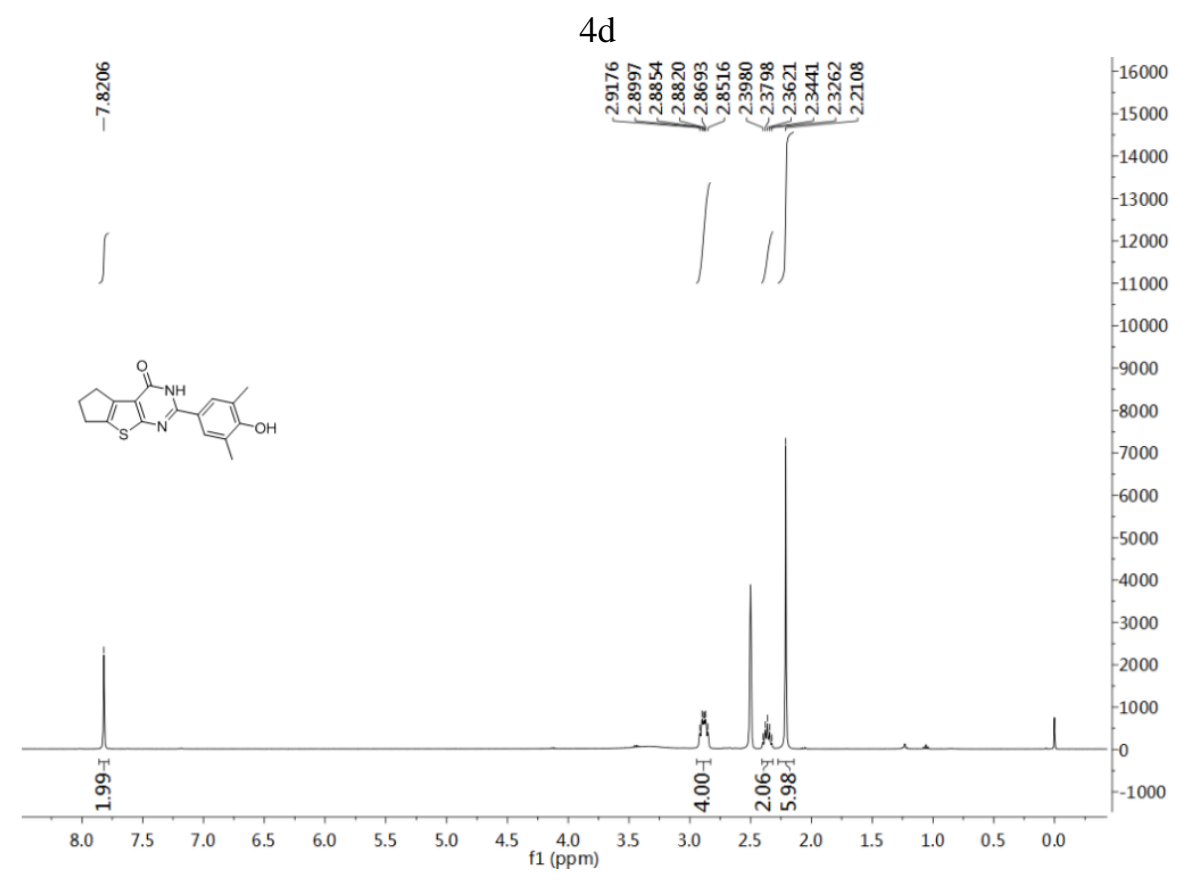




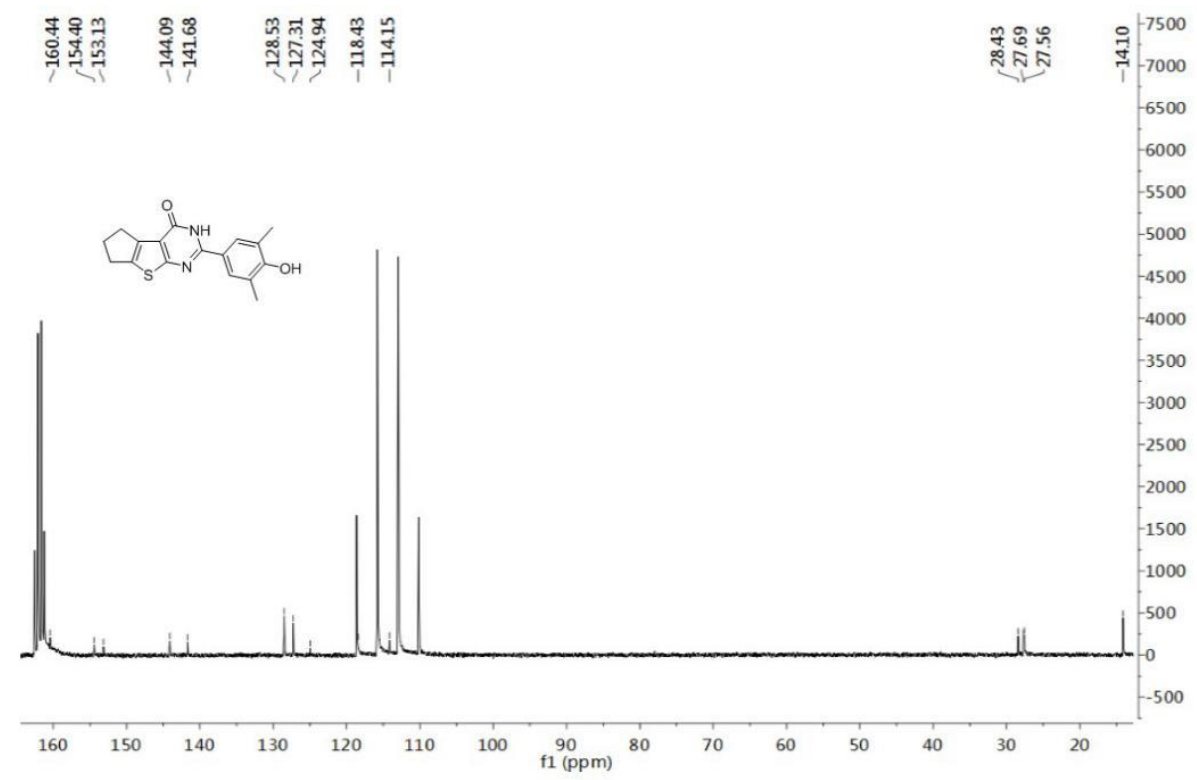

HPLC

Methanol $/$ water $(\mathrm{v} / \mathrm{v})=80: 20,1 \mathrm{ml} / \mathrm{min}$

$\mathrm{mAU}$

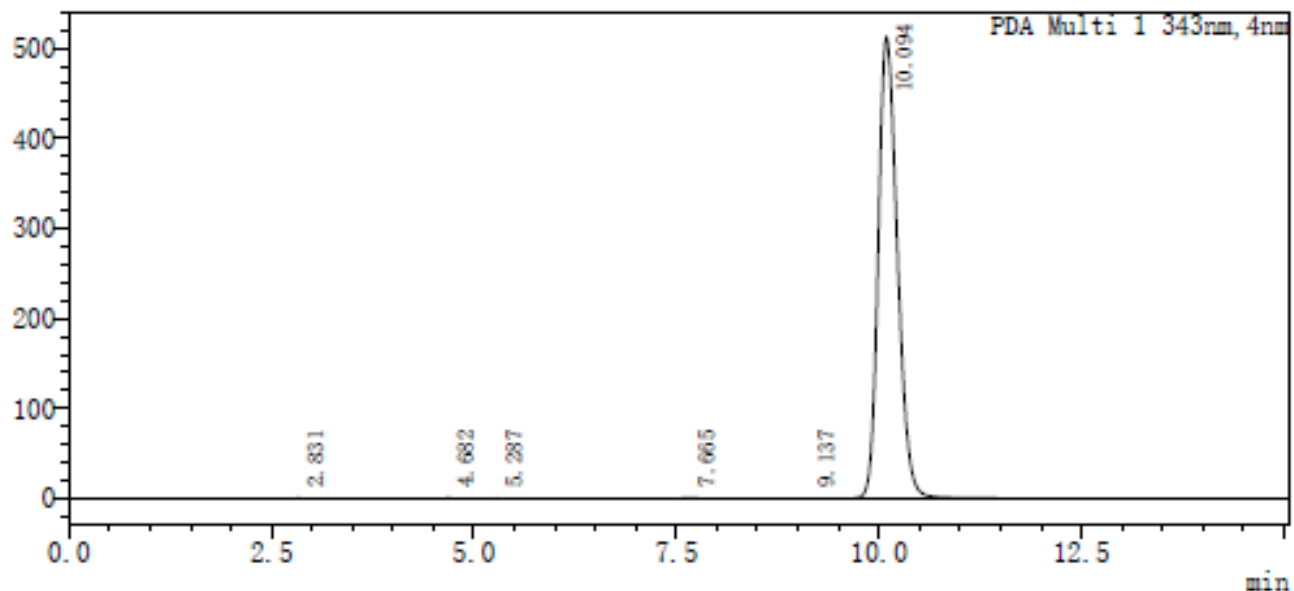

〈峰表〉

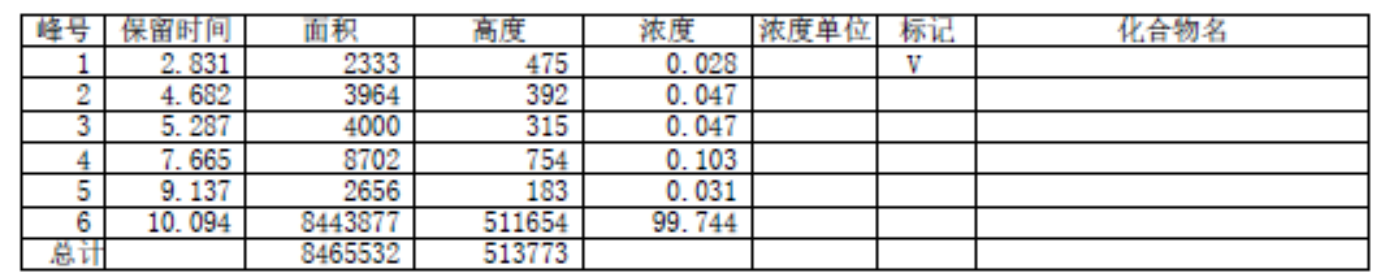



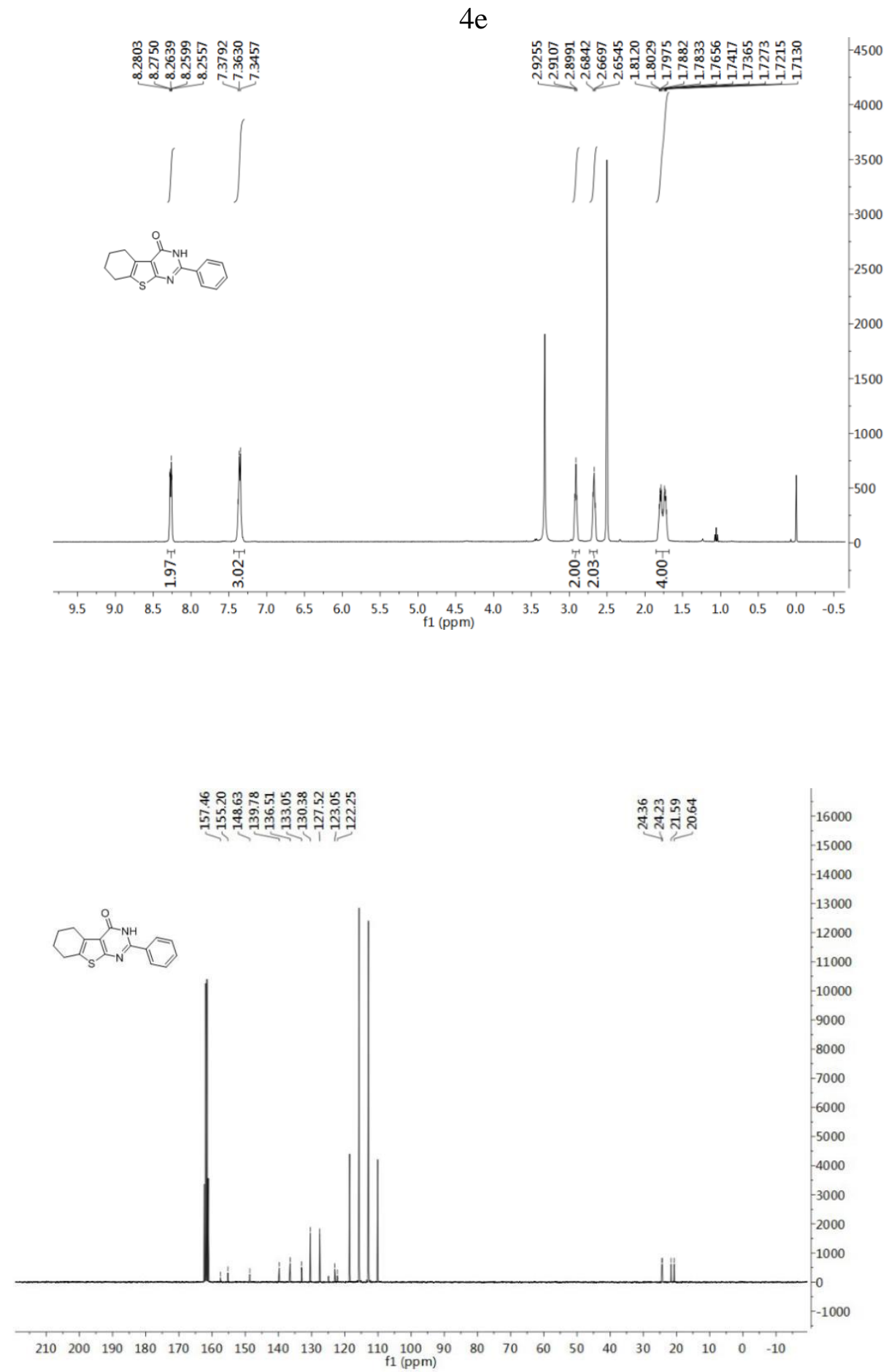
HPLC

Methanol/water(v/v)=80:20, $1 \mathrm{ml} / \mathrm{min}$

$\mathrm{mAU}$

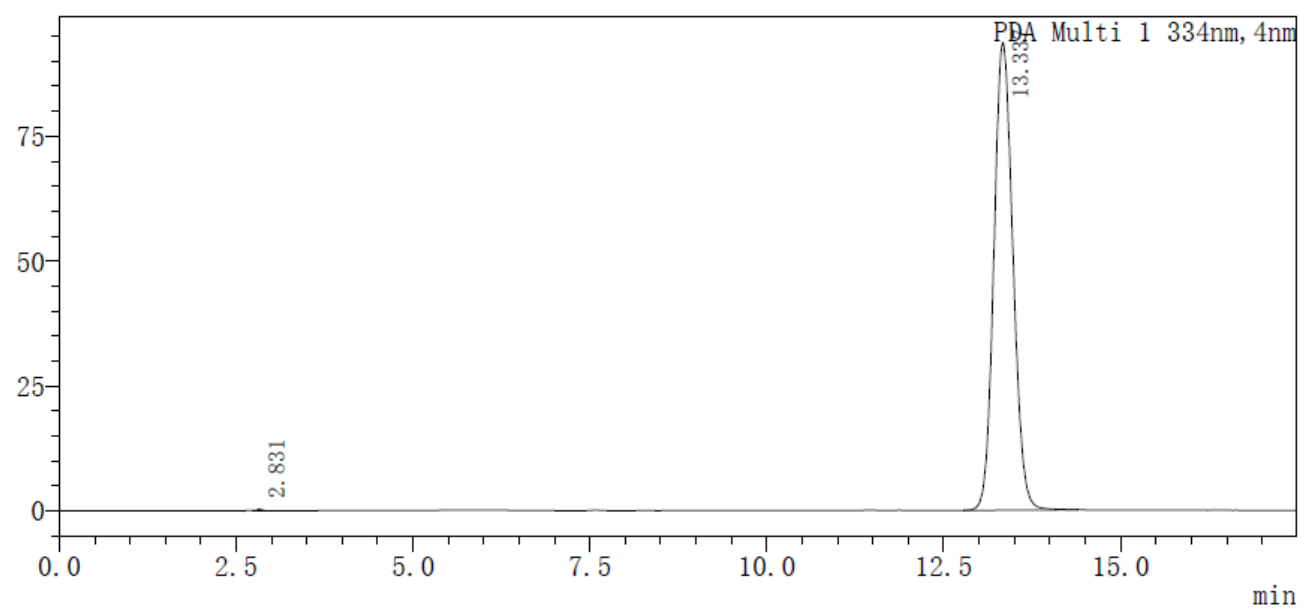

〈峰表〉

\begin{tabular}{|r|r|r|r|r|r|r|r|}
\hline 峰号 & 保留时间 & \multicolumn{1}{|c|}{ 面积 } & \multicolumn{1}{|c|}{ 高度 } & \multicolumn{1}{|c|}{ 浓度 } & 浓度单位 & 标记 & 化合物名 \\
\hline 1 & 2.831 & 1894 & 389 & 0.108 & & $\mathrm{~V}$ & \\
\hline 2 & 13.337 & 1754205 & 93578 & 99.892 & & & \\
\hline 总计 & & 1756099 & 93967 & & & & \\
\hline
\end{tabular}

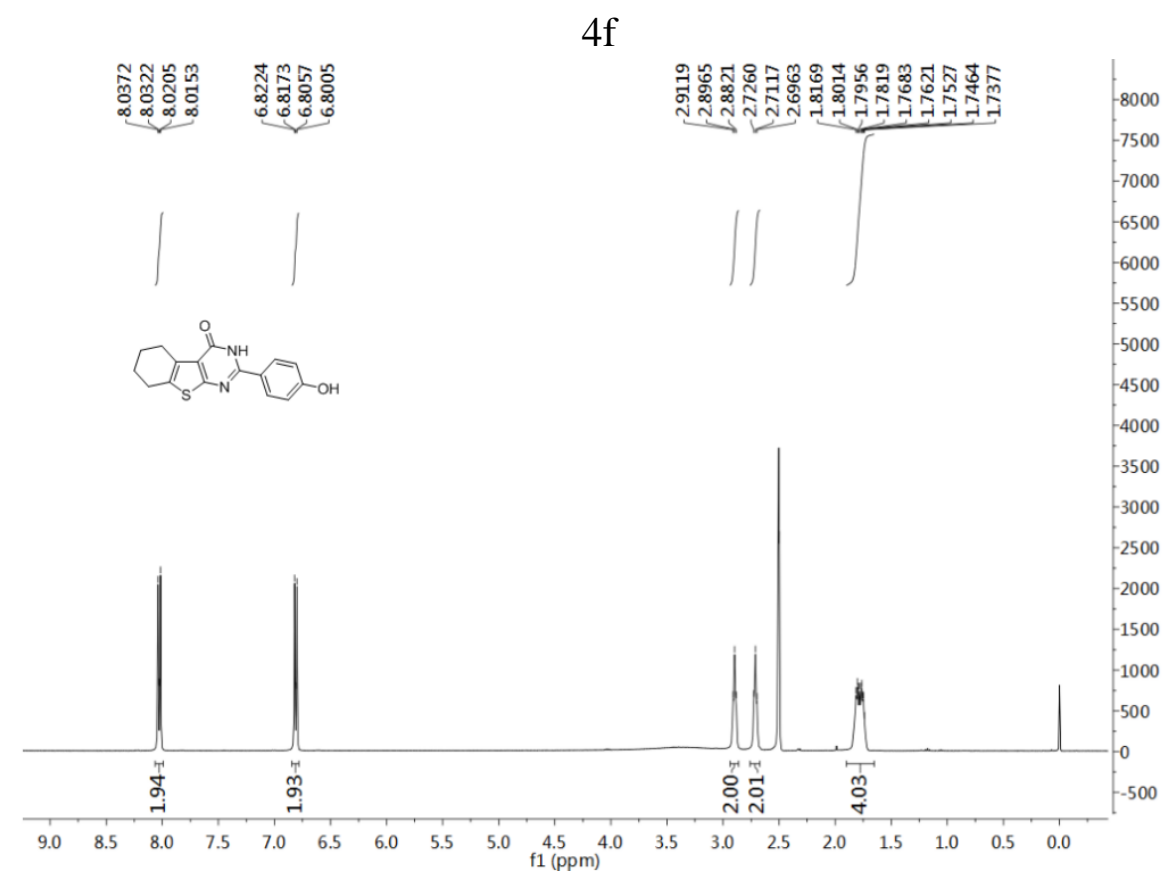




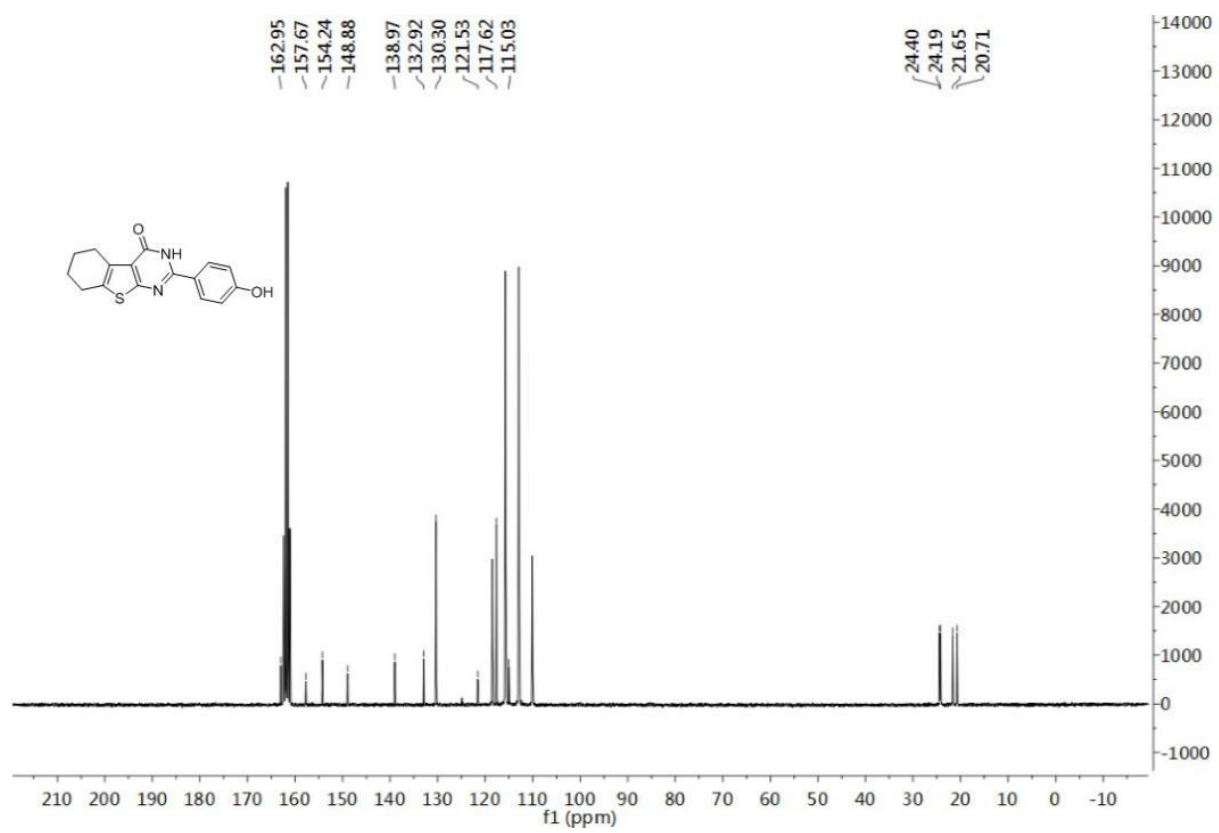

HPLC

Methanol $/$ water $(\mathrm{v} / \mathrm{v})=80: 20,1 \mathrm{ml} / \mathrm{min}$

$\mathrm{mAU}$

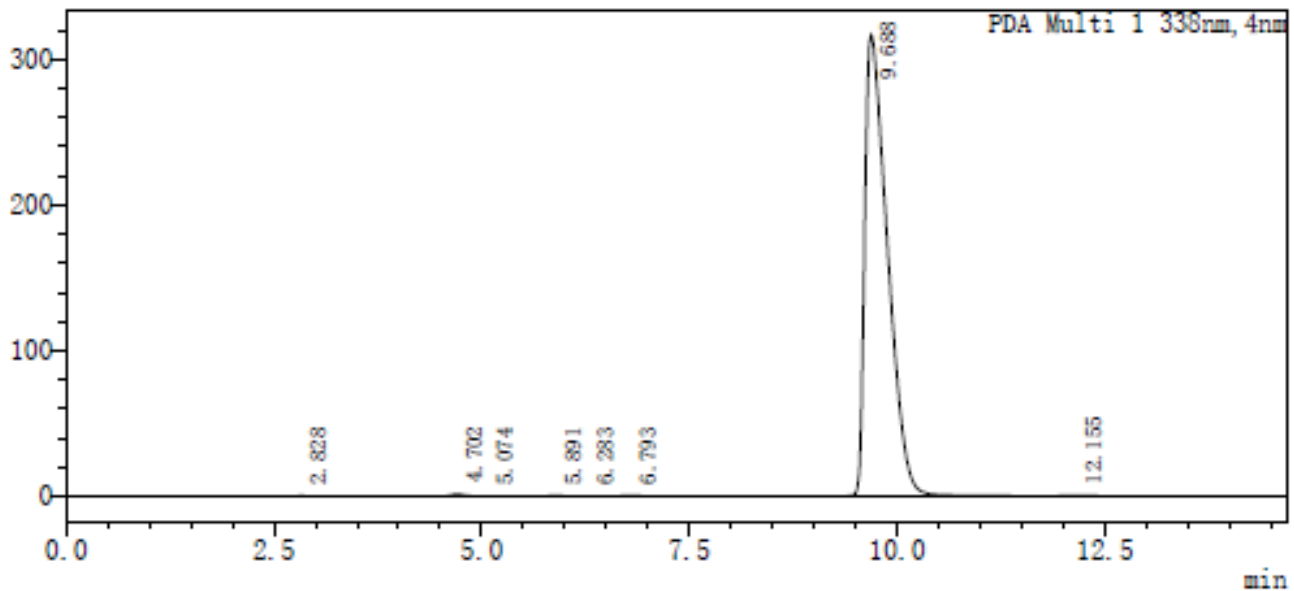

〈峰表〉

\begin{tabular}{|r|r|r|r|r|r|r|l|}
\hline 峰号 & 保留时间 & 面积 & \multicolumn{1}{c|}{ 高度 } & \multicolumn{1}{c|}{ 浓度 } & 浓度单位 & 标记 & 化合物名 \\
\hline 1 & 2.828 & 2098 & 437 & 0.035 & & $\mathrm{~V}$ & \\
\hline 2 & 4.702 & 14316 & 1410 & 0.238 & & & \\
\hline 3 & 5.074 & 1165 & 117 & 0.019 & & $\mathrm{~V}$ & \\
\hline 4 & 5.891 & 2863 & 230 & 0.048 & & & \\
\hline 5 & 6.283 & 1302 & 95 & 0.022 & & $\mathrm{~V}$ & \\
\hline 6 & 6.793 & 5202 & 421 & 0.086 & & $\mathrm{~V}$ & \\
\hline 7 & 9.688 & 5992216 & 316452 & 99.430 & & & \\
\hline 8 & 12.155 & 7418 & 400 & 0.123 & & & \\
\hline 总计 & & 6026581 & 319562 & & & & \\
\hline
\end{tabular}



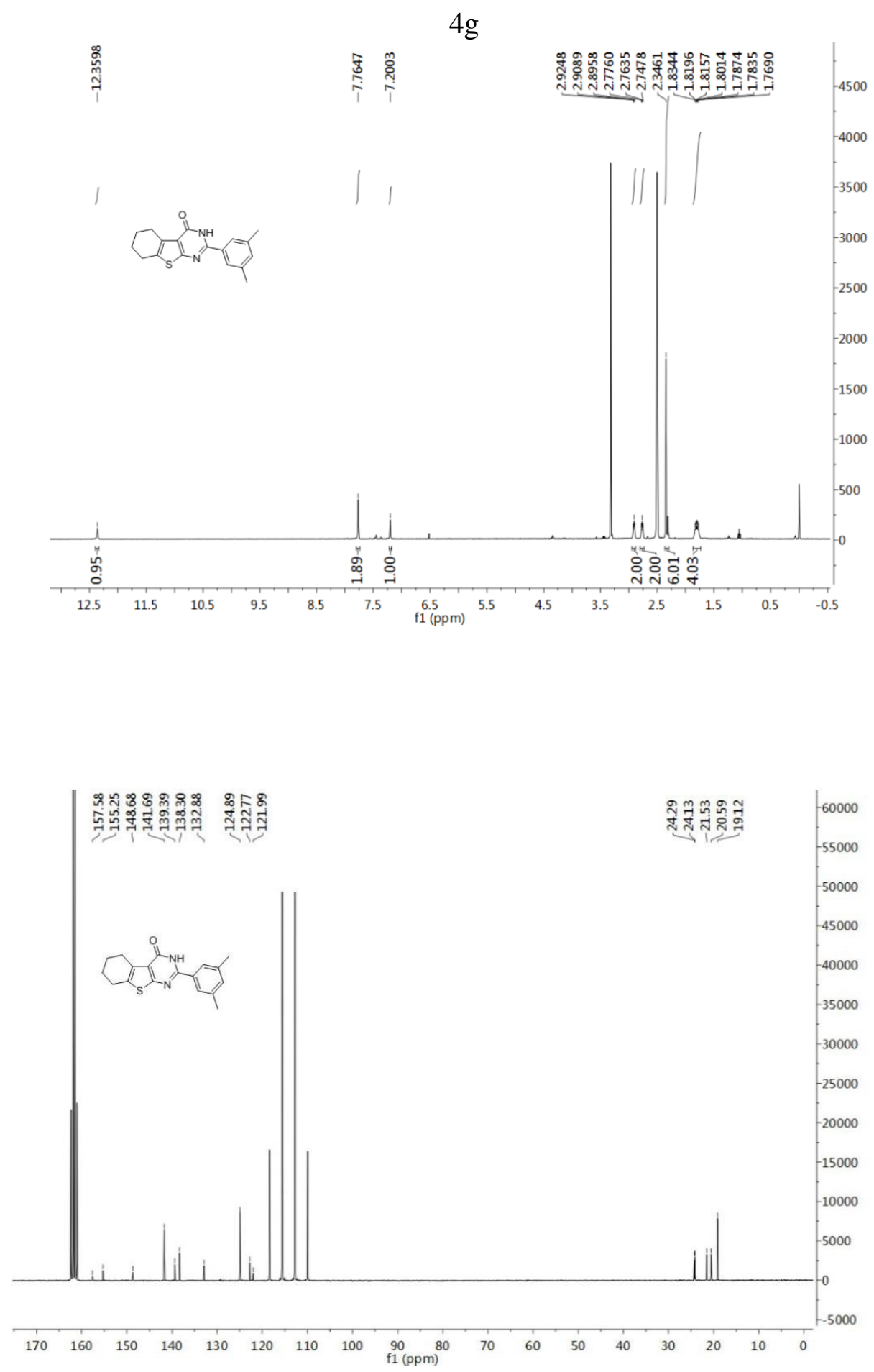
HPLC

Methanol $/$ water $(\mathrm{v} / \mathrm{v})=80: 20,1 \mathrm{ml} / \mathrm{min}$

mAU

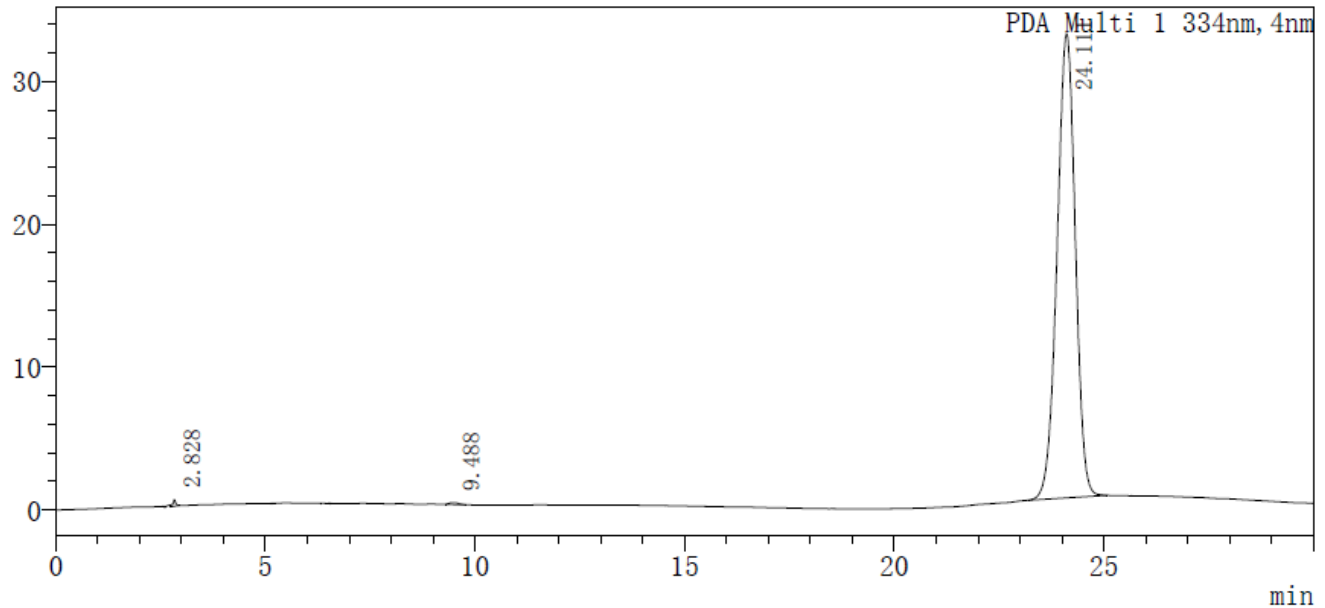

〈峰表〉

\begin{tabular}{|r|r|r|r|r|r|r|r|}
\hline 峰号 & 保留时间 & \multicolumn{1}{c|}{ 面积 } & \multicolumn{1}{c|}{ 高度 } & \multicolumn{1}{c|}{ 浓度 } & 浓度单位 & 标记 & 化合物名 \\
\hline 1 & 2.828 & 2184 & 436 & 0.221 & & V & \\
\hline 2 & 9.488 & 1852 & 135 & 0.187 & & & \\
\hline 3 & 24.111 & 984850 & 32499 & 99.592 & & & \\
\hline 总计 & & 988886 & 33071 & & & & \\
\hline
\end{tabular}

$4 \mathrm{~h}$

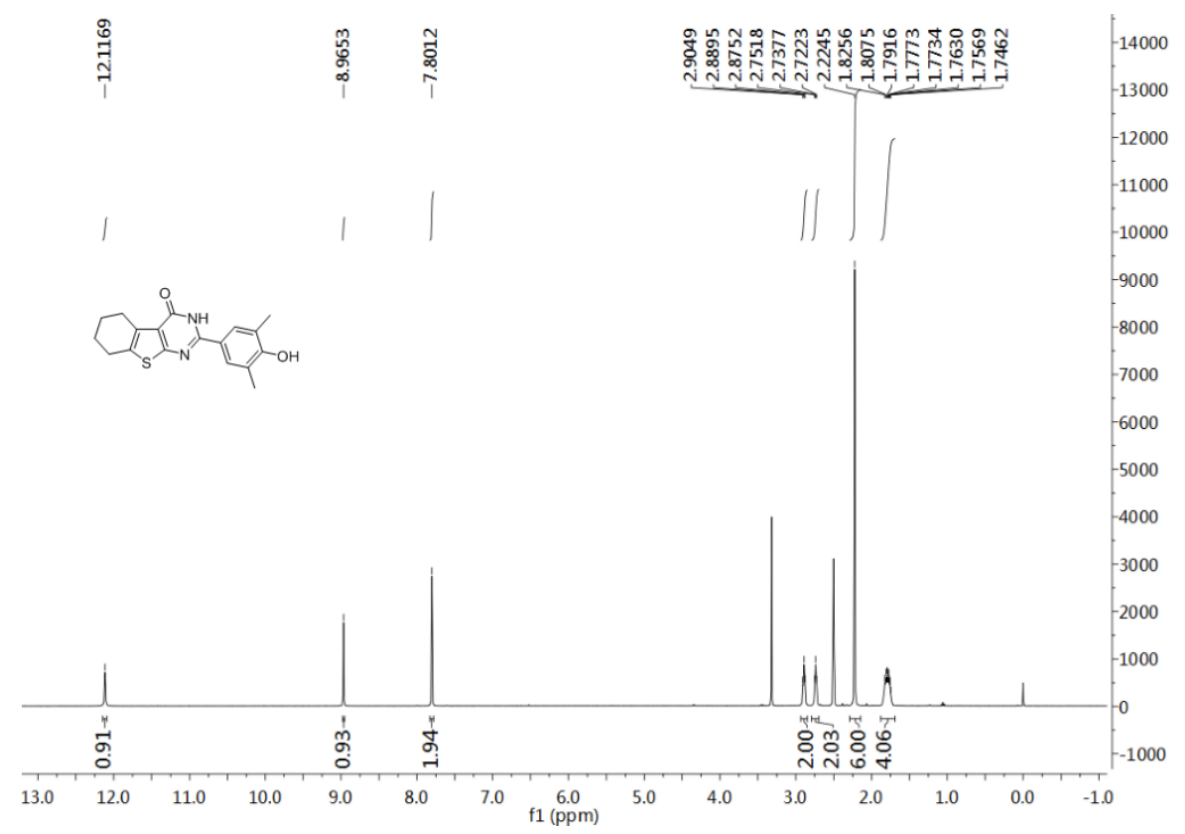




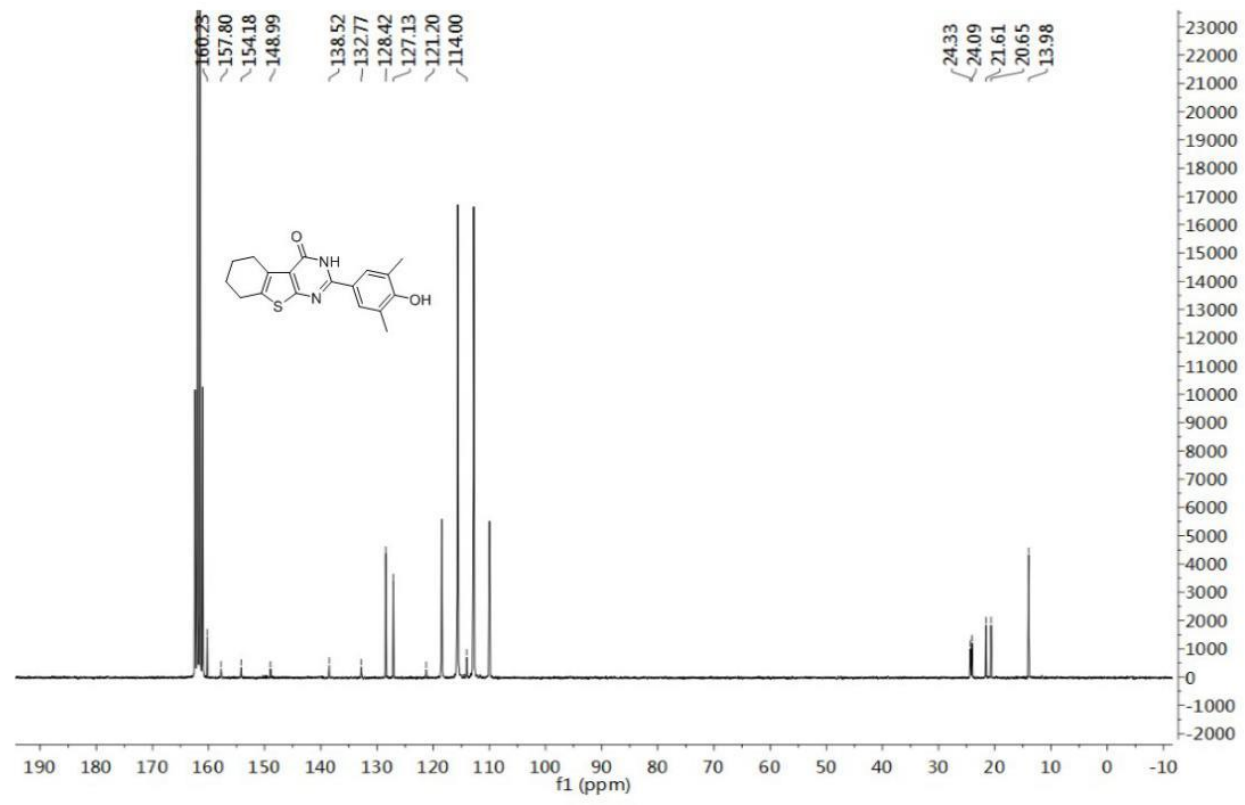

\section{HPLC}

Methanol $/$ water $(\mathrm{v} / \mathrm{v})=80: 20,1 \mathrm{ml} / \mathrm{min}$

$\mathrm{mAU}$

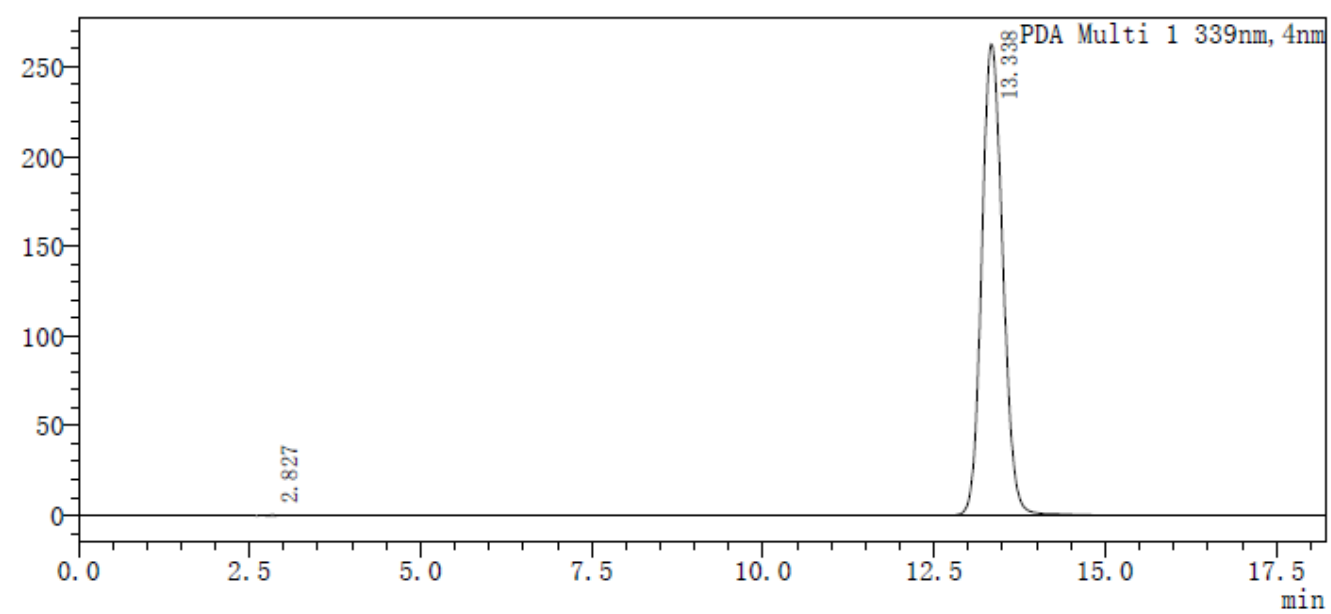

〈峰表〉

\begin{tabular}{|r|r|r|r|r|r|r|r|}
\hline 峰号 & 保留时间 & \multicolumn{1}{|c|}{ 面积 } & \multicolumn{1}{c|}{ 高度 } & \multicolumn{1}{c|}{ 浓度 } & 浓度单位 & 标记 & 化合物名 \\
\hline 1 & 2.827 & 2277 & 477 & 0.041 & & V & \\
\hline 2 & 13.338 & 5609664 & 262212 & 99.959 & & & \\
\hline 总计 & & 5611941 & 262689 & & & & \\
\hline
\end{tabular}



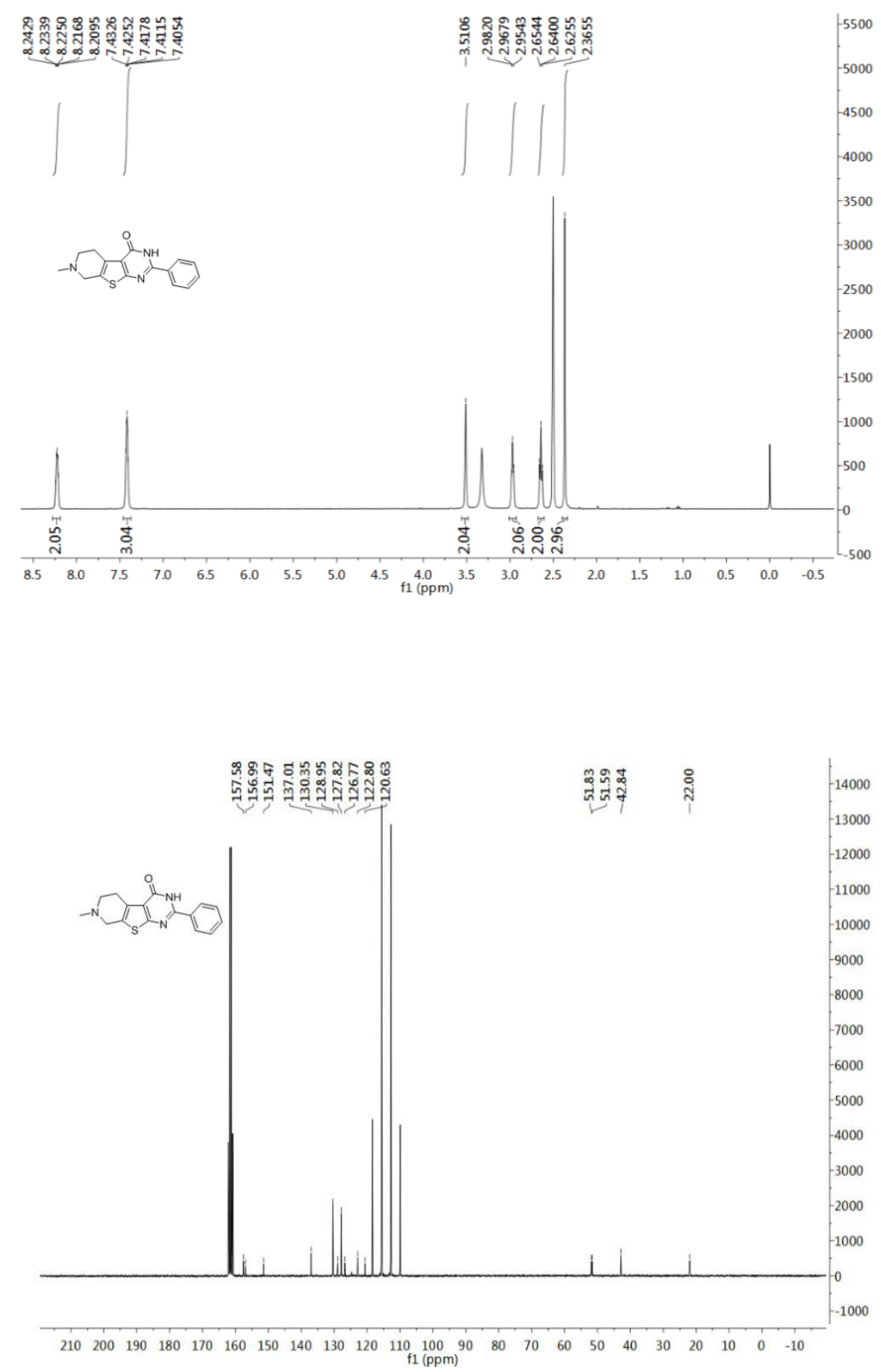
HPLC

Methanol/water(v/v)=80:20, $1 \mathrm{ml} / \mathrm{min}$

$\mathrm{mAU}$

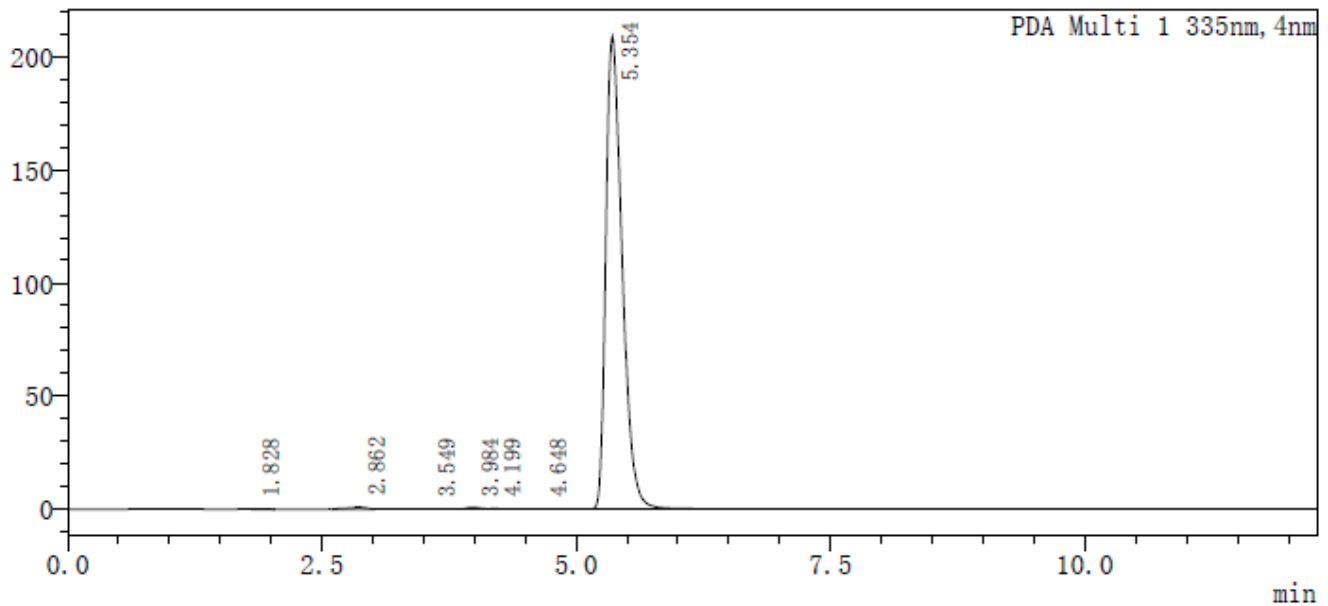

〈峰表〉

\begin{tabular}{|r|r|r|r|r|r|r|l|}
\hline 峰号 & 保留时间 & \multicolumn{1}{|c|}{ 面积 } & \multicolumn{1}{c|}{ 高度 } & \multicolumn{1}{c|}{ 浓度 } & 浓度单位 & 标记 & 化合物名 \\
\hline 1 & 1.828 & 1441 & 241 & 0.061 & & & \\
\hline 2 & 2.862 & 12954 & 966 & 0.549 & & & \\
\hline 3 & 3.549 & 1823 & 179 & 0.077 & & & \\
\hline 4 & 3.984 & 8460 & 727 & 0.358 & & $\mathrm{~V}$ & \\
\hline 5 & 4.199 & 3524 & 302 & 0.149 & & $\mathrm{~V}$ & \\
\hline 6 & 4.648 & 1421 & 126 & 0.060 & & $\mathrm{~V}$ & \\
\hline 7 & 5.354 & 2330515 & 208866 & 98.745 & & & \\
\hline 总计 & & 2360137 & 211408 & & & & \\
\hline
\end{tabular}

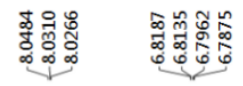

$4 \mathrm{j}$

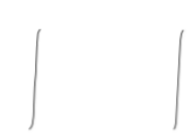

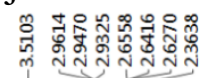

6000

5500

5000

4500

-

$-4000$

3000

2500

1500

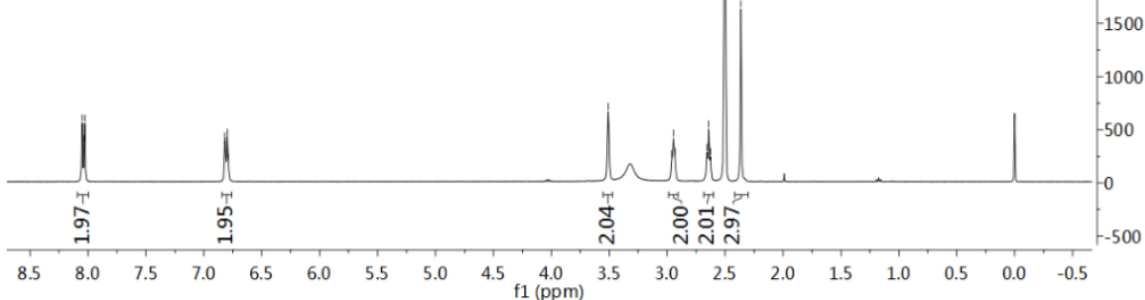




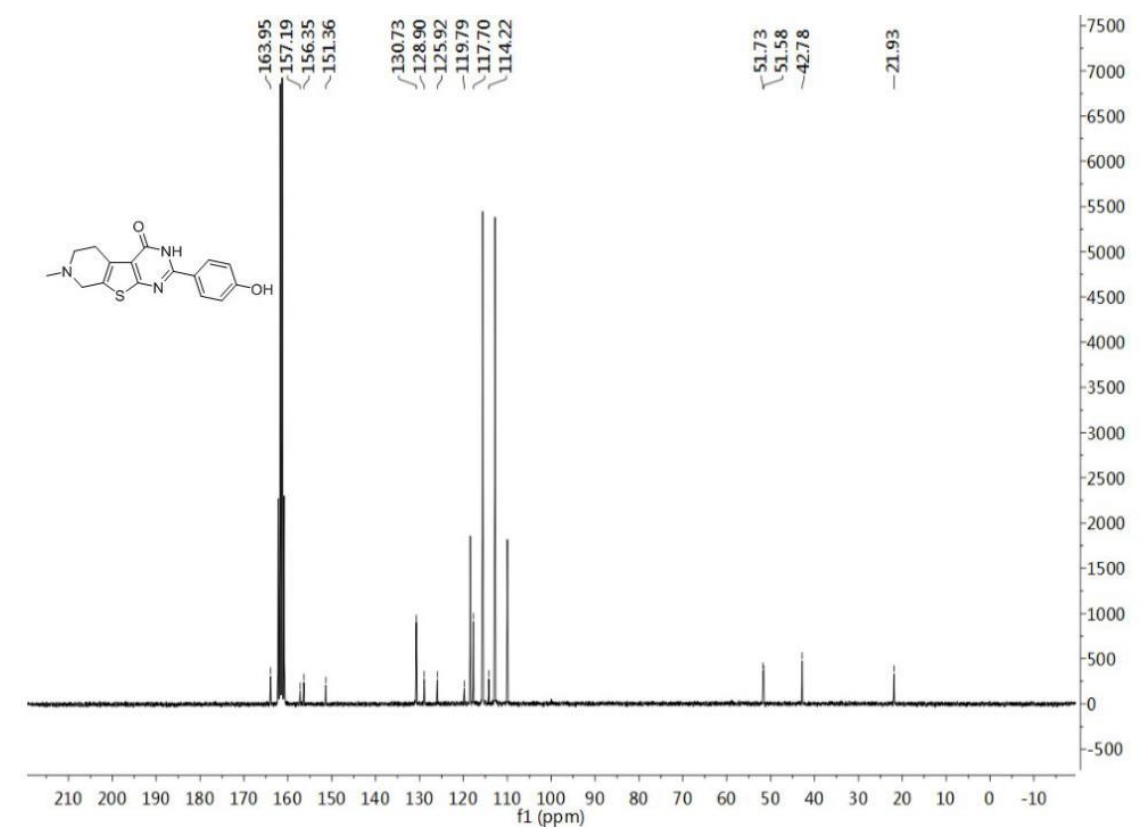

HPLC

Methanol/water $(\mathrm{v} / \mathrm{v})=80: 20,1 \mathrm{ml} / \mathrm{min}$

$\mathrm{mAU}$

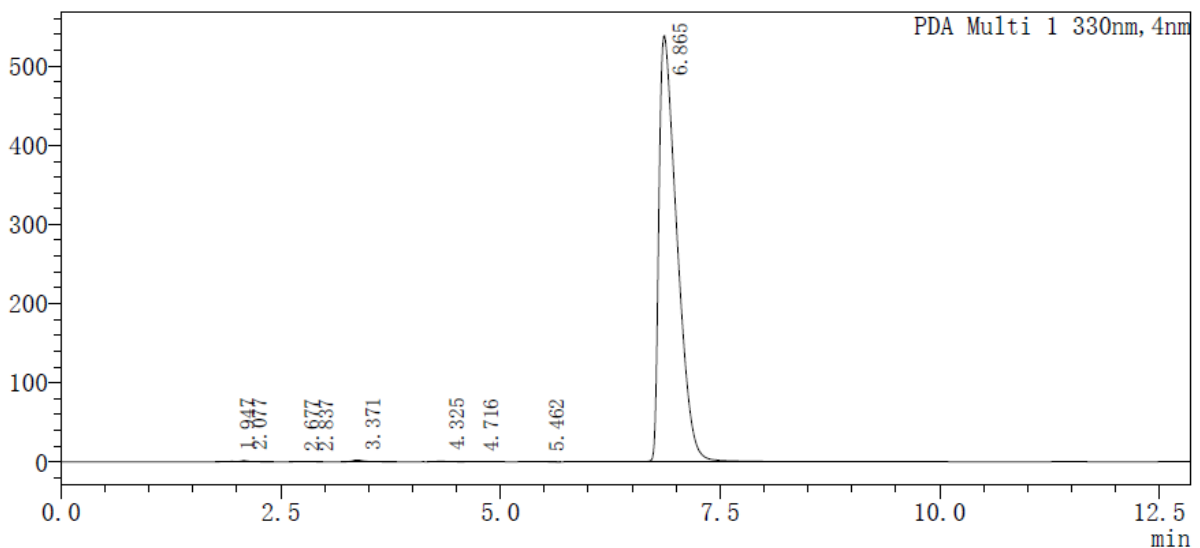

〈峰表〉

\begin{tabular}{|r|r|r|r|r|r|r|r|}
\hline 峰号 & 保留时间 & \multicolumn{1}{|c|}{ 面积 } & \multicolumn{1}{c|}{ 高度 } & \multicolumn{1}{c|}{ 浓度 } & 浓度单位 & 标记 & 化合物名 \\
\hline 1 & 1.947 & 2604 & 485 & 0.034 & & & \\
\hline 2 & 2.077 & 7482 & 1386 & 0.098 & & $\mathrm{~V}$ & \\
\hline 3 & 2.677 & 1128 & 123 & 0.015 & & & \\
\hline 4 & 2.837 & 1555 & 360 & 0.020 & & $\mathrm{~V}$ & \\
\hline 5 & 3.371 & 17053 & 1969 & 0.222 & & & \\
\hline 6 & 4.325 & 4629 & 549 & 0.060 & & & \\
\hline 7 & 4.716 & 2255 & 247 & 0.029 & & & \\
\hline 8 & 5.462 & 1746 & 172 & 0.023 & & & \\
\hline 9 & 6.865 & 7632578 & 538284 & 99.499 & & & \\
\hline 总计 & & 7671031 & 543574 & & & & \\
\hline
\end{tabular}



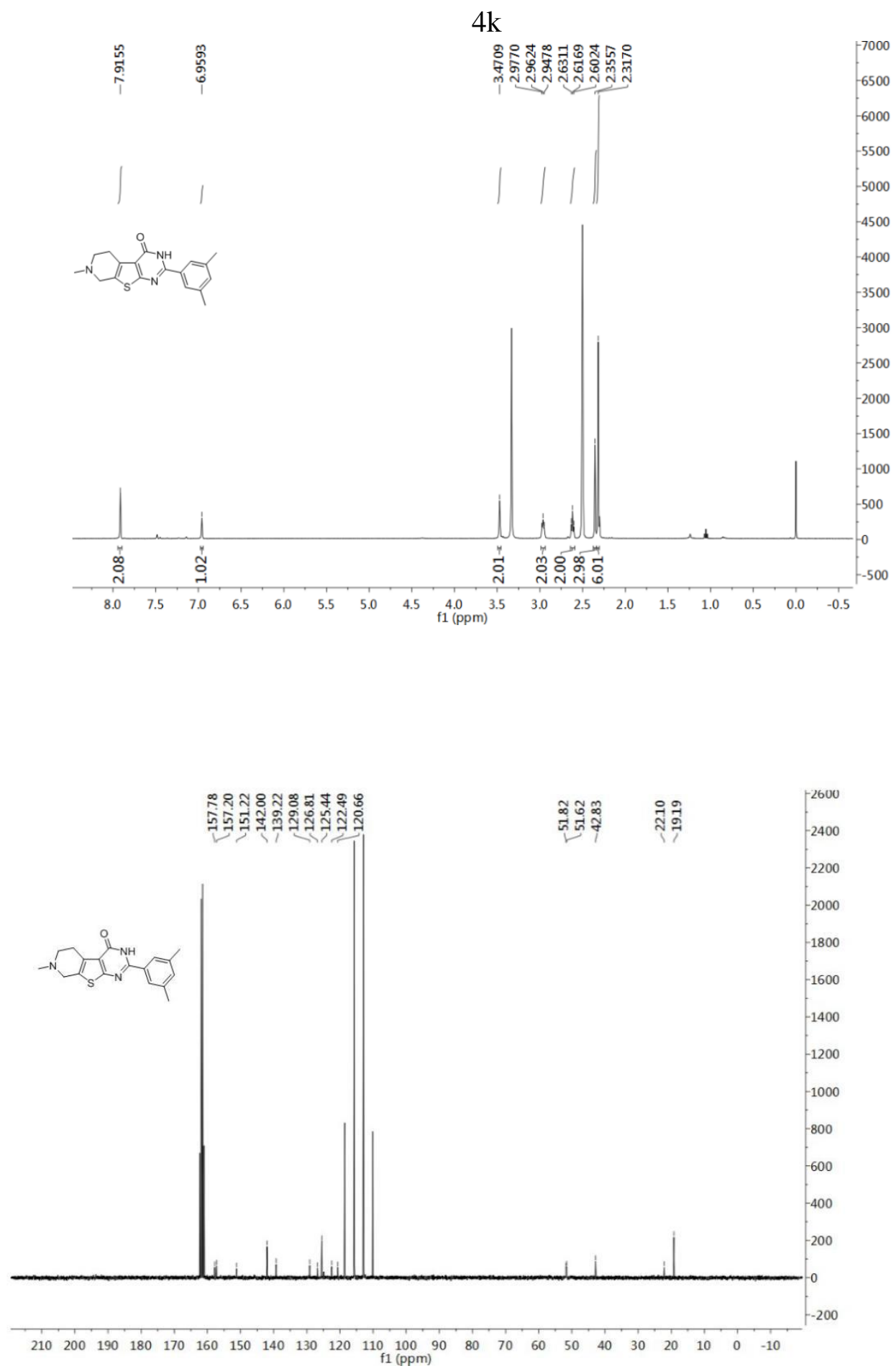
HPLC

Methanol/water $(\mathrm{v} / \mathrm{v})=80: 20,1 \mathrm{ml} / \mathrm{min}$

mAU

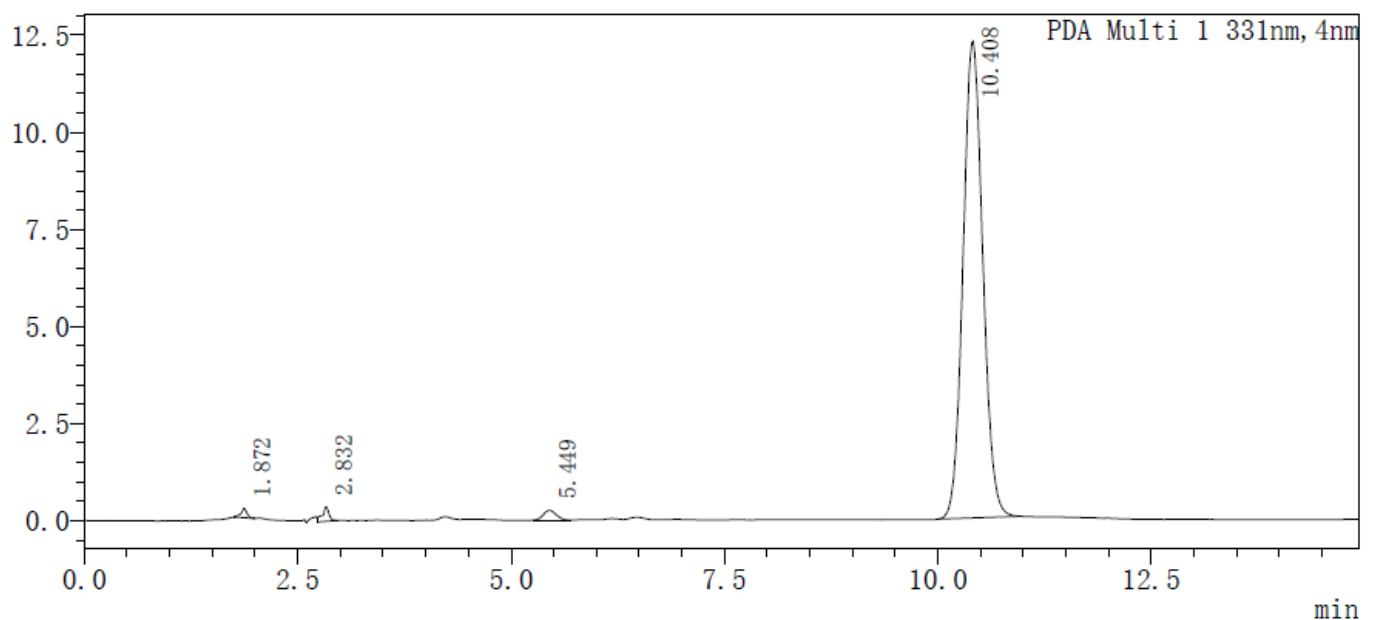

〈峰表〉

PDA Ch1 331nm

\begin{tabular}{|c|c|c|c|c|c|c|c|}
\hline 峰号 & 保留时间 & 面积 & 高度 & 浓度 & 浓度单位 & 标记 & 化合物名 \\
\hline 1 & 1.872 & 1132 & 235 & 0.557 & & & \\
\hline 2 & 2.832 & 1977 & 376 & 0.973 & & V & \\
\hline 3 & 5.449 & 2662 & 251 & 1. 310 & & & \\
\hline 4 & 10.408 & 197358 & 12273 & 97.159 & & & \\
\hline 总计 & & 203128 & 13135 & & & & \\
\hline
\end{tabular}

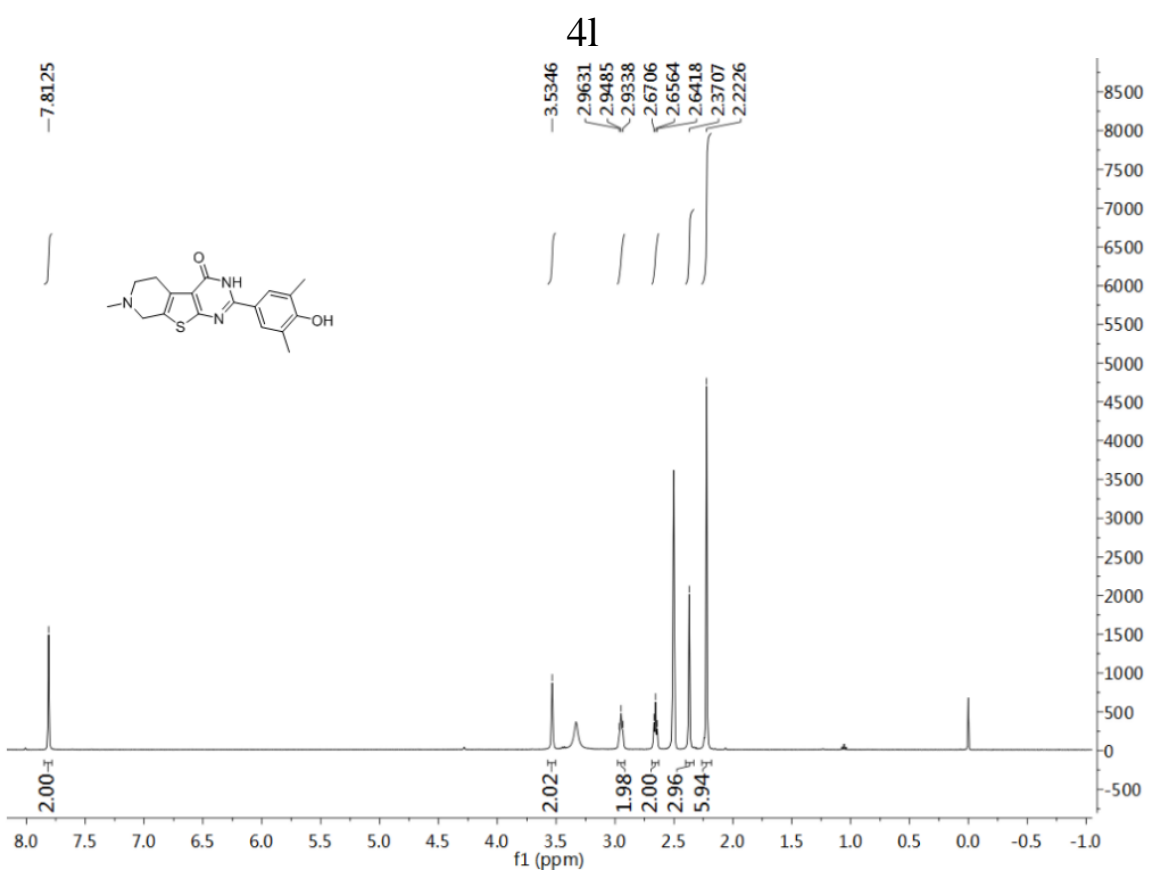




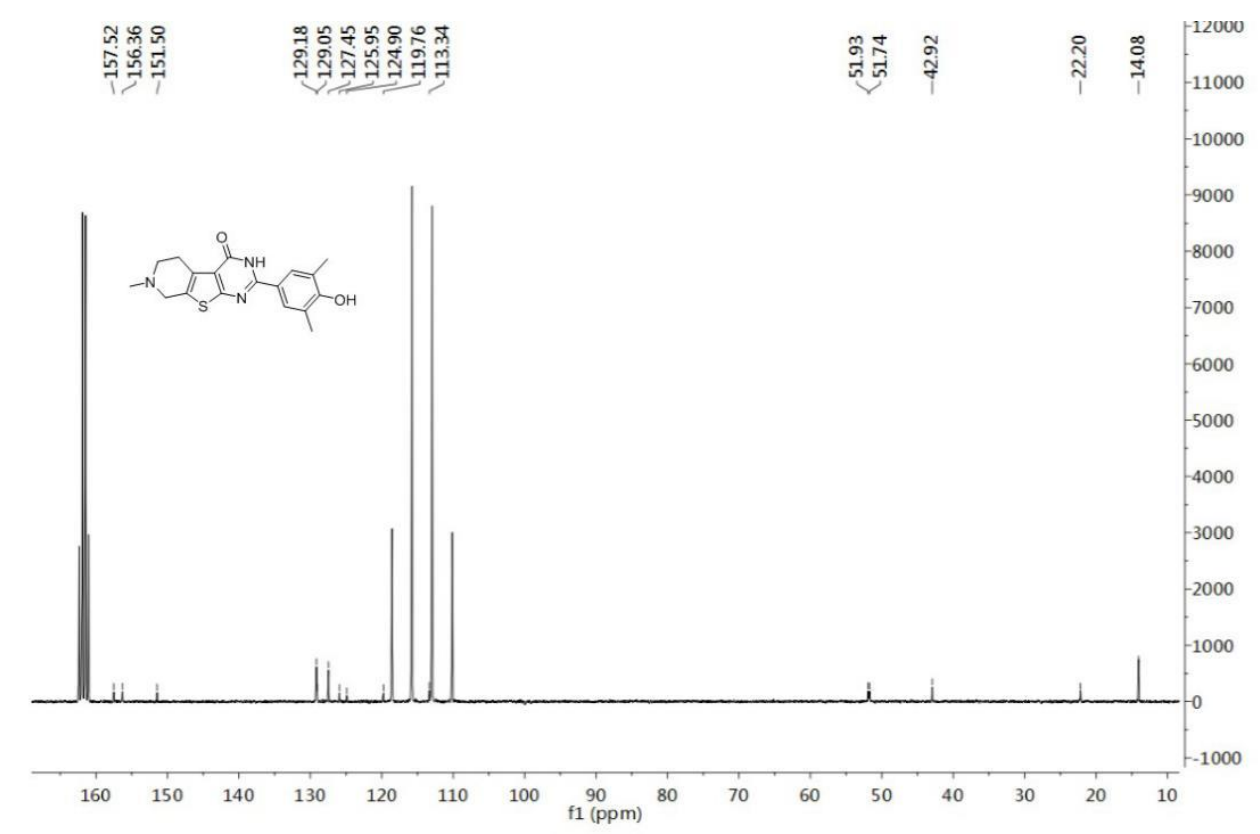

HPLC

Methanol $/$ water $(\mathrm{v} / \mathrm{v})=80: 20,1 \mathrm{ml} / \mathrm{min}$

mAU

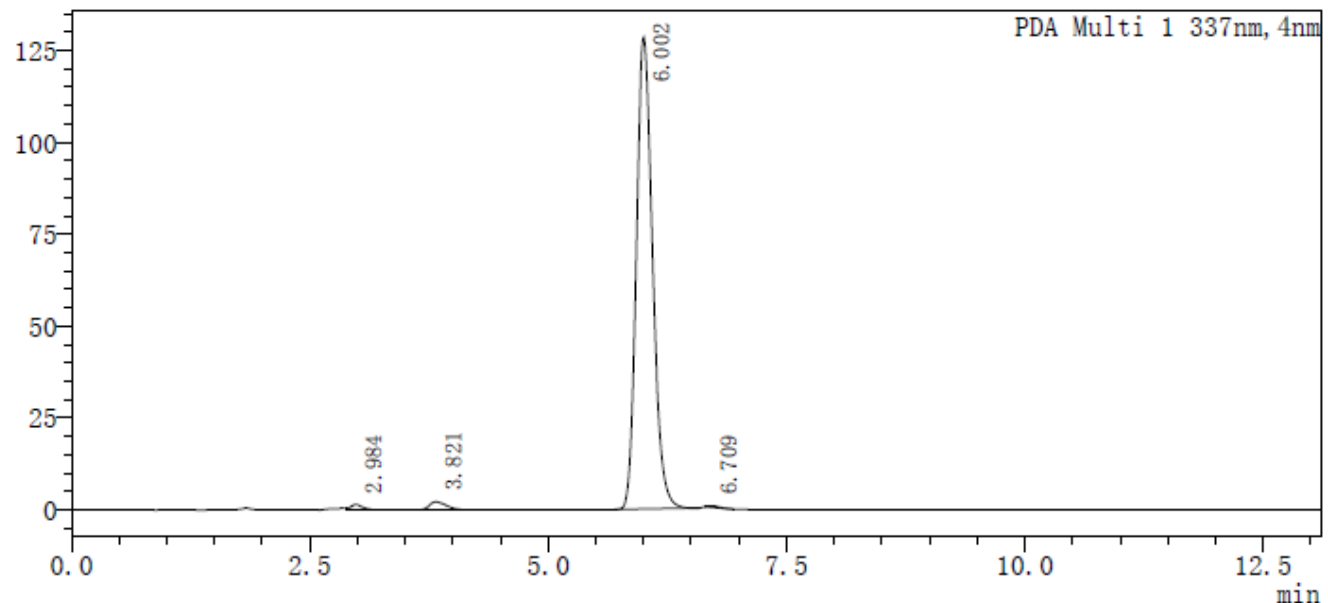

〈峰表〉

PDA Ch1 $337 \mathrm{~nm}$

\begin{tabular}{|c|c|c|c|c|c|c|c|}
\hline 峰号 & 保留时间 & 面积 & 高度 & 浓度 & 浓度单位 & 标记 & 化合物名 \\
\hline 1 & 2.984 & 13326 & 1485 & 0.855 & & & \\
\hline 2 & 3.821 & 26075 & 2153 & 1.673 & & & \\
\hline 3 & 6.002 & 1516091 & 128343 & 97.295 & & $M$ & \\
\hline 4 & 6.709 & 2745 & 389 & 0.176 & & M & \\
\hline 总计 & & 1558237 & 132370 & & & & \\
\hline
\end{tabular}



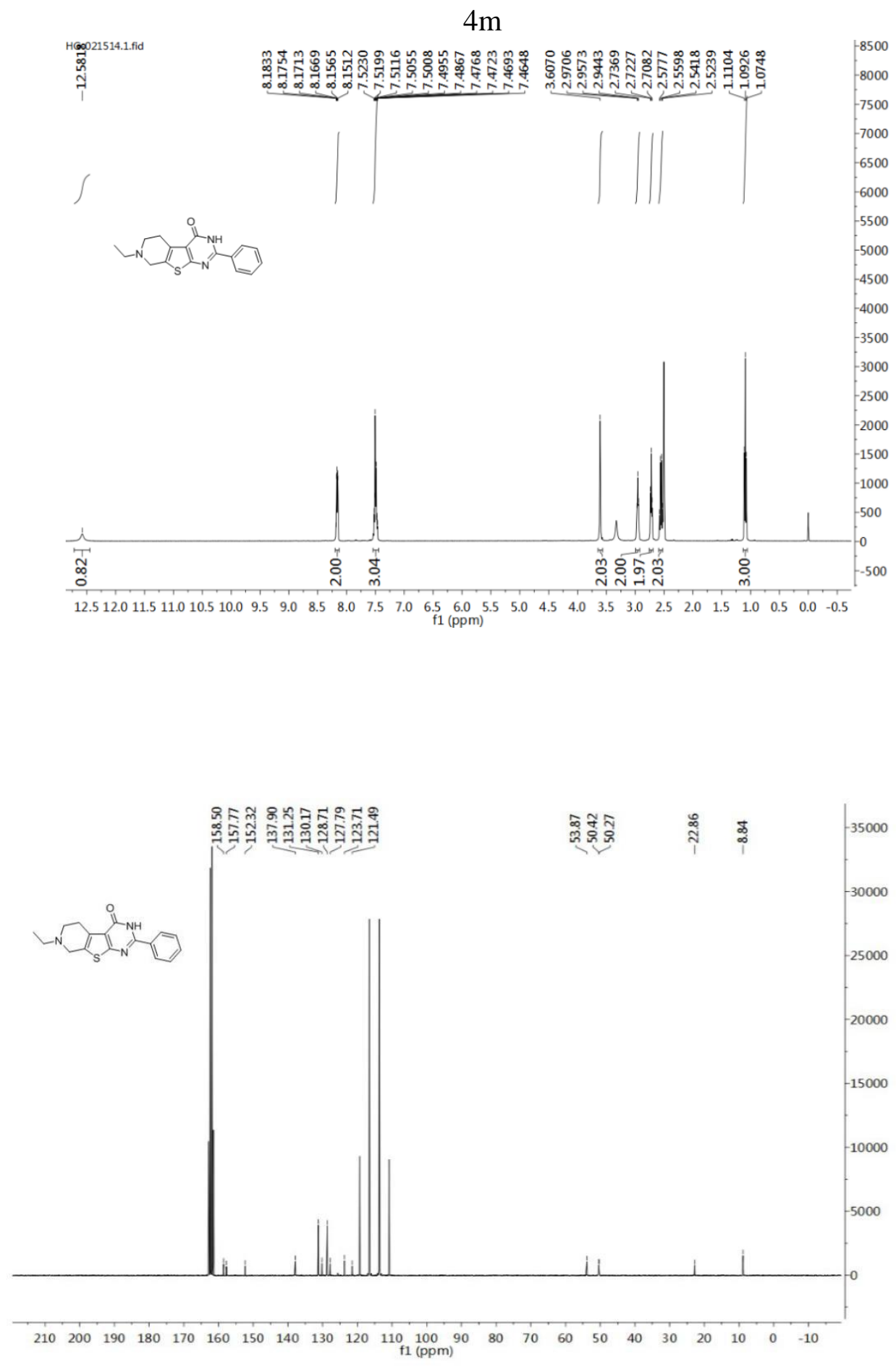
HPLC

Methanol/water $(\mathrm{v} / \mathrm{v})=80: 20,1 \mathrm{ml} / \mathrm{min}$

$\mathrm{mAU}$

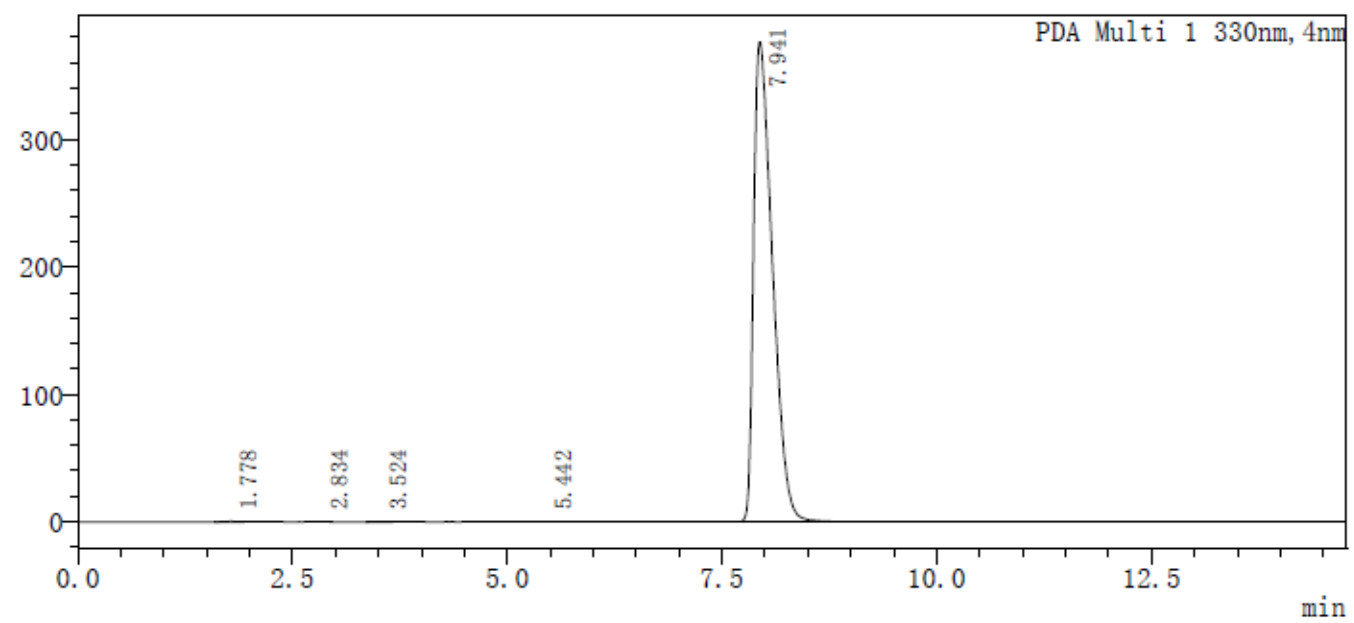

〈峰表〉

PDA Ch1 330nm

\begin{tabular}{|r|r|r|r|r|r|r|r|}
\hline 峰号 & 保留时间 & \multicolumn{1}{|c|}{ 面积 } & \multicolumn{1}{c|}{ 高度 } & \multicolumn{1}{c|}{ 浓度 } & 浓度单位 & 标记 & 化合物名 \\
\hline 1 & 1.778 & 5075 & 600 & 0.088 & & & \\
\hline 2 & 2.834 & 1851 & 357 & 0.032 & & V & \\
\hline 3 & 3.524 & 3489 & 400 & 0.061 & & & \\
\hline 4 & 5.442 & 2977 & 178 & 0.052 & & & \\
\hline 5 & 7.941 & 5748978 & 376020 & 99.768 & & & \\
\hline 总计 & & 5762369 & 377555 & & & & \\
\hline
\end{tabular}

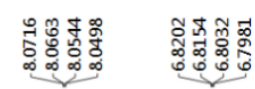

$4 n$

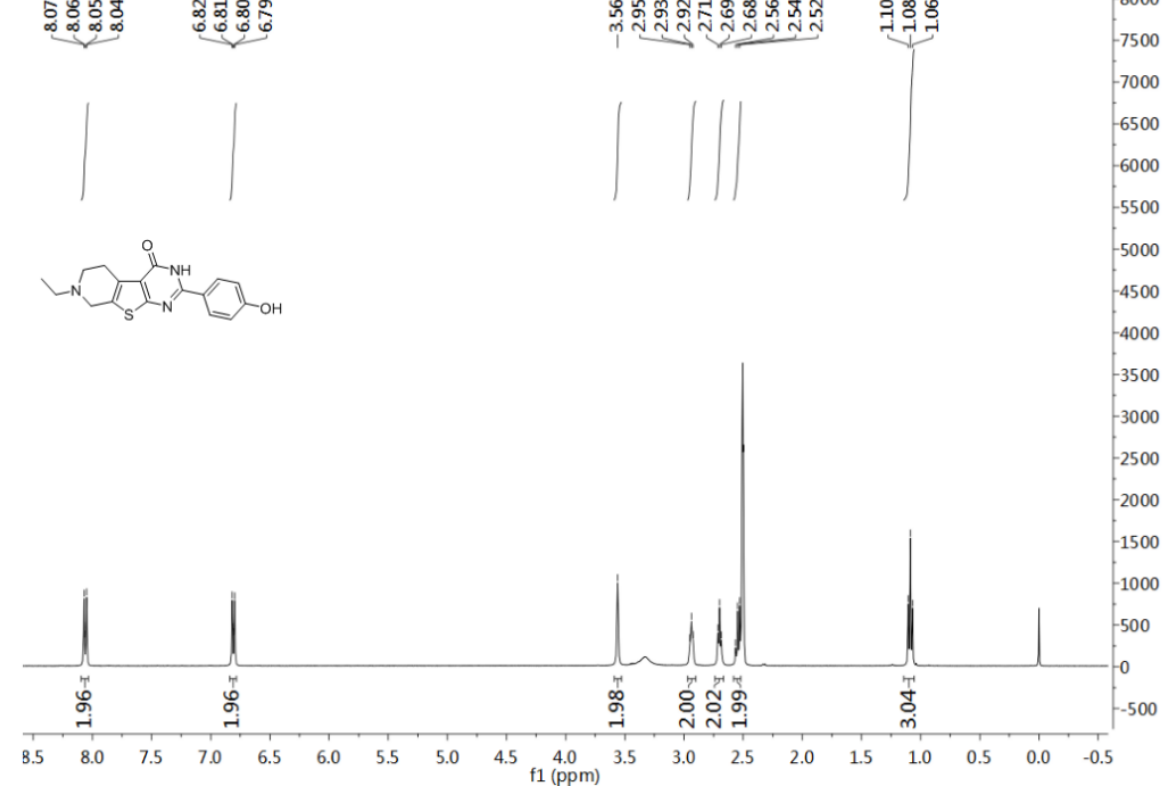




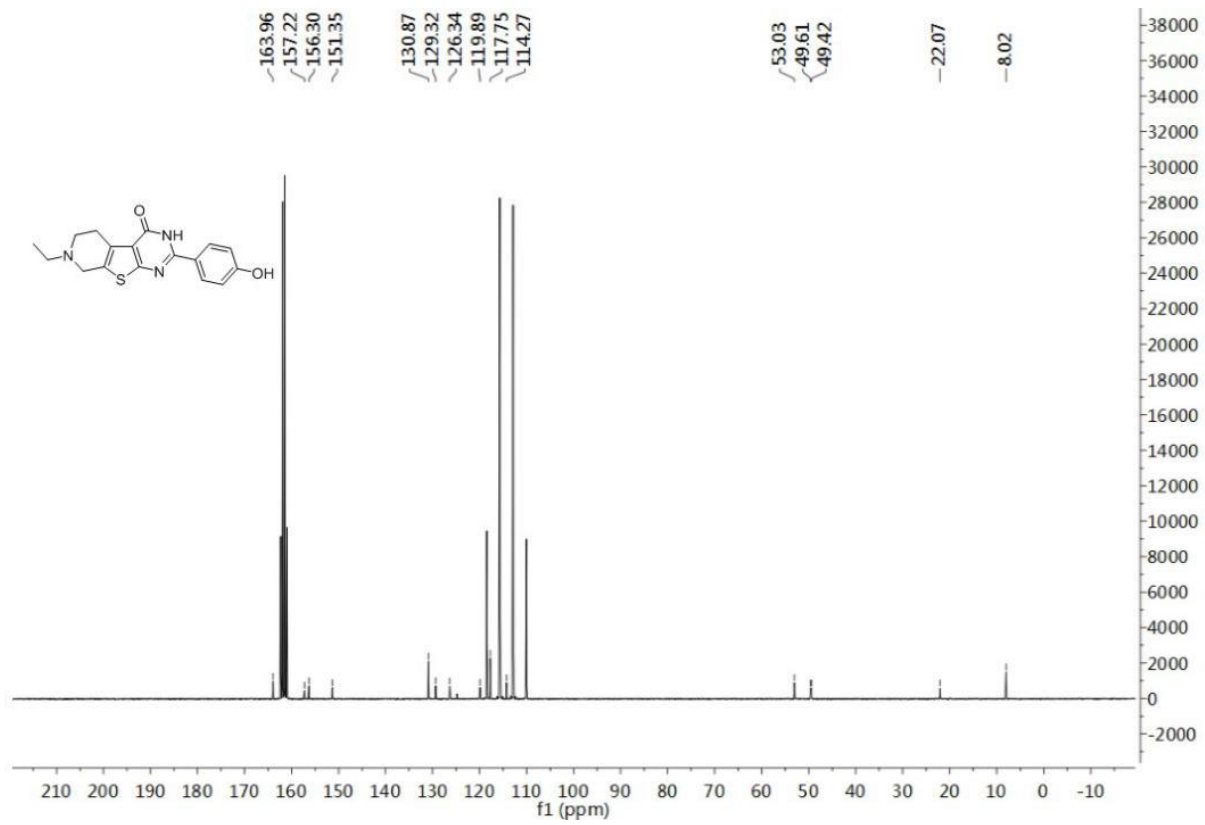

HPLC

Methanol/water(v/v)=80:20,1 $1 \mathrm{ml} / \mathrm{min}$

mAU

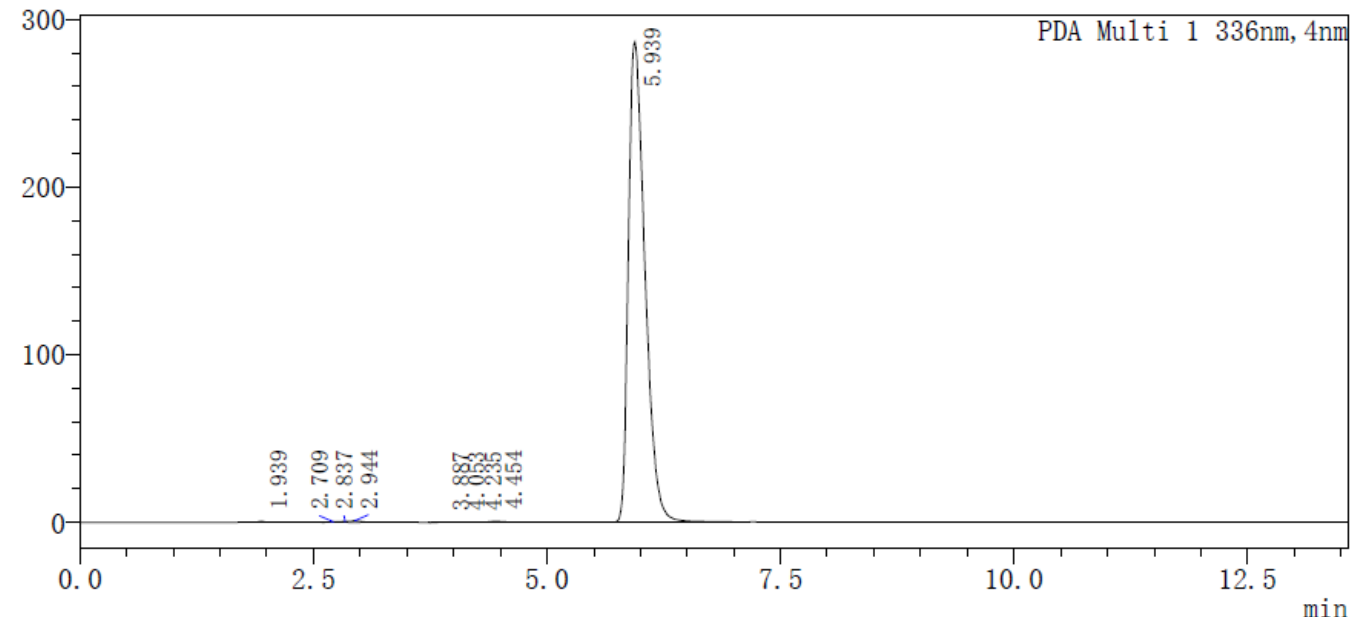

〈峰表〉

PDA Ch1 336nm

\begin{tabular}{|r|r|r|r|r|r|r|r|}
\hline PDA C 1 琒号 & 保留时间 & \multicolumn{1}{|c|}{ 面积 } & \multicolumn{1}{c|}{ 高度 } & \multicolumn{1}{c|}{ 浓度 } & 浓度单位 & 标记 & 化合物名 \\
\hline 1 & 1.939 & 2383 & 463 & 0.067 & & & \\
\hline 2 & 2.709 & 1384 & 262 & 0.039 & & & \\
\hline 3 & 2.837 & 3176 & 560 & 0.089 & & $\mathrm{~V}$ & \\
\hline 4 & 2.944 & 6902 & 875 & 0.194 & & $\mathrm{~V}$ & \\
\hline 5 & 3.887 & 1152 & 141 & 0.032 & & & \\
\hline 6 & 4.053 & 1189 & 115 & 0.033 & & $\mathrm{~V}$ & \\
\hline 7 & 4.235 & 1430 & 165 & 0.040 & & $\mathrm{~V}$ & \\
\hline 8 & 4.454 & 5669 & 496 & 0.160 & & $\mathrm{~V}$ & \\
\hline 9 & 5.939 & 3529142 & 286508 & 99.345 & & & \\
\hline 总计 & & 3552428 & 289586 & & & & \\
\hline
\end{tabular}



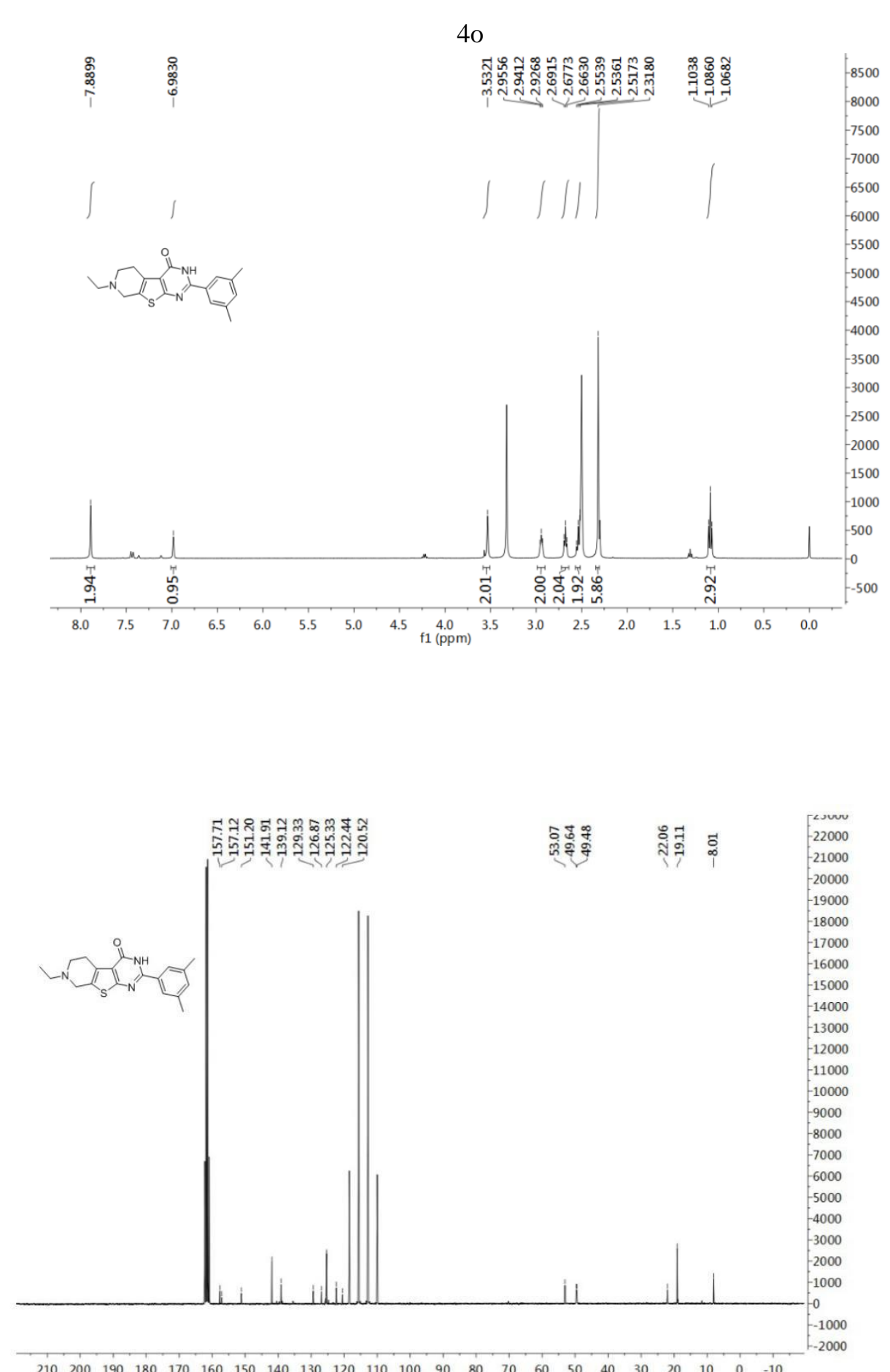

$\begin{array}{llllllllllllllllllllllll}210 & 200 & 190 & 180 & 170 & 160 & 150 & 140 & 130 & 120 & 110 & 100 & 90 & 80 & 70 & 60 & 50 & 40 & 30 & 20 & 10 & 0 & -10\end{array}$ 
HPLC

Methanol/water $(\mathrm{v} / \mathrm{v})=80: 20,1 \mathrm{ml} / \mathrm{min}$

$\mathrm{mAU}$

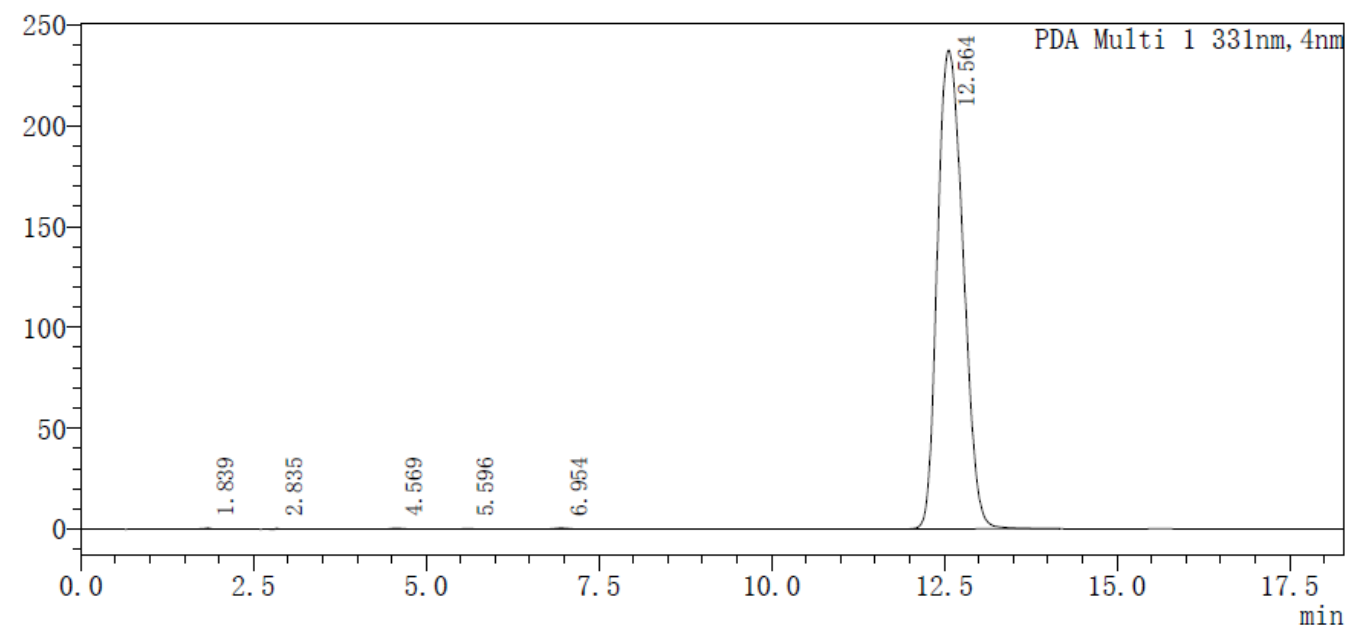

〈峰表〉

PDA Ch1 331nm

\begin{tabular}{|c|c|c|c|c|c|c|c|}
\hline 峰号 & 保留时间 & 面积 & 高度 & 浓度 & 浓度单位 & 标记 & 化合物名 \\
\hline 1 & 1.839 & 3524 & 488 & 0.057 & & & \\
\hline 2 & 2.835 & 1887 & 369 & 0.031 & & $\mathrm{~V}$ & \\
\hline 3 & 4.569 & 4888 & 367 & 0.079 & & & \\
\hline 4 & 5.596 & 2392 & 252 & 0.039 & & & \\
\hline 5 & 6.954 & 5665 & 467 & 0.092 & & & \\
\hline 6 & 12.564 & 6147843 & 237368 & 99.702 & & & \\
\hline 总计 & & 6166199 & 239312 & & & & \\
\hline
\end{tabular}

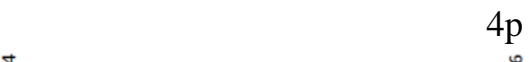

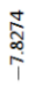

$4 \mathrm{p}$

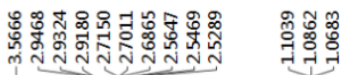

6000

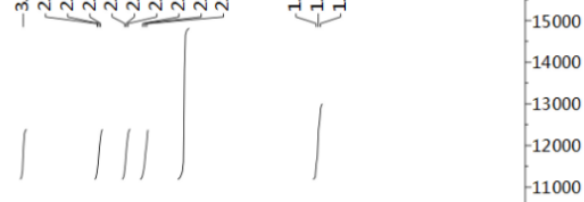
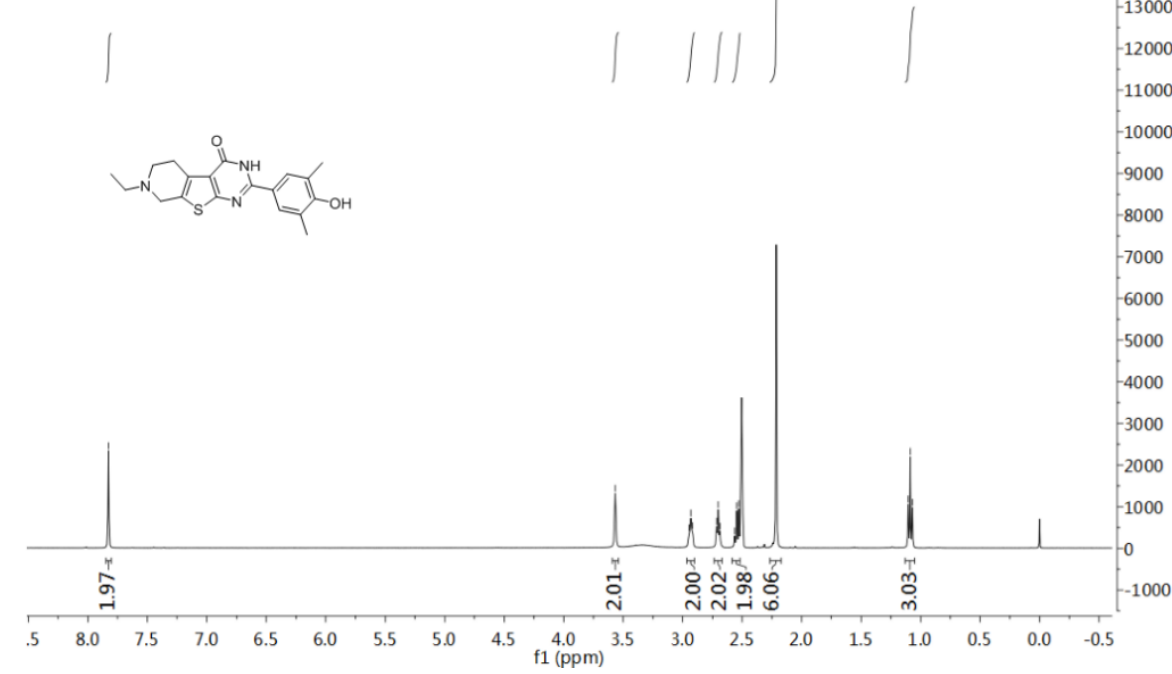


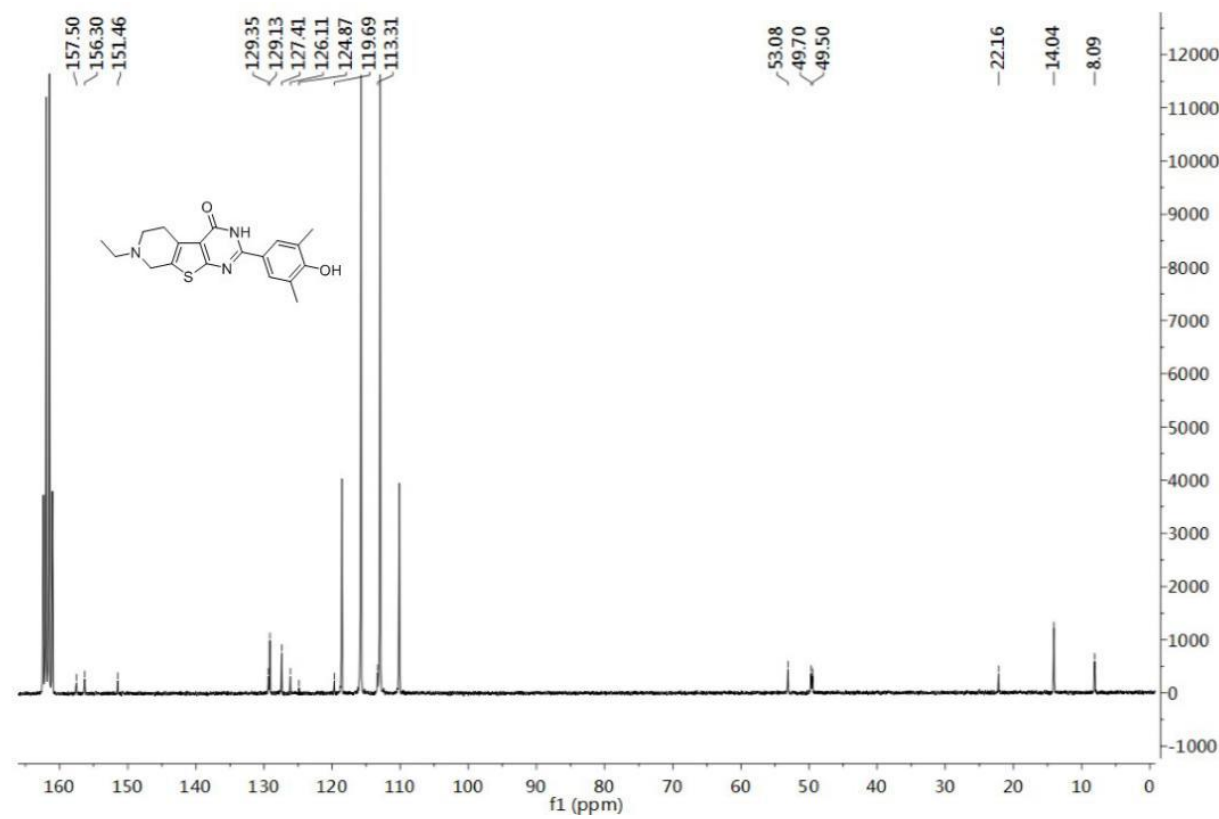

\section{HPLC}

Methanol $/$ water $(\mathrm{v} / \mathrm{v})=80: 20,1 \mathrm{ml} / \mathrm{min}$

$\mathrm{mAU}$

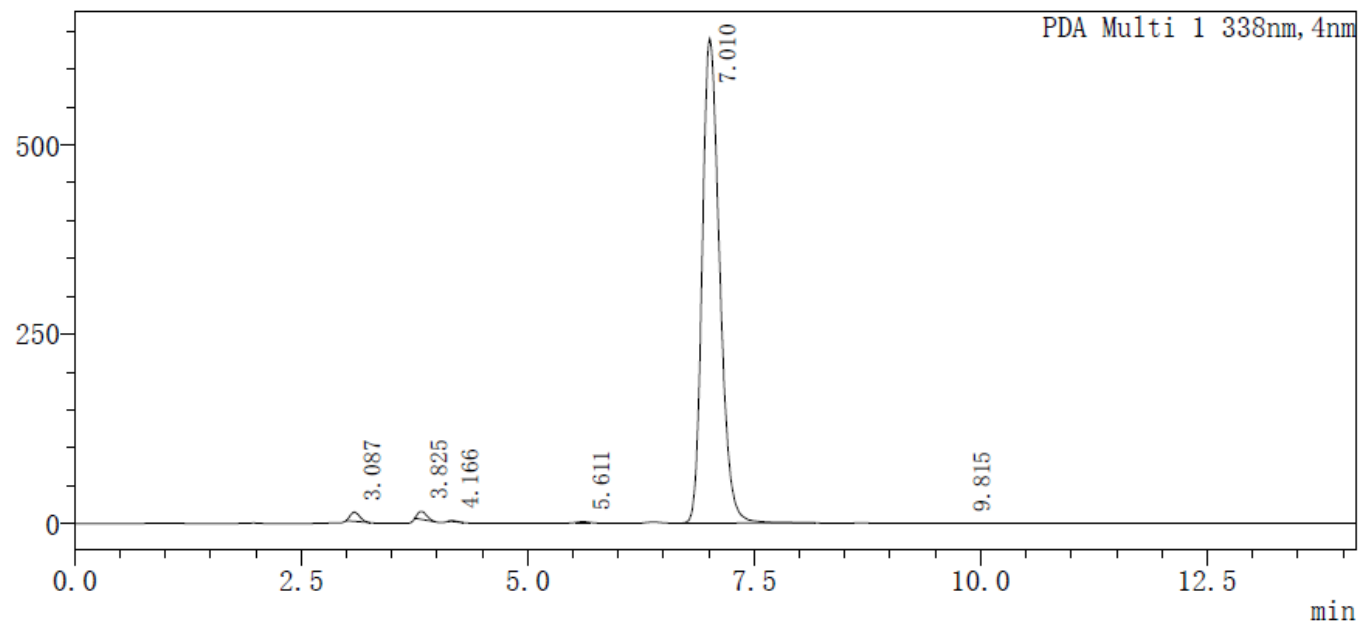

〈峰表〉

PDA Ch1 338nm

\begin{tabular}{|r|r|r|r|r|r|r|r|}
\hline \multicolumn{1}{|r|}{ 峰号 } & 保留时间 & \multicolumn{1}{|c|}{ 面积 } & \multicolumn{1}{c|}{ 高度 } & \multicolumn{1}{|c|}{ 浓度 } & 浓度单位 & 标记 & 化合物名 \\
\hline 1 & 3.087 & 86004 & 11961 & 0.981 & & $\mathrm{M}$ & \\
\hline 2 & 3.825 & 72125 & 10649 & 0.823 & & $\mathrm{M}$ & \\
\hline 3 & 4.166 & 5029 & 988 & 0.057 & & $\mathrm{M}$ & \\
\hline 4 & 5.611 & 4820 & 809 & 0.055 & & $\mathrm{M}$ & \\
\hline 5 & 7.010 & 8596269 & 640316 & 98.079 & & $\mathrm{M}$ & \\
\hline 6 & 9.815 & 361 & 45 & 0.004 & & $\mathrm{M}$ & \\
\hline 总计 & & 8764608 & 664767 & & & &
\end{tabular}



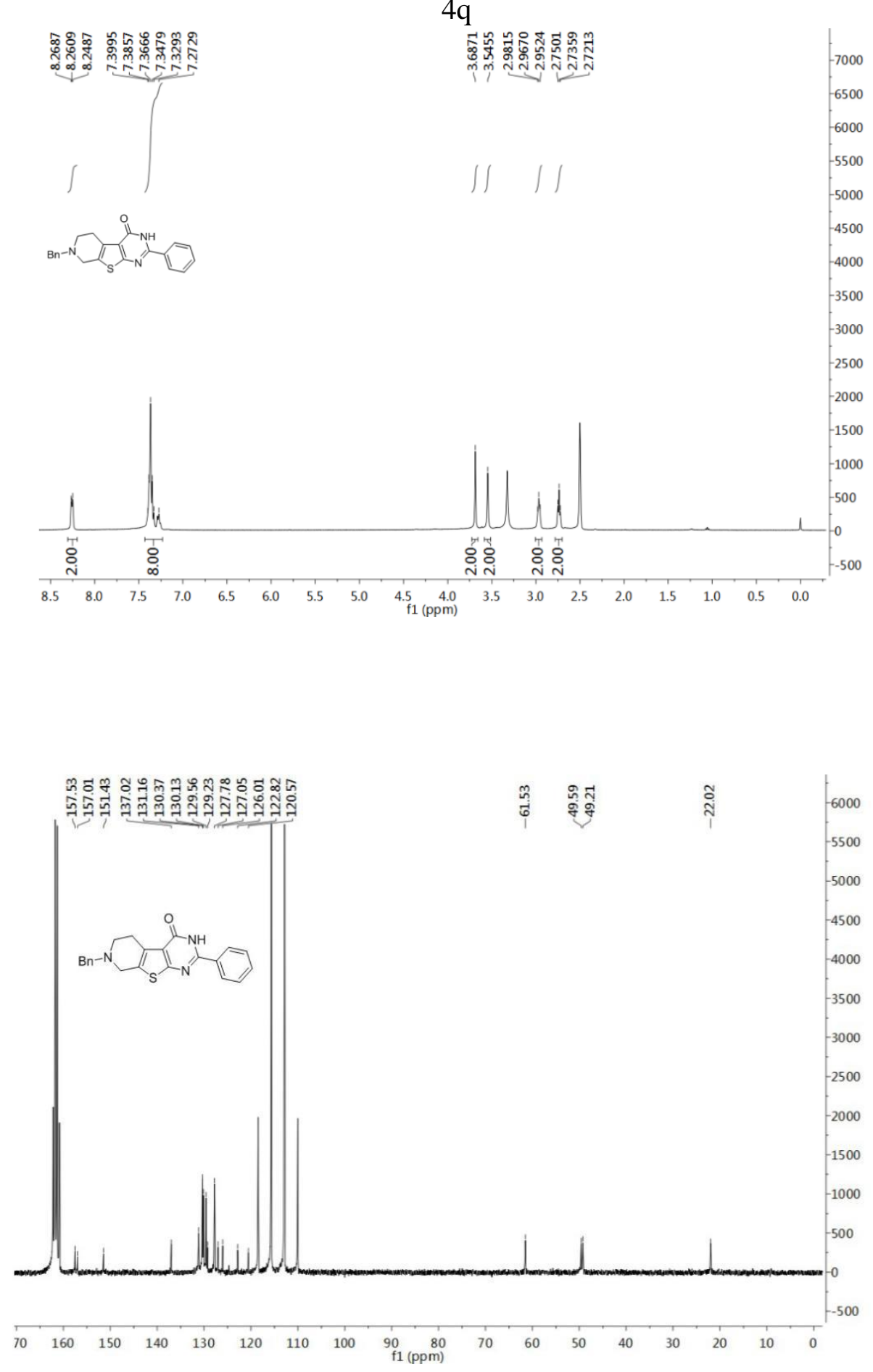
HPLC

Methanol/water $(\mathrm{v} / \mathrm{v})=80: 20,1 \mathrm{ml} / \mathrm{min}$

$\mathrm{mAU}$

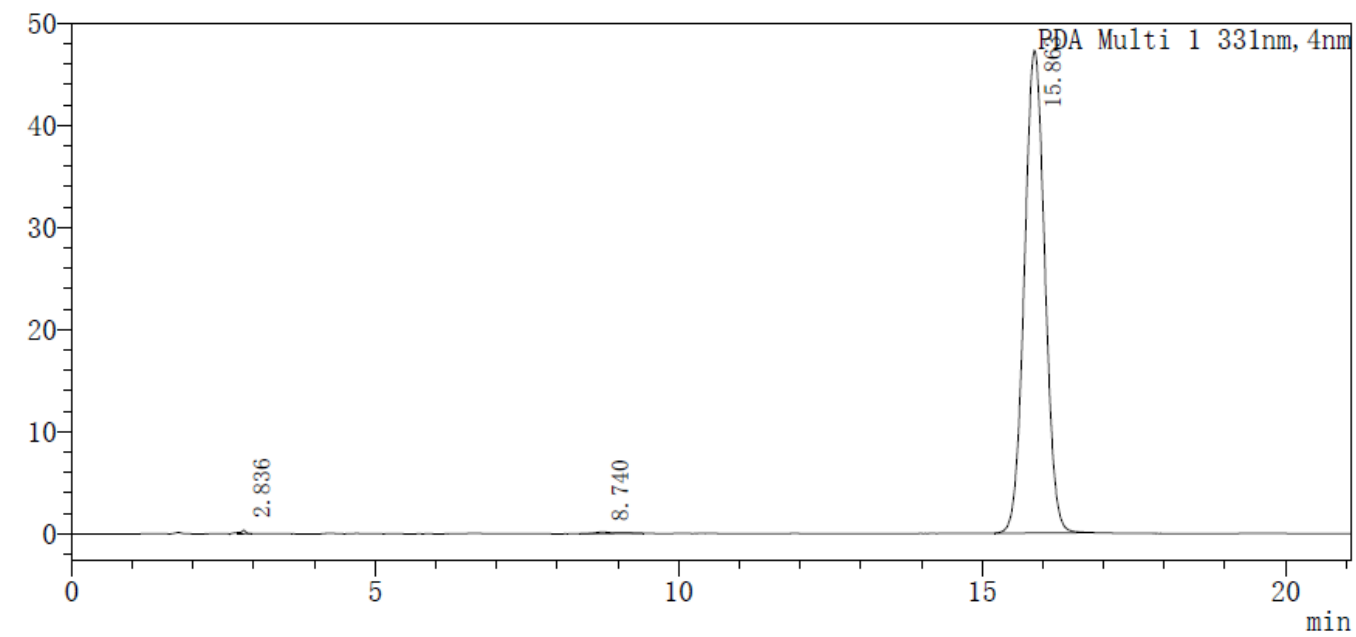

〈峰表〉

PDA Ch1 331nm

\begin{tabular}{|r|r|r|r|r|r|r|r|}
\hline PDA C峰号 & 保留时间 & \multicolumn{1}{|c|}{ 面积 } & \multicolumn{1}{|c|}{ 高度 } & \multicolumn{1}{|c|}{ 浓度 } & 浓度单位 & 标记 & 化合物名 \\
\hline 1 & 2.836 & 1852 & 372 & 0.167 & & $\mathrm{~V}$ & \\
\hline 2 & 8.740 & 2764 & 127 & 0.249 & & $\mathrm{M}$ & \\
\hline 3 & 15.863 & 1104418 & 47247 & 99.584 & & & \\
\hline 总计 & & 1109034 & 47746 & & & & \\
\hline
\end{tabular}

$4 \mathrm{r}$

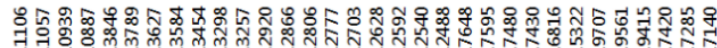

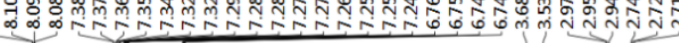

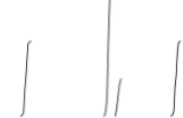

管

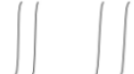

9000

8000

7000

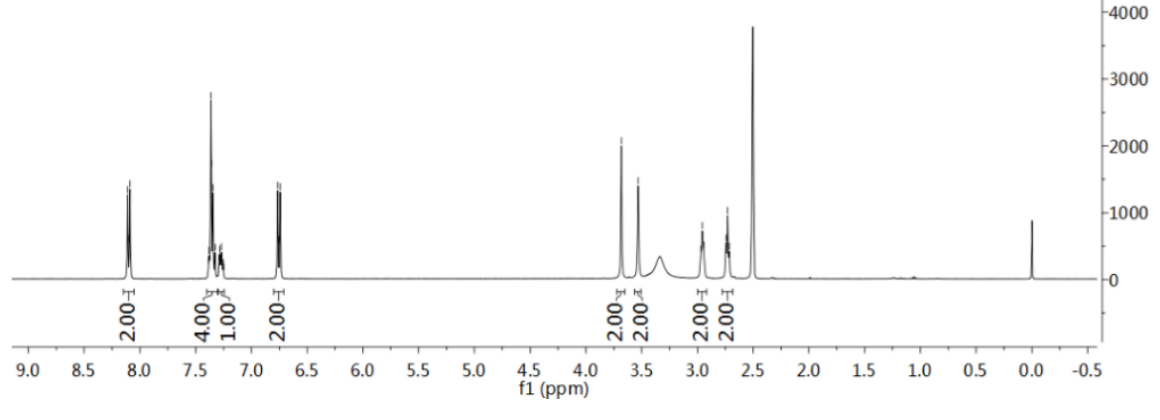




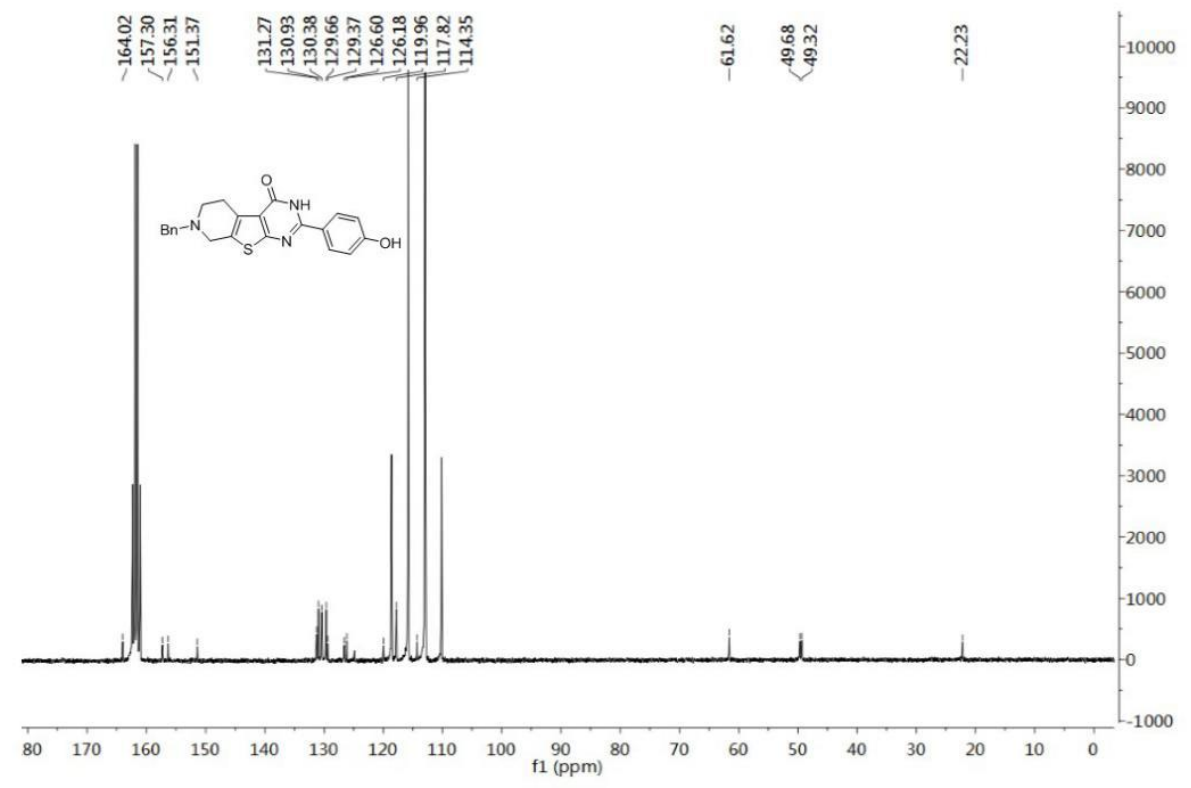

\section{HPLC}

Methanol $/$ water $(\mathrm{v} / \mathrm{v})=80: 20,1 \mathrm{ml} / \mathrm{min}$

$\mathrm{mAU}$

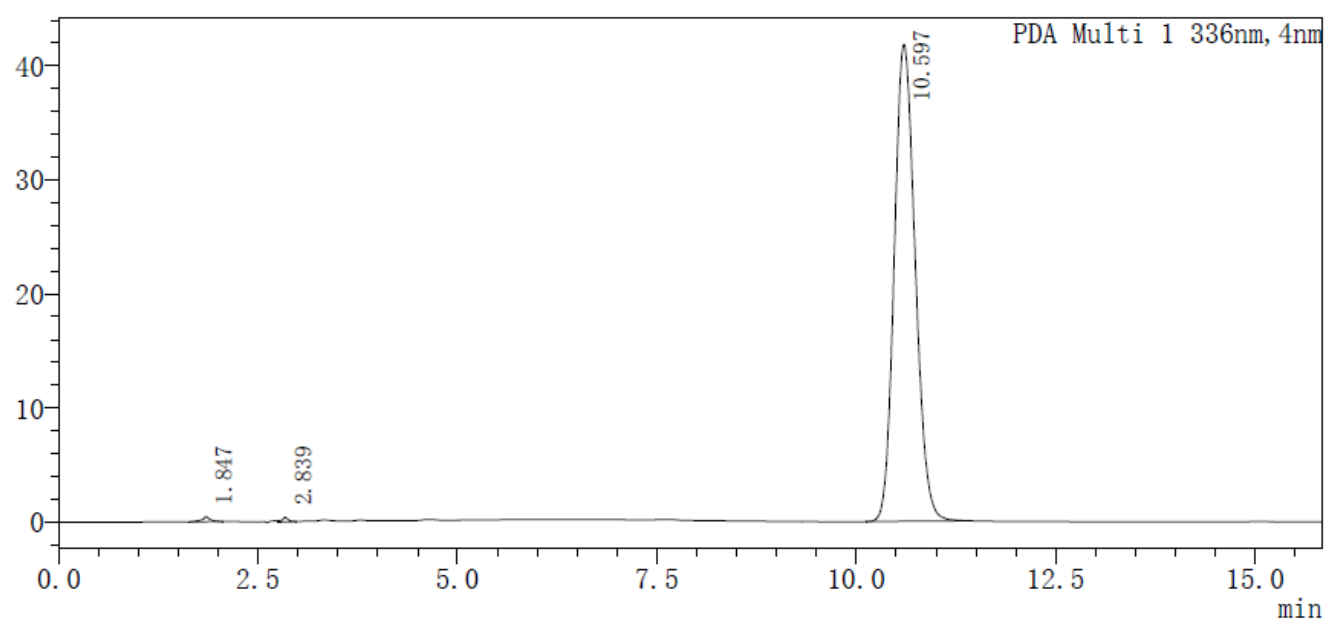

〈峰表〉

PDA Ch1 336nm

\begin{tabular}{|r|r|r|r|r|r|r|r|}
\hline \multicolumn{1}{|c|}{ 峰号 } & 保留时间 & \multicolumn{1}{|c|}{ 面积 } & \multicolumn{1}{c|}{ 高度 } & \multicolumn{1}{c|}{ 浓度 } & 浓度单位 & 标记 & 化合物名 \\
\hline 1 & 1.847 & 2891 & 447 & 0.376 & & & \\
\hline 2 & 2.839 & 1985 & 404 & 0.258 & & $\mathrm{~V}$ & \\
\hline 3 & 10.597 & 764640 & 41797 & 99.366 & & & \\
\hline 总计 & & 769516 & 42648 & & & & \\
\hline
\end{tabular}


$4 \mathrm{~s}$
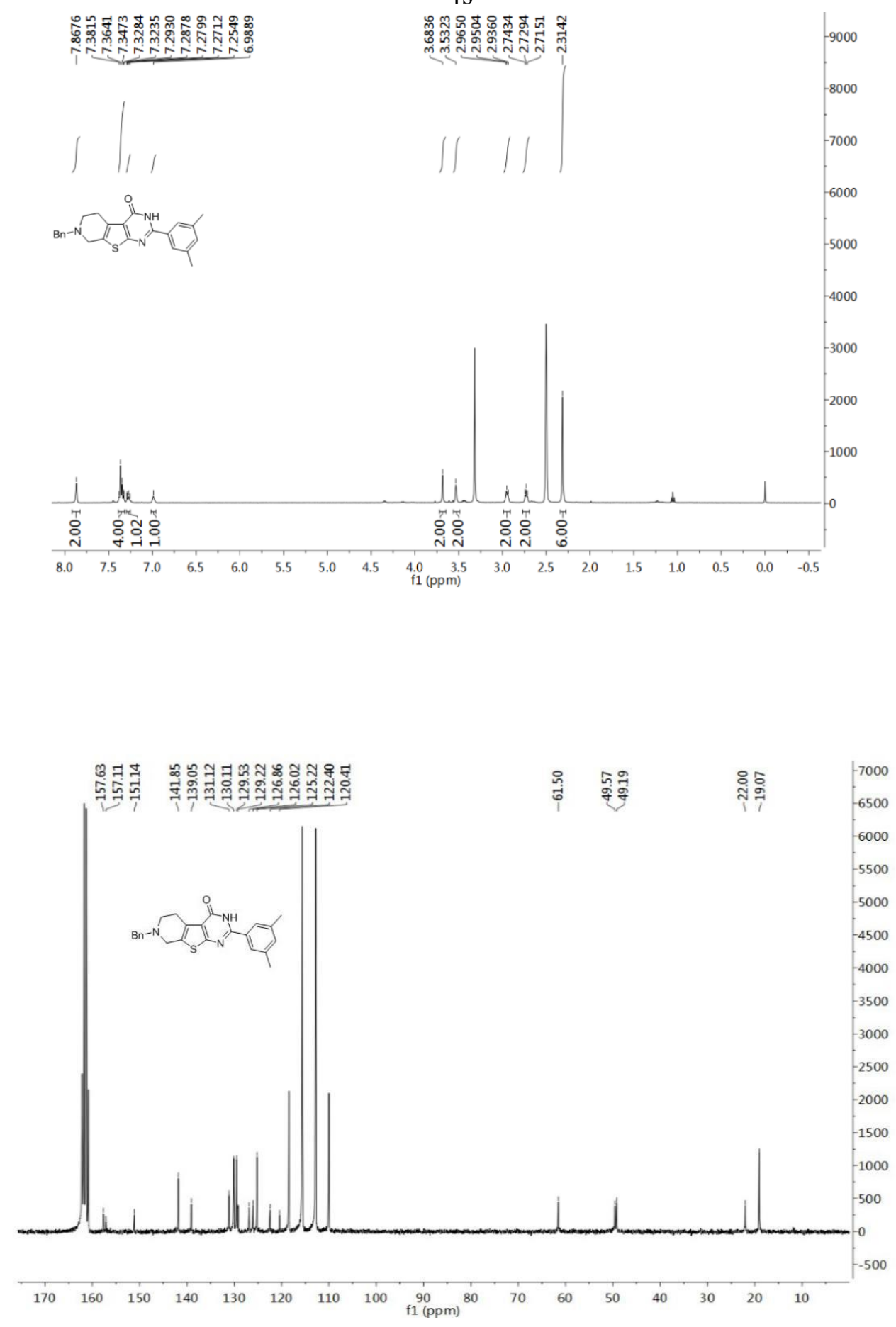
HPLC

Methanol/water $(\mathrm{v} / \mathrm{v})=80: 20,1 \mathrm{ml} / \mathrm{min}$

$\mathrm{mAU}$

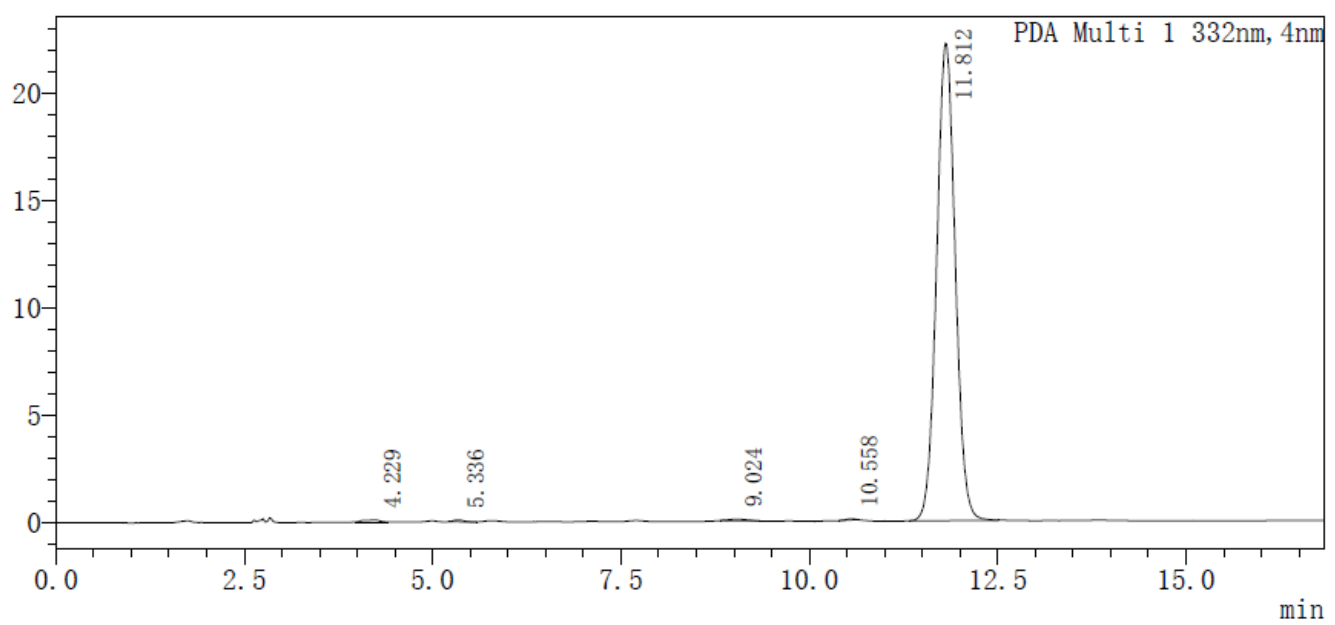

〈峰表〉

PDA Ch1 332nm

\begin{tabular}{|c|c|c|c|c|c|c|c|}
\hline 峰号 & 保留时间 & 面积 & 高度 & 浓度 & 浓度单位 & 标记 & 化合物名 \\
\hline 1 & 4.229 & 1298 & 101 & 0.336 & & & \\
\hline 2 & 5.336 & 644 & 81 & 0.167 & & M & \\
\hline 3 & 9.024 & 1333 & 75 & 0.345 & & M & \\
\hline 4 & 10.558 & 459 & 53 & 0.119 & & M & \\
\hline 5 & 11.812 & 382323 & 22218 & 99.033 & & & \\
\hline 总计 & & 386057 & 22529 & & & & \\
\hline
\end{tabular}

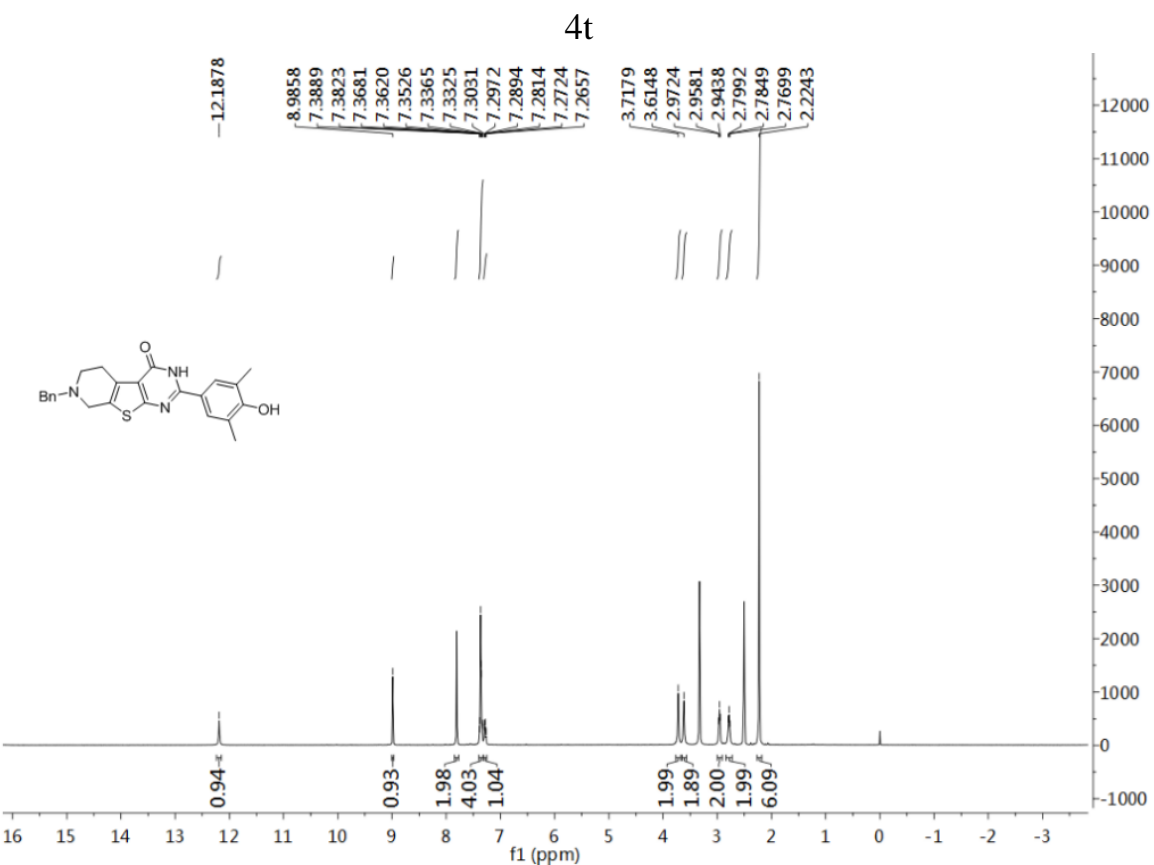




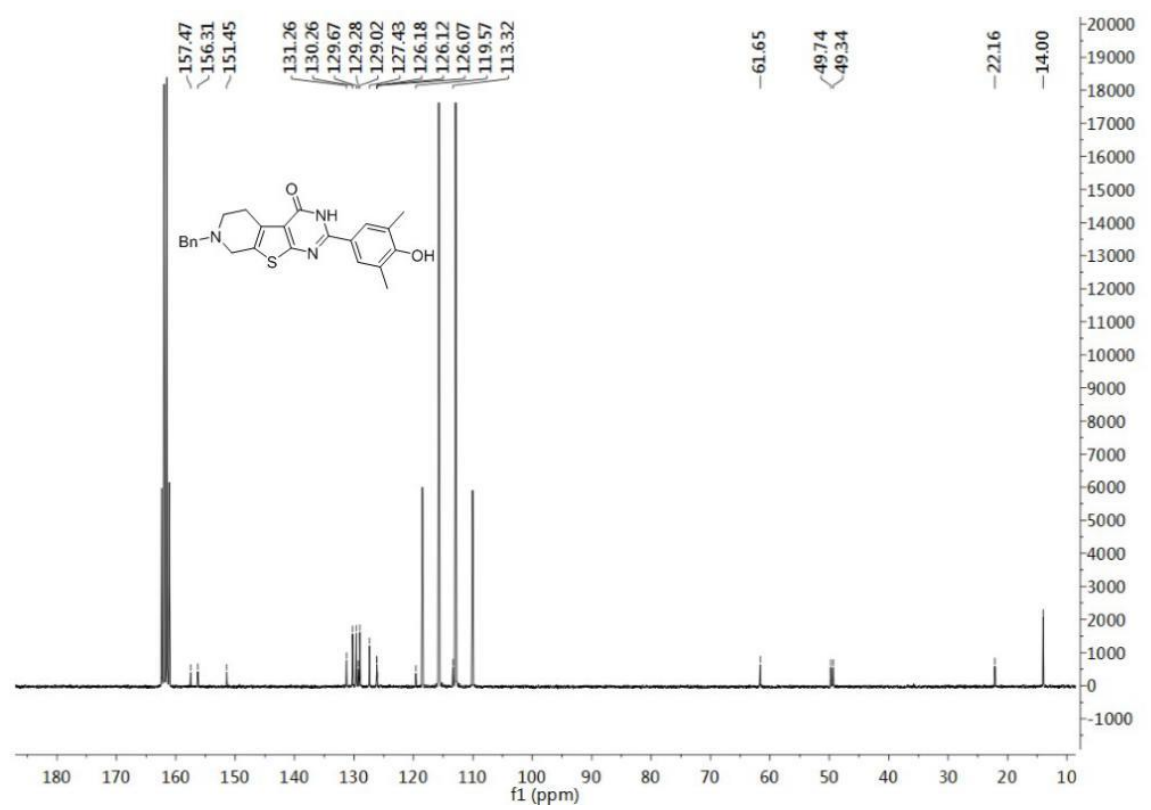

HPLC

Methanol $/$ water $(\mathrm{v} / \mathrm{v})=80: 20,1 \mathrm{ml} / \mathrm{min}$

$\mathrm{mAU}$

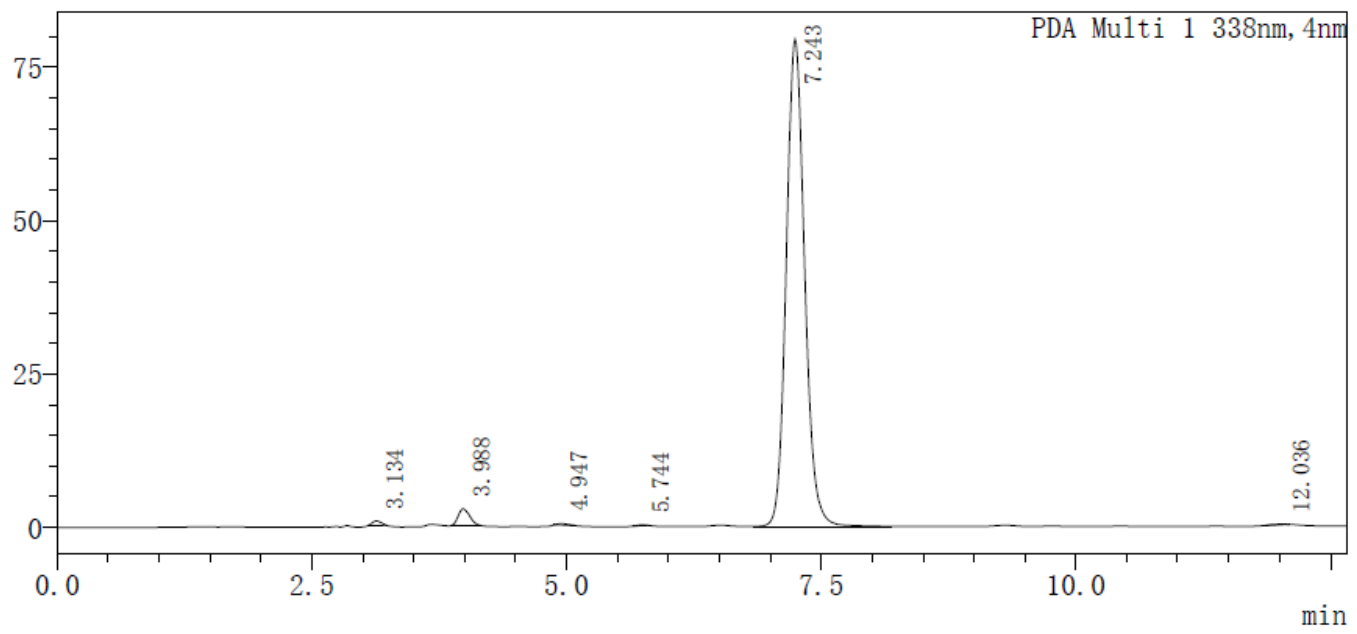

〈峰表〉

PDA Ch1 338nm

\begin{tabular}{|r|r|r|r|r|r|r|r|}
\hline \hline 峰号 & 保留时间 & \multicolumn{1}{|c|}{ 面积 } & \multicolumn{1}{c|}{ 高度 } & \multicolumn{1}{c|}{ 浓度 } & 浓度单位 & 标记 & 化合物名 \\
\hline 1 & 3.134 & 4533 & 737 & 0.443 & & $\mathrm{M}$ & \\
\hline 2 & 3.988 & 19633 & 2650 & 1.921 & & $\mathrm{M}$ & \\
\hline 3 & 4.947 & 1659 & 231 & 0.162 & & $\mathrm{M}$ & \\
\hline 4 & 5.744 & 731 & 123 & 0.072 & & $\mathrm{M}$ & \\
\hline 5 & 7.243 & 994384 & 79424 & 97.274 & & & \\
\hline 6 & 12.036 & 1311 & 105 & 0.128 & & $\mathrm{M}$ & \\
\hline 总计 & & 1022252 & 83270 & & & & \\
\hline
\end{tabular}




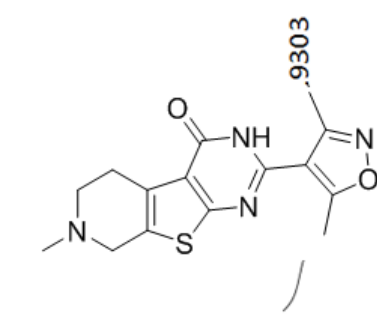

$9 \mathrm{a}$

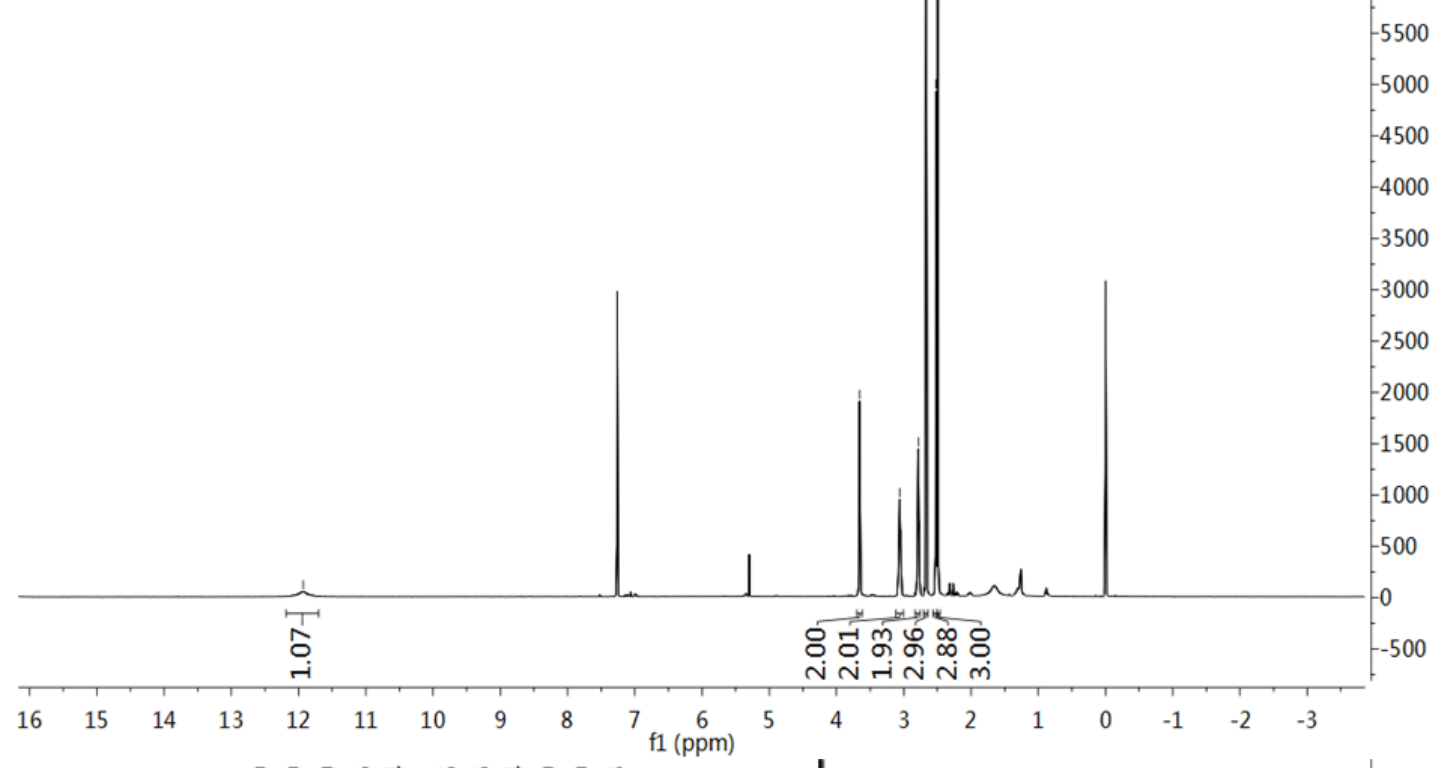

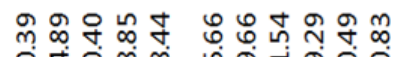

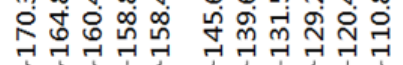

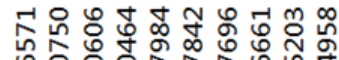

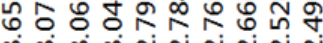

$-8500$

m m m n N N N N

$-7500$

$-7000$

$-6500$

$-6000$

500

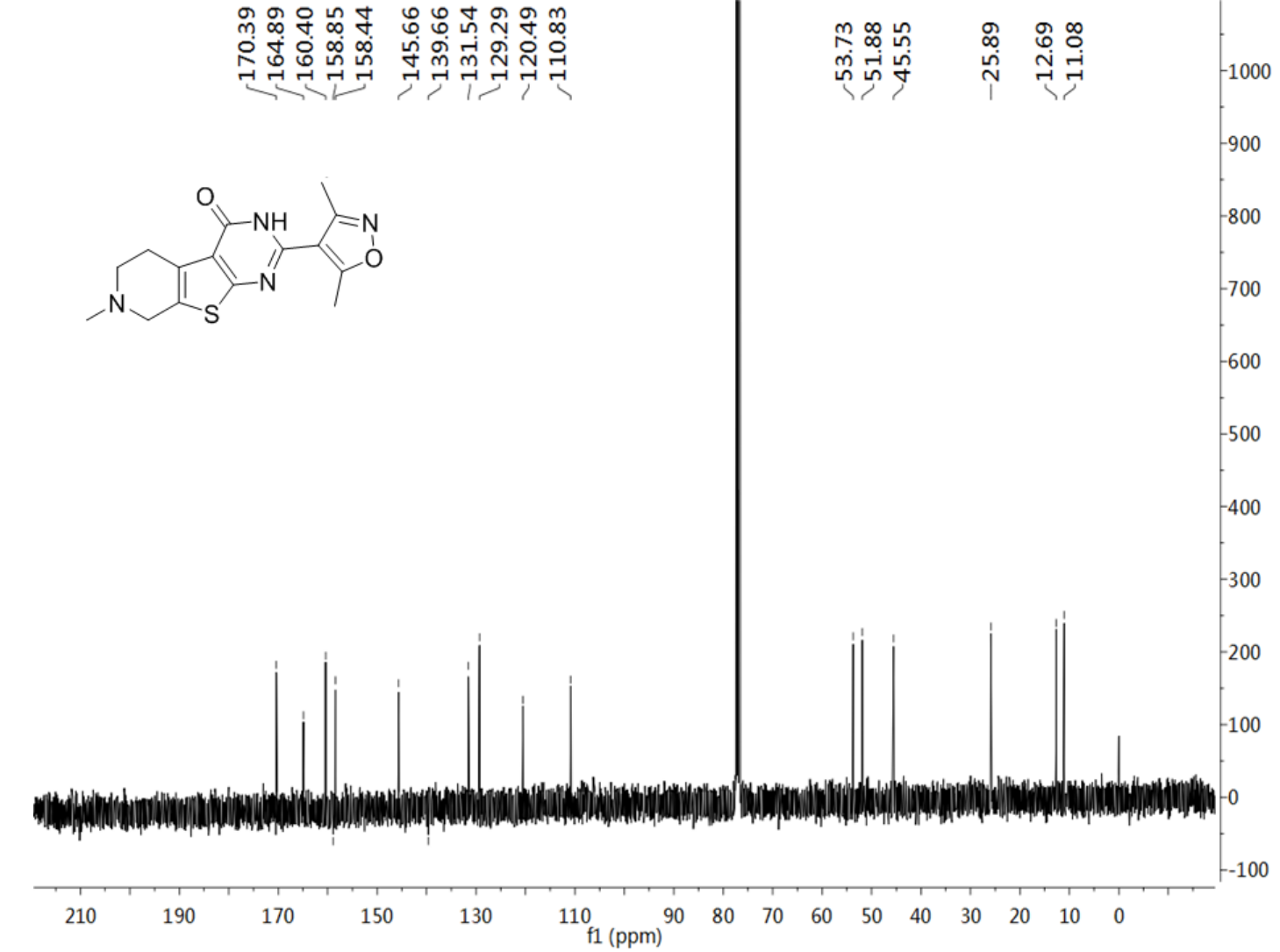


HPLC

Methanol/water(v/v)=90:10,1 $\mathrm{ml} / \mathrm{min}$

mAU

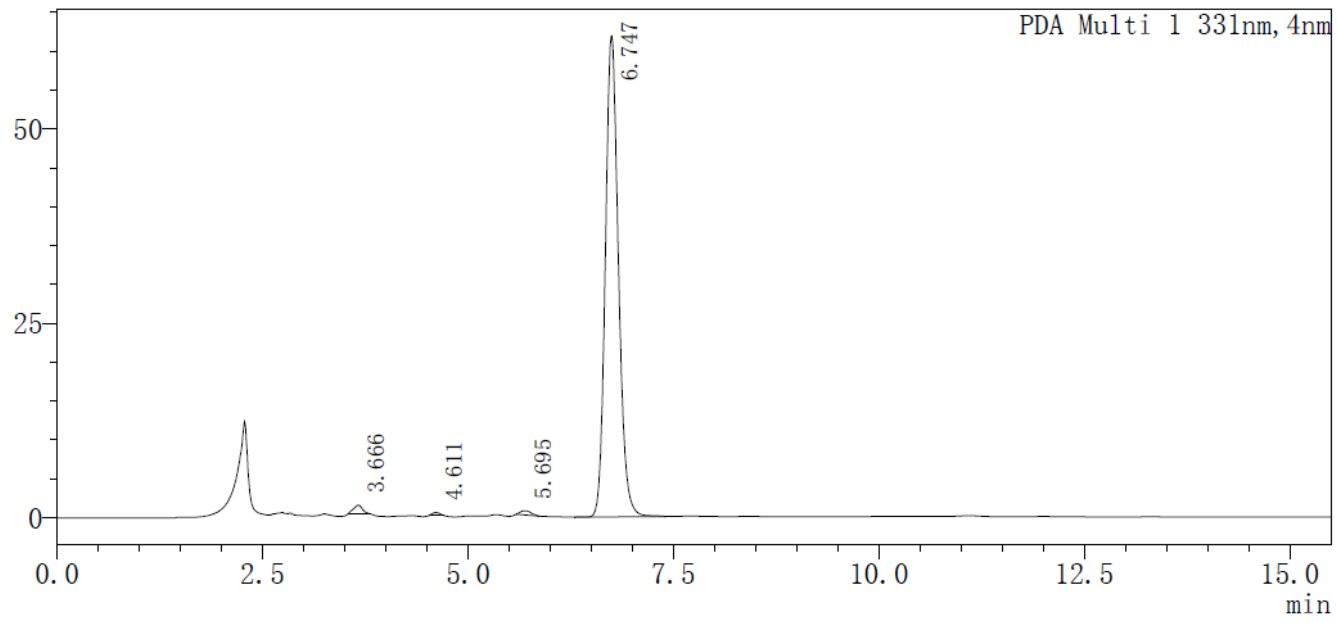

〈峰表〉

PDA Ch1 331nm

\begin{tabular}{|r|r|r|r|r|r|r|r|}
\hline 峰号 & 保留时间 & \multicolumn{1}{|c|}{ 面积 } & \multicolumn{1}{|c|}{ 高度 } & \multicolumn{1}{|c|}{ 浓度 } & 浓度单位 & 标记 & 化合物名 \\
\hline 1 & 3.666 & 8890 & 1124 & 1.264 & & $\mathrm{M}$ & \\
\hline 2 & 4.611 & 2143 & 351 & 0.305 & & $\mathrm{M}$ & \\
\hline 3 & 5.695 & 4813 & 552 & 0.685 & & $\mathrm{M}$ & \\
\hline 4 & 6.747 & 687305 & 61819 & 97.746 & & $\mathrm{M}$ & \\
\hline 总计 & & 703151 & 63846 & & & & \\
\hline
\end{tabular}

$9 b$

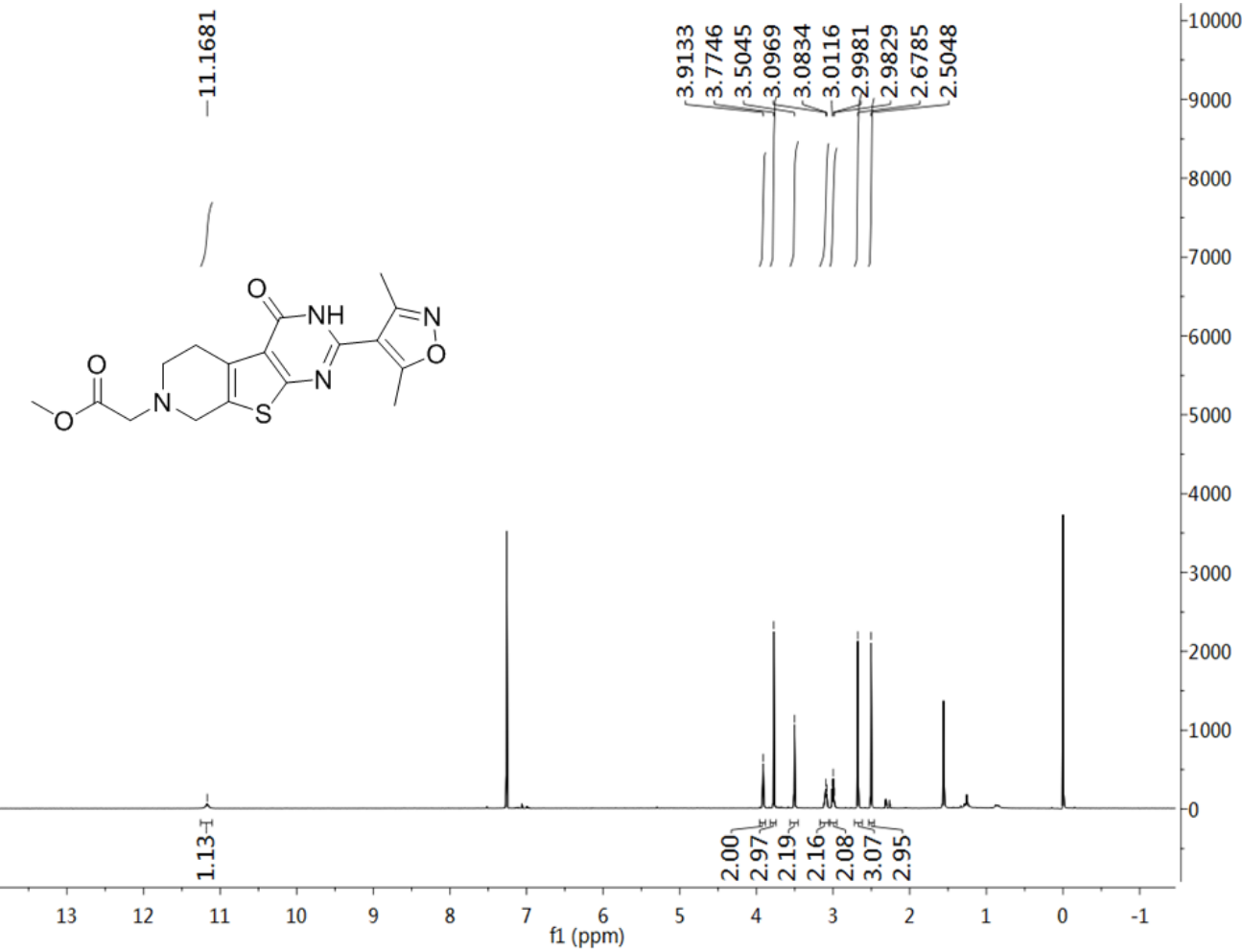




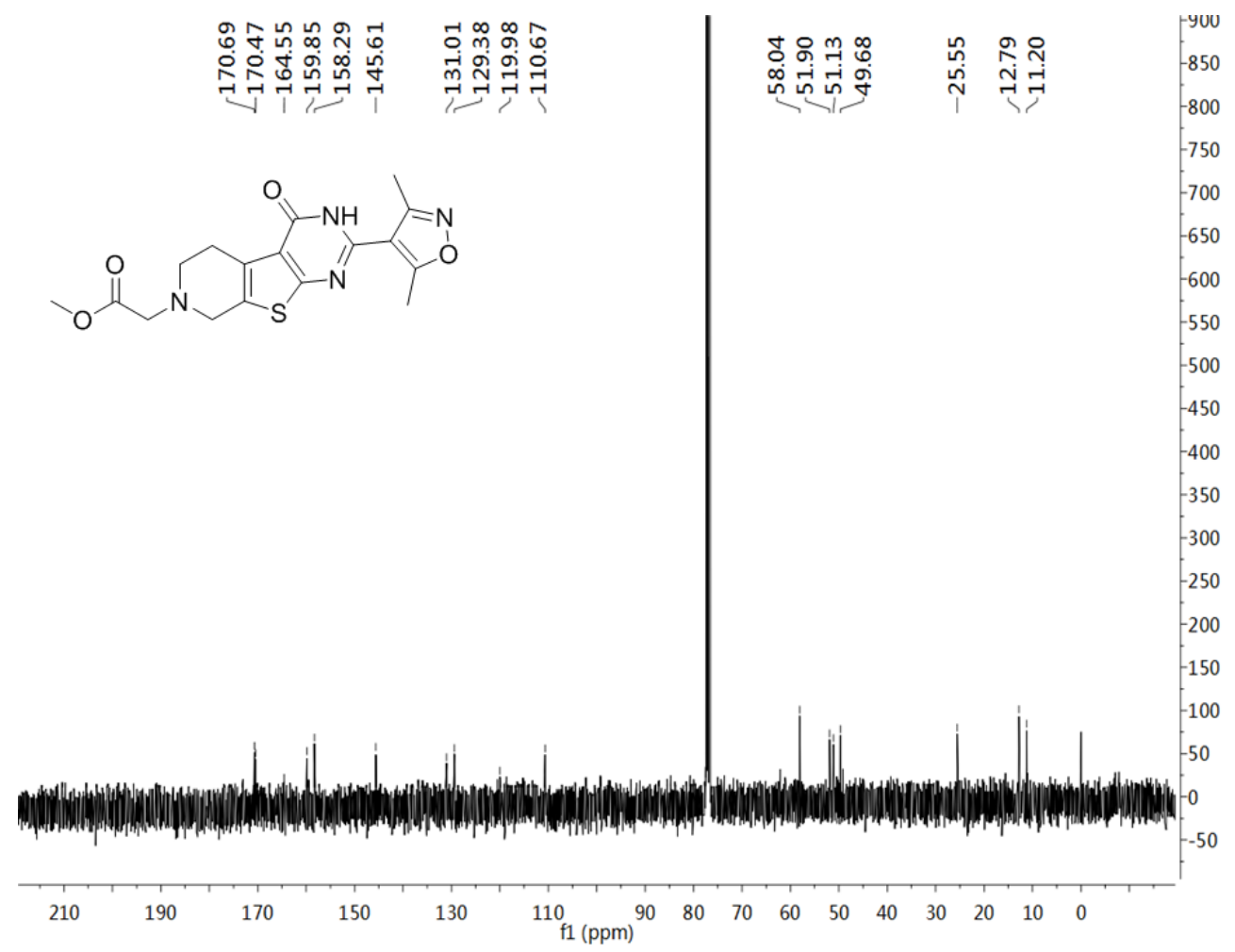

HPLC

Methanol/water(v/v)=90:10, $1 \mathrm{ml} / \mathrm{min}$

mAU

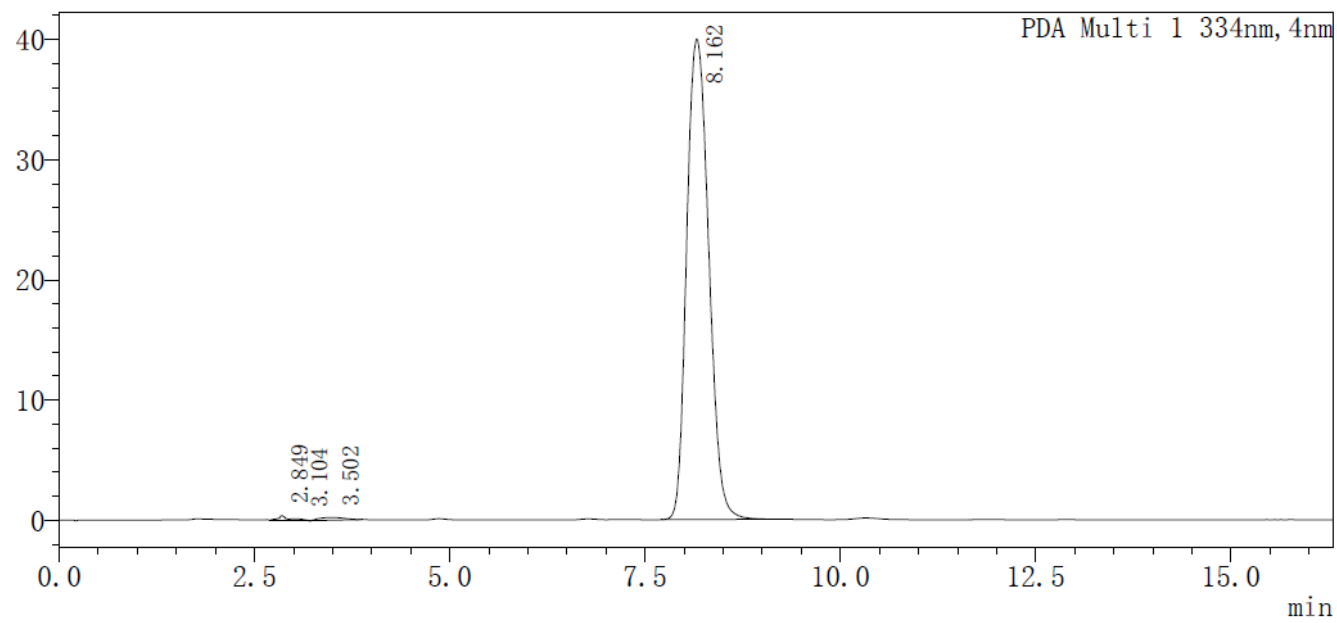

〈峰表〉

PDA Ch1 334nm

\begin{tabular}{|c|c|c|c|c|c|c|c|}
\hline 峰号 & 保留时间 & 面积 & 高度 & 浓度 & 浓度单位 & 标记 & 化合物名 \\
\hline 1 & 2.849 & 2385 & 388 & 0.301 & & & \\
\hline 2 & 3.104 & 1396 & 100 & 0.176 & & $\mathrm{~V}$ & \\
\hline 3 & 3.502 & 5108 & 230 & 0.644 & & & \\
\hline 4 & 8.162 & 784003 & 39957 & 98.879 & & & \\
\hline 总计 & & 792893 & 40676 & & & & \\
\hline
\end{tabular}




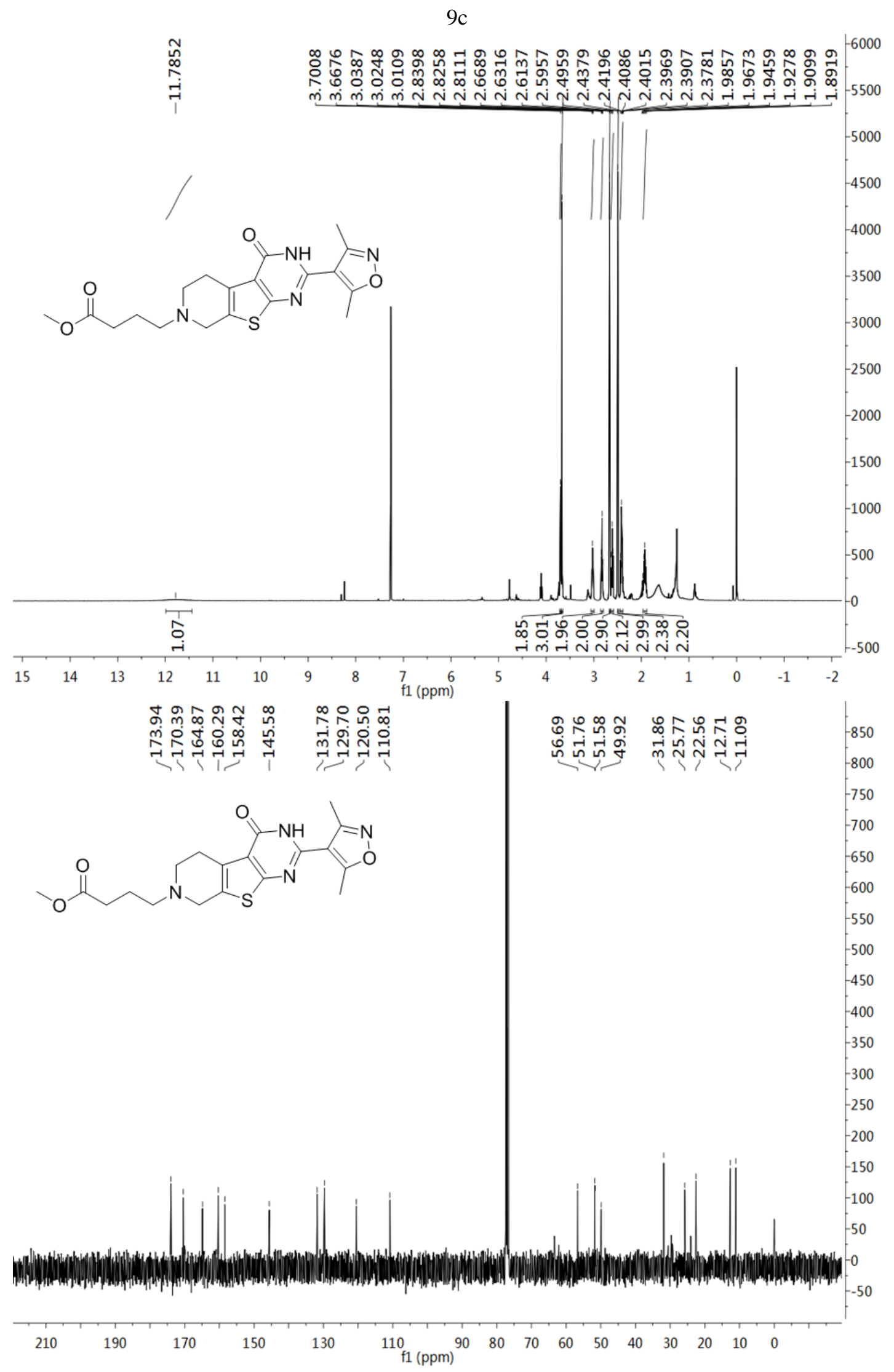


HPLC

Methanol/water(v/v)=80:20, $1 \mathrm{ml} / \mathrm{min}$

mAU

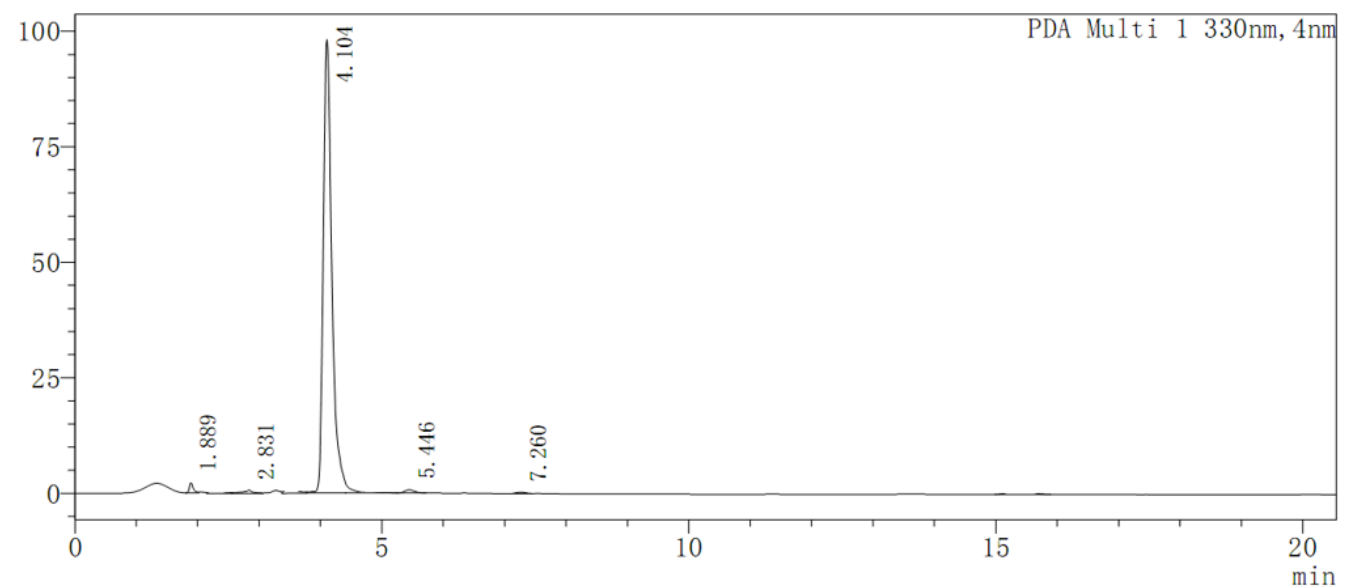

〈峰表〉

\begin{tabular}{|c|c|c|c|c|c|c|c|}
\hline 峰号 & 保留时间 & 面积 & 高度 & 浓度 & 浓度单位 & 标记 & 化合物名 \\
\hline 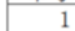 & 1.889 & 10357 & 2303 & 1.053 & & & \\
\hline 2 & 2.831 & 6573 & 712 & 0.668 & & M & \\
\hline 3 & 4.104 & 955810 & 98153 & 97.161 & & M & \\
\hline 4 & 5.446 & 7742 & 707 & 0.787 & & M & \\
\hline 5 & 7.260 & 3252 & 295 & 0.331 & & & \\
\hline & & 983734 & 102170 & & & & \\
\hline
\end{tabular}

9d

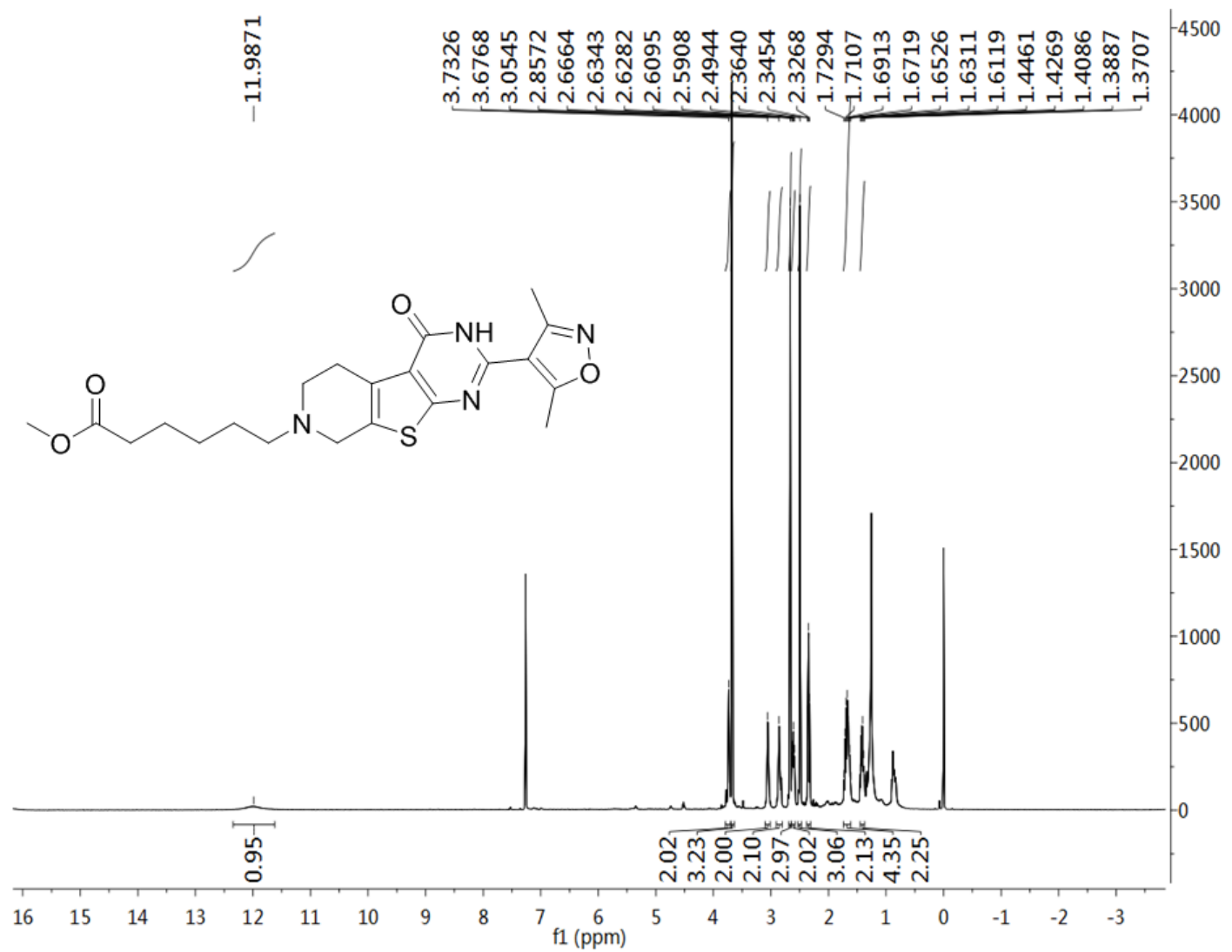




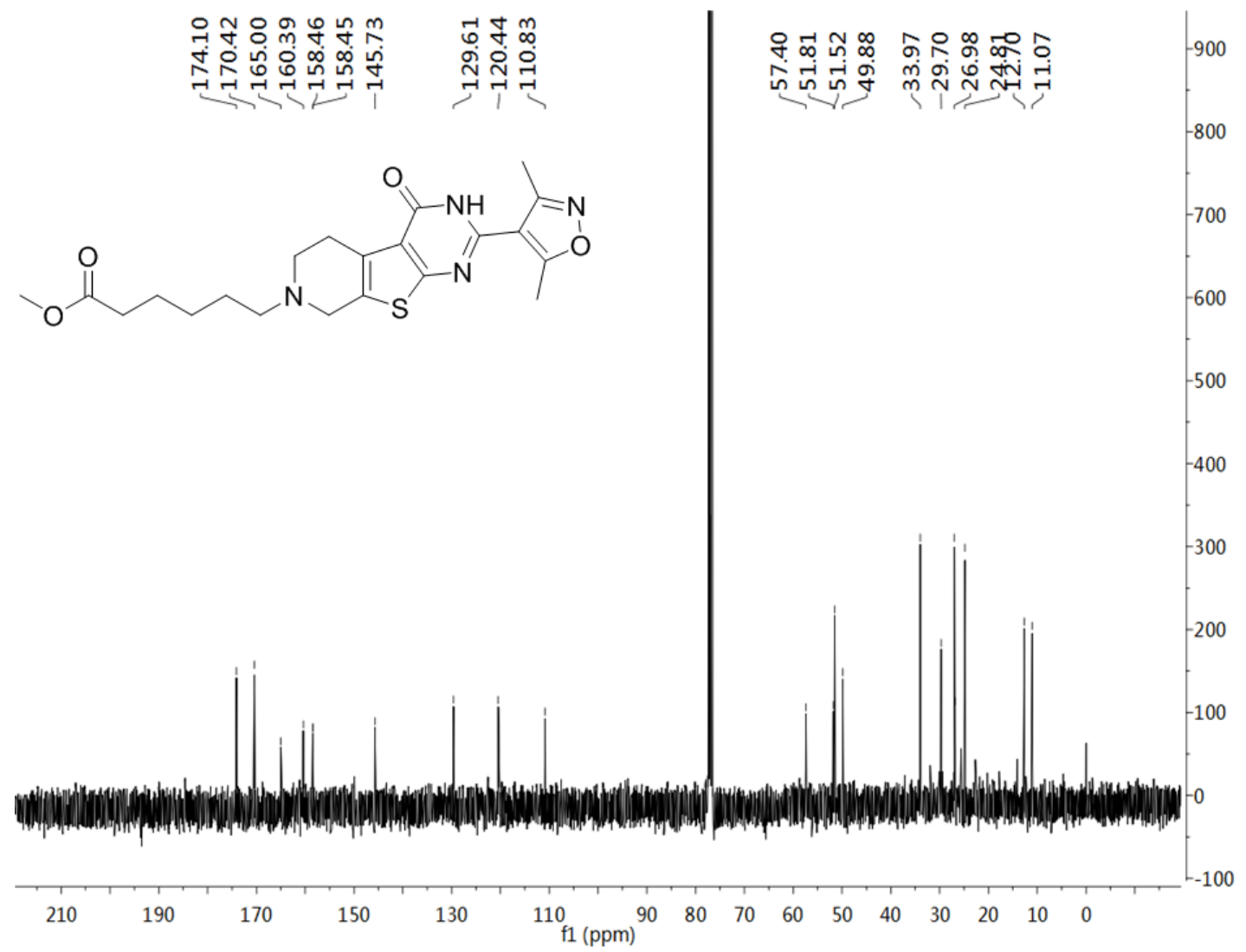

HPLC

Methanol $/$ water $(\mathrm{v} / \mathrm{v})=90: 10,1 \mathrm{ml} / \mathrm{min}$

$\mathrm{mAU}$

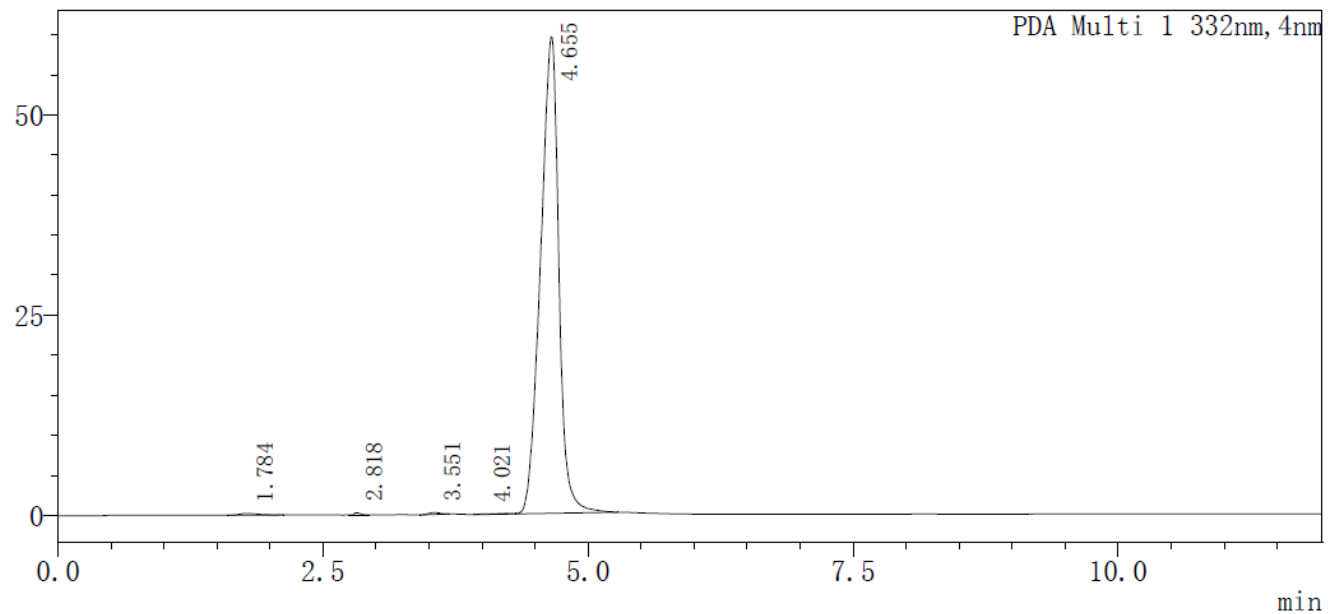

〈峰表〉

PDA Ch1 332nm

\begin{tabular}{|r|r|r|r|r|r|r|r|}
\hline \multicolumn{1}{|c|}{ 峰号 } & 保留时间 & \multicolumn{1}{|c|}{ 面积 } & \multicolumn{1}{c|}{ 高度 } & \multicolumn{1}{|c|}{ 浓度 } & 浓度单位 & 标记 & 化合物名 \\
\hline 1 & 1.784 & 2880 & 228 & 0.401 & & & \\
\hline 2 & 2.818 & 1115 & 284 & 0.155 & & & \\
\hline 3 & 3.551 & 1915 & 253 & 0.266 & & & \\
\hline 4 & 4.021 & 1125 & 57 & 0.157 & & & \\
\hline 5 & 4.655 & 711559 & 59446 & 99.021 & & $\mathrm{~V}$ & \\
\hline 总计 & & 718593 & 60268 & & & & \\
\hline
\end{tabular}


16a

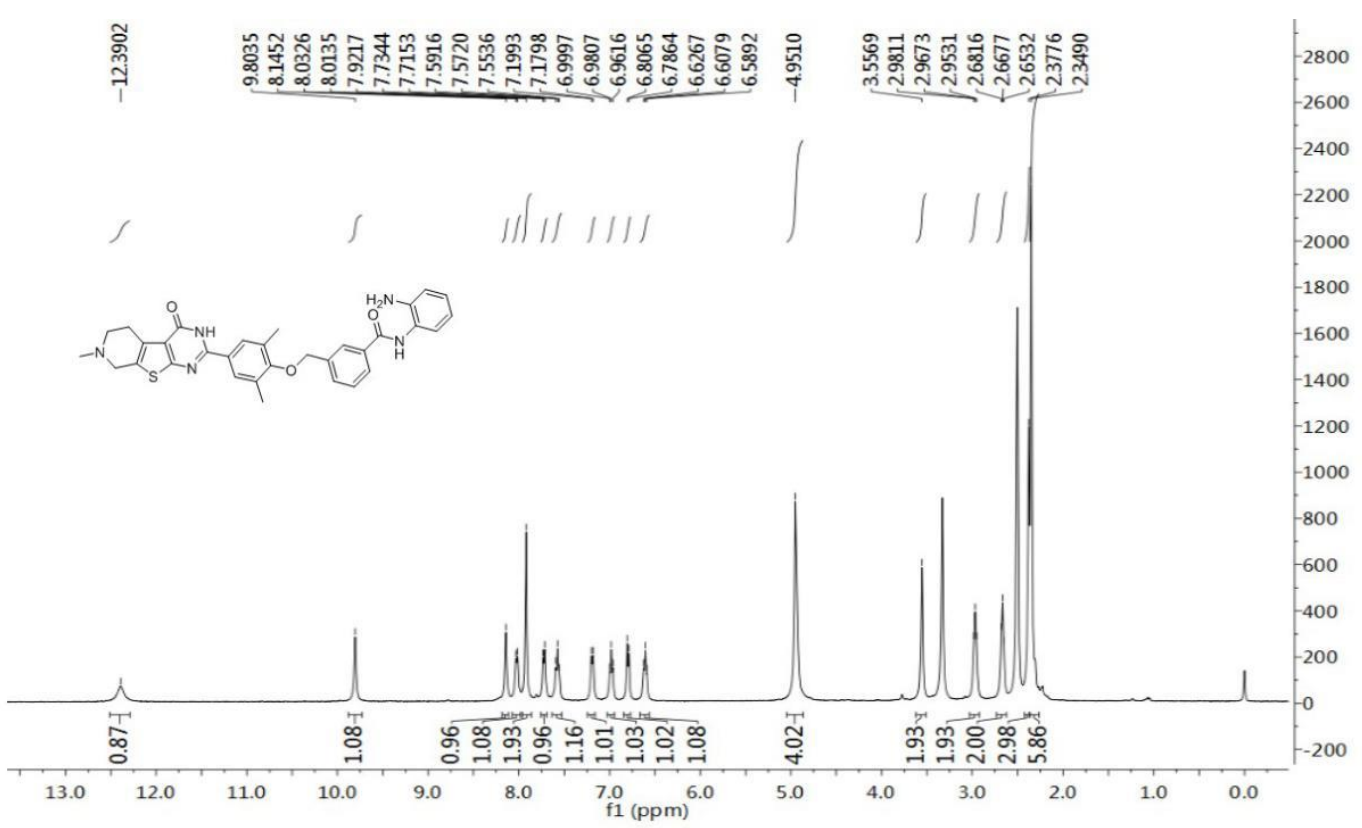

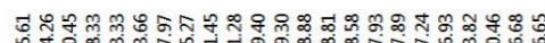

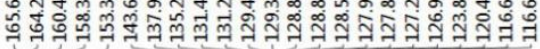

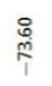
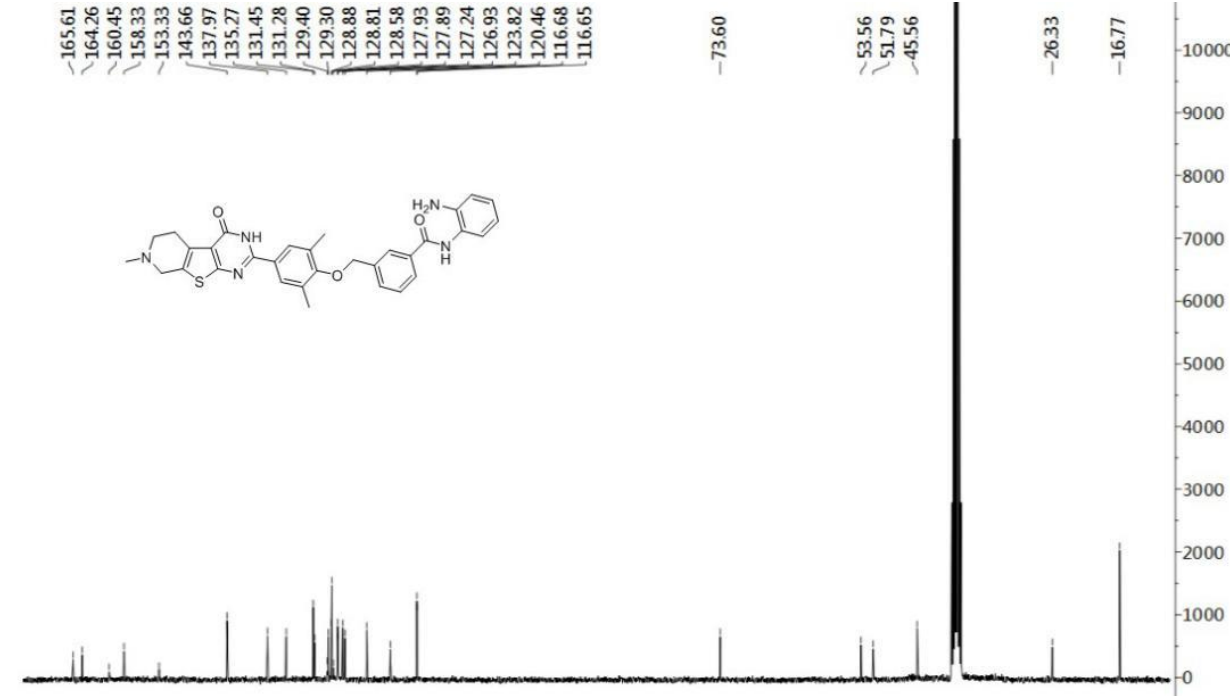

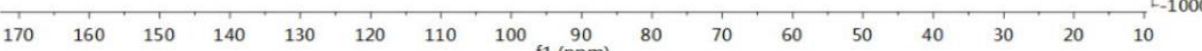


HPLC

Methanol/water(v/v)=80:20,1 $1 \mathrm{ml} / \mathrm{min}$

mAU

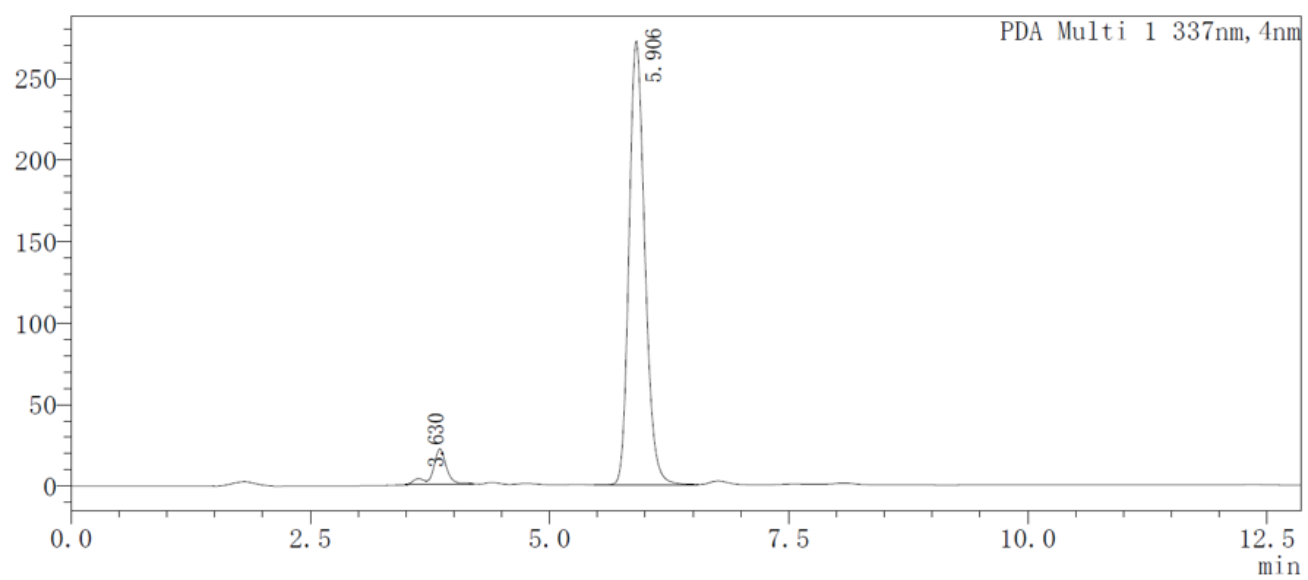

〈峰表〉

PDA Ch1 337nm

\begin{tabular}{|c|c|c|c|c|c|c|c|}
\hline 峰号 & 保留时间 & 面积 & 高度 & 浓度 & 浓度单位 & 标记 & 化合物名 \\
\hline 1 & 3.630 & 38232 & 4199 & 1. 204 & & V & \\
\hline 2 & 5.906 & 3137002 & 272328 & 98.796 & & & \\
\hline 总计 & & 3175234 & 276527 & & & & \\
\hline
\end{tabular}

$16 b$

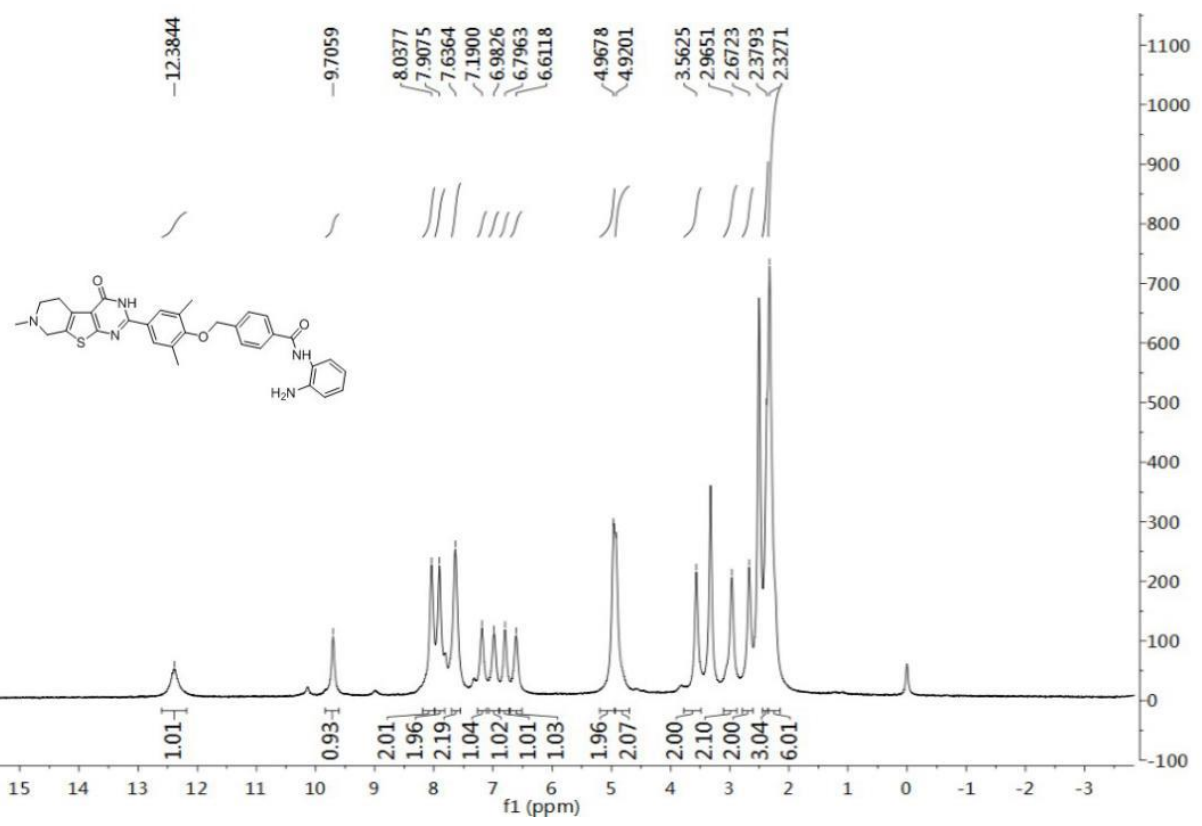




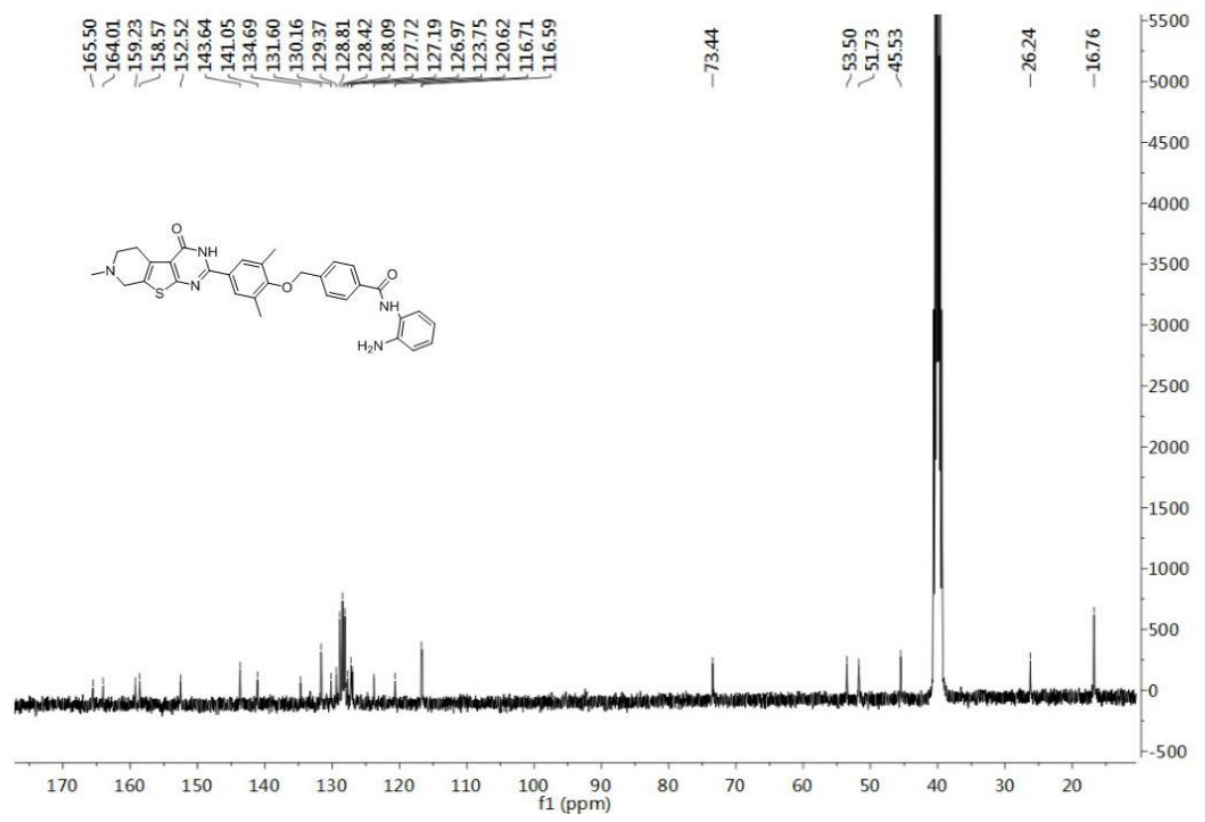

HPLC

Methanol $/$ water $(\mathrm{v} / \mathrm{v})=60: 40,1 \mathrm{ml} / \mathrm{min}$

$\mathrm{mAU}$

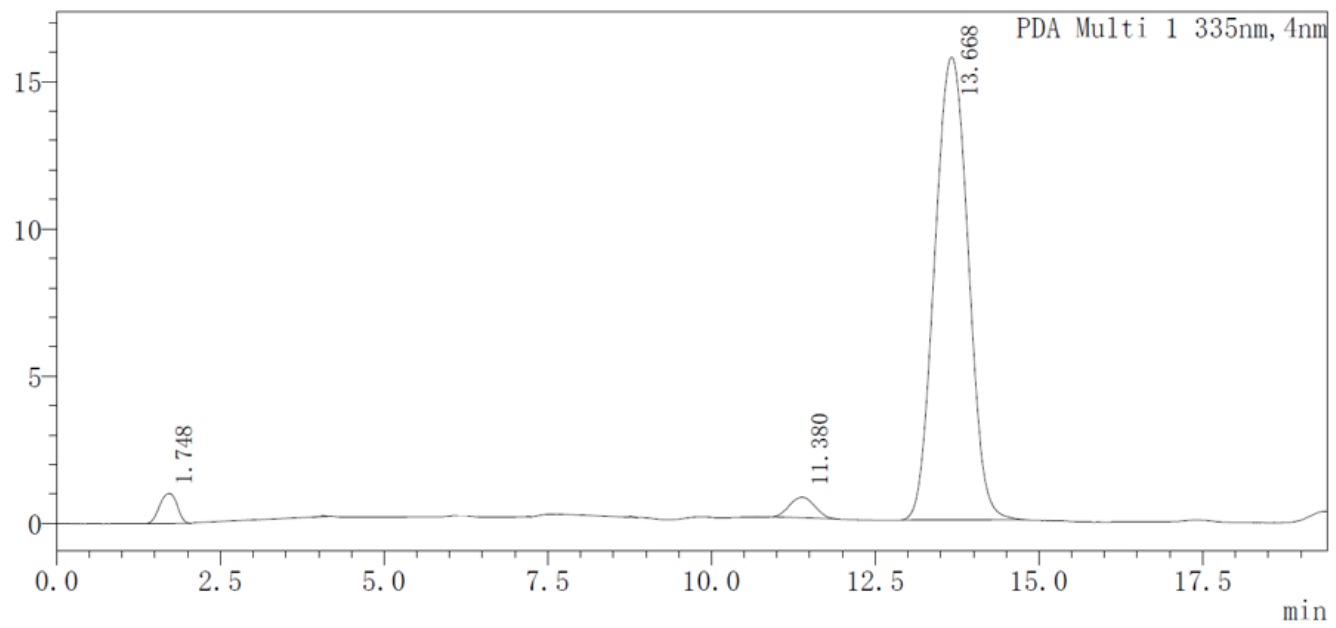

〈峰表〉

PDA Ch1 335nm

PDA Ch1 335nm
\begin{tabular}{|r|r|r|r|r|r|r|r|}
\hline 峰号 & 保留时间 & \multicolumn{1}{|c|}{ 面积 } & \multicolumn{1}{|c|}{ 高度 } & \multicolumn{1}{c|}{ 浓度 } & 浓度单位 & 标记 & 化合物名 \\
\hline 1 & 1.748 & 13040 & 1485 & 2.206 & & & \\
\hline 2 & 11.380 & 18572 & 692 & 3.142 & & & \\
\hline 3 & 13.668 & 559227 & 15710 & 94.621 & & & \\
\hline 总计 & & 591019 & 17887 & & & & \\
\hline
\end{tabular}



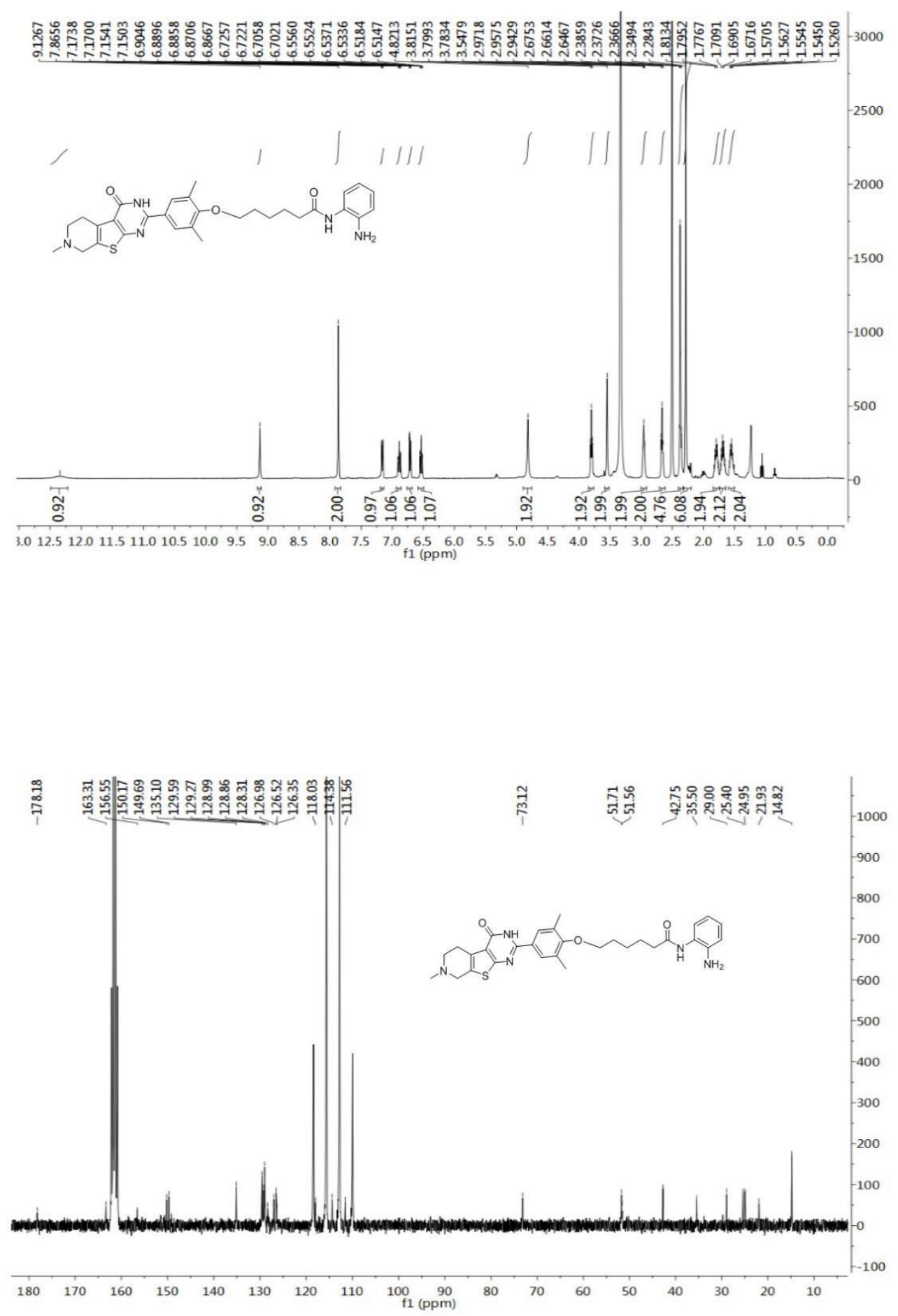
HPLC

Methanol/water $(\mathrm{v} / \mathrm{v})=60: 40,1 \mathrm{ml} / \mathrm{min}$

$\mathrm{mAU}$

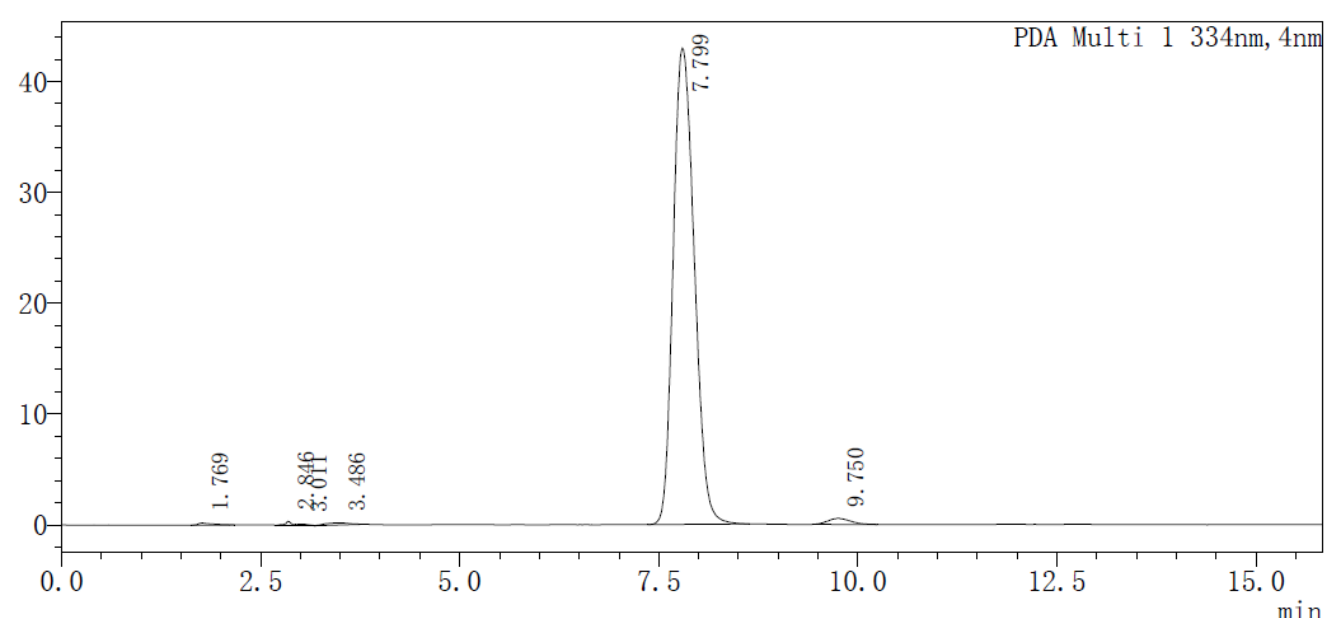

〈峰表〉

PDA Ch1 334nm

\begin{tabular}{|c|c|c|c|c|c|c|c|}
\hline 峰号 & 保留时间 & 面积 & 高度 & 浓度 & 浓度单位 & 标记 & 化合物名 \\
\hline 1 & 1. 769 & 2394 & 193 & 0.295 & & & \\
\hline 2 & 2.846 & 2159 & 376 & 0.266 & & & \\
\hline 3 & 3.011 & 1156 & 131 & 0.142 & & $\mathrm{~V}$ & \\
\hline 4 & 3.486 & 3916 & 196 & 0.482 & & & \\
\hline 5 & 7. 799 & 791899 & 42930 & 97.473 & & & \\
\hline 6 & 9.750 & 10905 & 544 & 1. 342 & & & \\
\hline 总计 & & 812428 & 44371 & & & & \\
\hline
\end{tabular}

$17 \mathrm{a}$

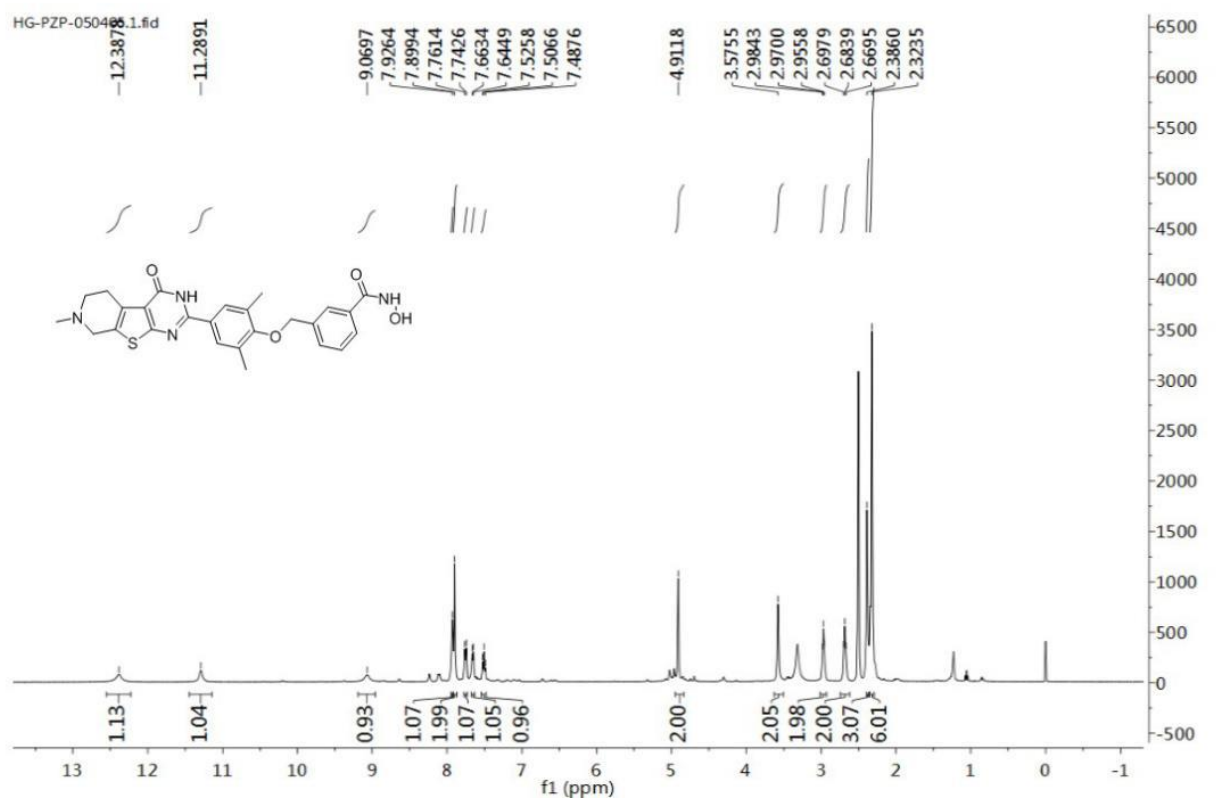




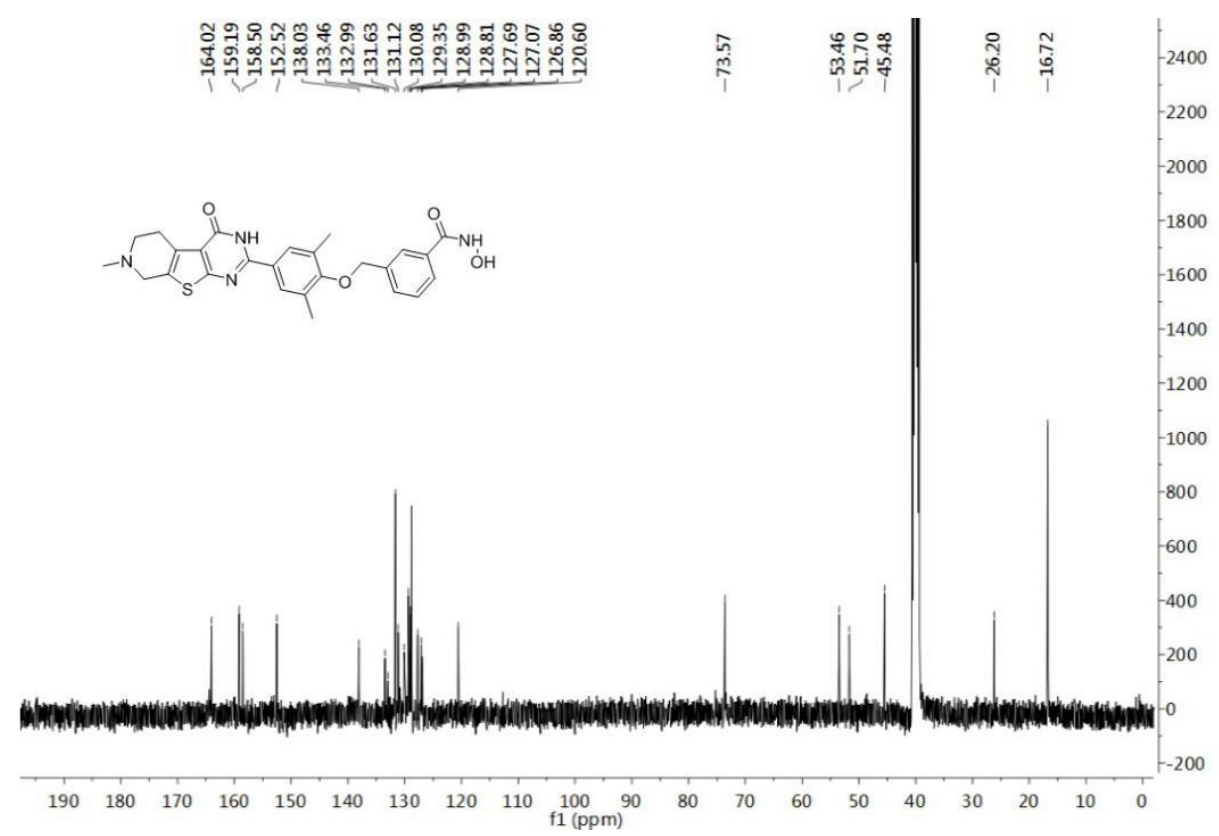

HPLC

Methanol $/$ water $(\mathrm{v} / \mathrm{v})=80: 20,1 \mathrm{ml} / \mathrm{min}$

$\mathrm{mAU}$

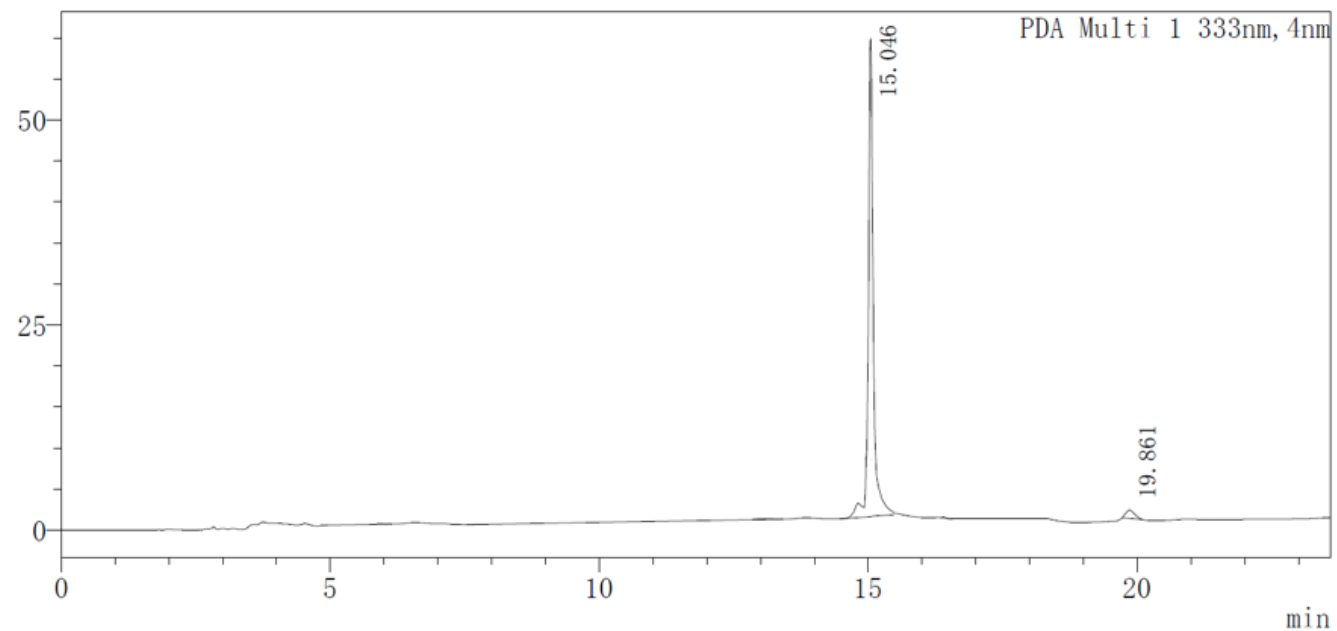

〈峰表〉

PDA Ch1 333nm

\begin{tabular}{|r|r|r|r|r|r|r|r|}
\hline \multicolumn{1}{|c|}{ 峰号 } & 保留时间 & \multicolumn{1}{|c|}{ 面积 } & \multicolumn{1}{c|}{ 高度 } & \multicolumn{1}{c|}{ 浓度 } & 浓度单位 & 标记 & 化合物名 \\
\hline 4 & 15.046 & 449444 & 58152 & 97.523 & & $\mathrm{M}$ & \\
\hline 8 & 19.861 & 11417 & 992 & 2.477 & & $\mathrm{M}$ & \\
\hline 总计 & & 460861 & 59144 & & & & \\
\hline
\end{tabular}


$17 b$
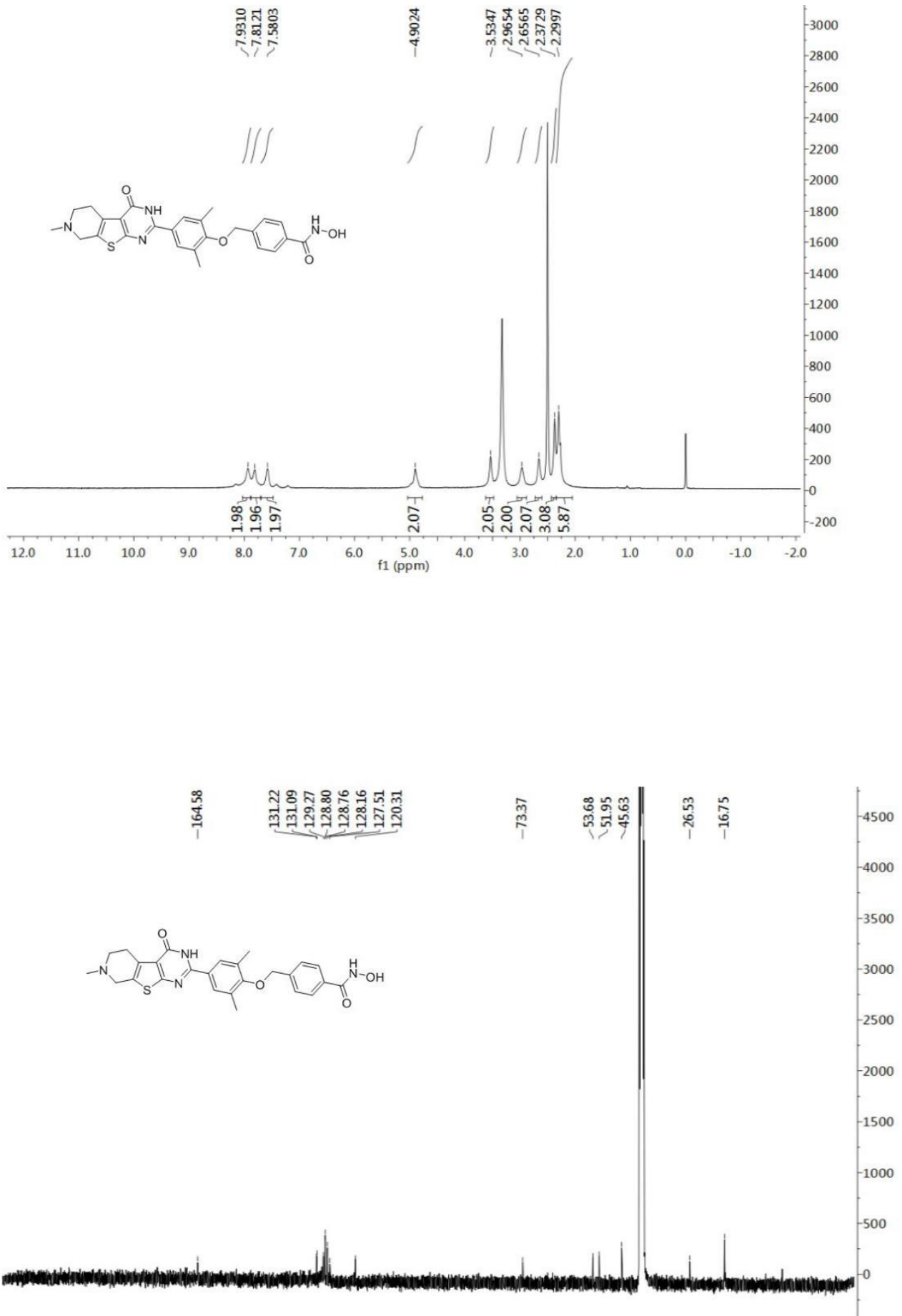

$\begin{array}{lllllllllllllllllllllllll}210 & 200 & 190 & 180 & 170 & 160 & 150 & 140 & 130 & 120 & 110 & 100 & 90 & 80 & 70 & 60 & 50 & 40 & 30 & 20 & 10 & 0 & -10\end{array}$ 
HPLC

Methanol $/$ water $(\mathrm{v} / \mathrm{v})=80: 20,1 \mathrm{ml} / \mathrm{min}$

mAU

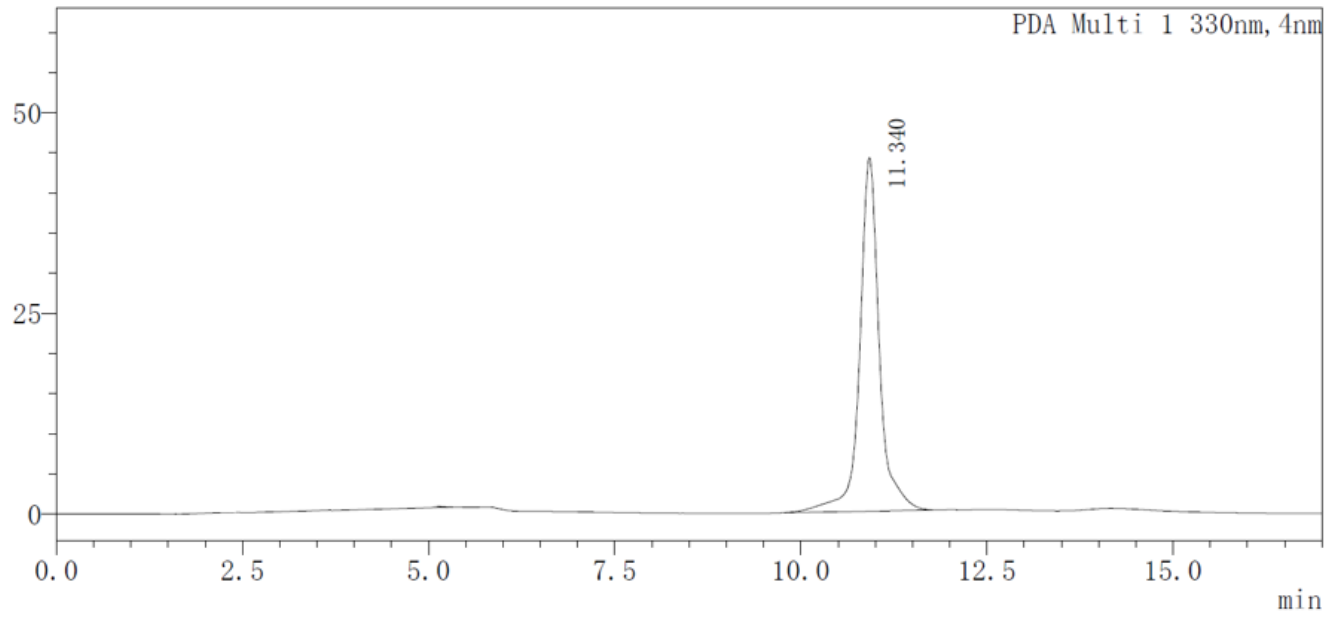

〈峰表〉

PDA Ch1 330nm

\begin{tabular}{|c|c|c|c|c|c|c|c|}
\hline 峰号 & 保留时间 & 面积 & 高度 & 浓度 & 浓度单位 & 标记 & 化合物名 \\
\hline 1 & 11.340 & 278542 & 41702 & 100.00 & & & \\
\hline 总训 & & 278542 & 41702 & & & & \\
\hline
\end{tabular}

$17 \mathrm{c}$

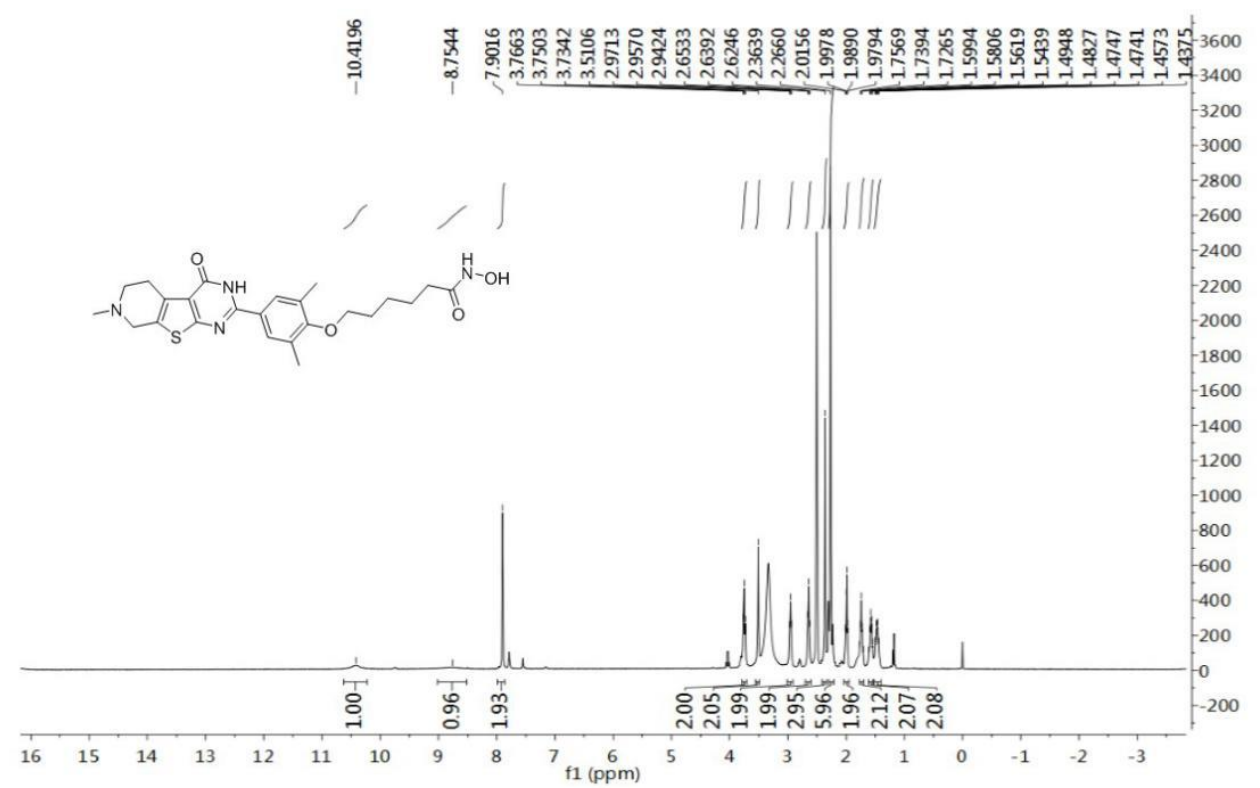




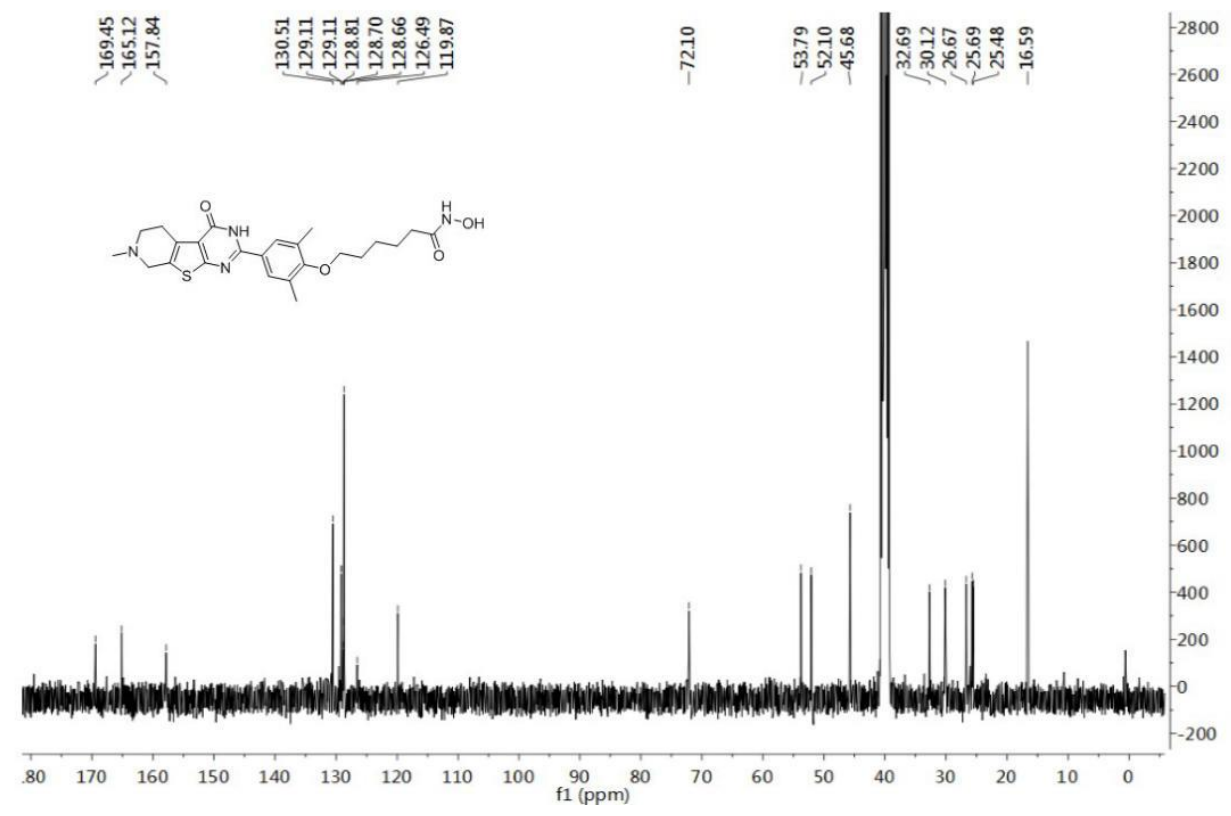

HPLC

Methanol/water(v/v)=80:20, $1 \mathrm{ml} / \mathrm{min}$

$\mathrm{mAU}$

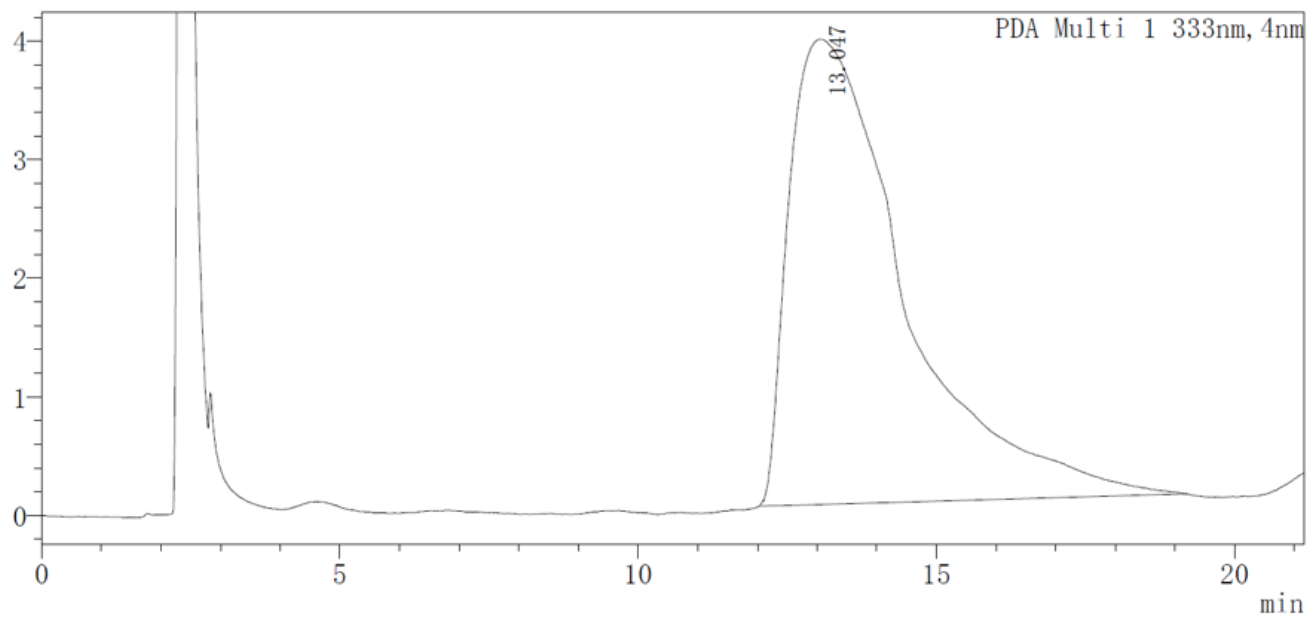

〈峰表〉

PDA Ch1 $333 \mathrm{~nm}$
\begin{tabular}{|r|r|r|r|r|r|r|r|}
\hline 峰号 & 保留时间 & 面积 & 高度 & 浓度 & 浓度单位 & 标记 & 化合物名 \\
\hline 1 & 13.047 & 595966 & 3877 & 100.00 & & & \\
\hline 总计 & & 595966 & 3877 & & & & \\
\hline
\end{tabular}


$17 d$
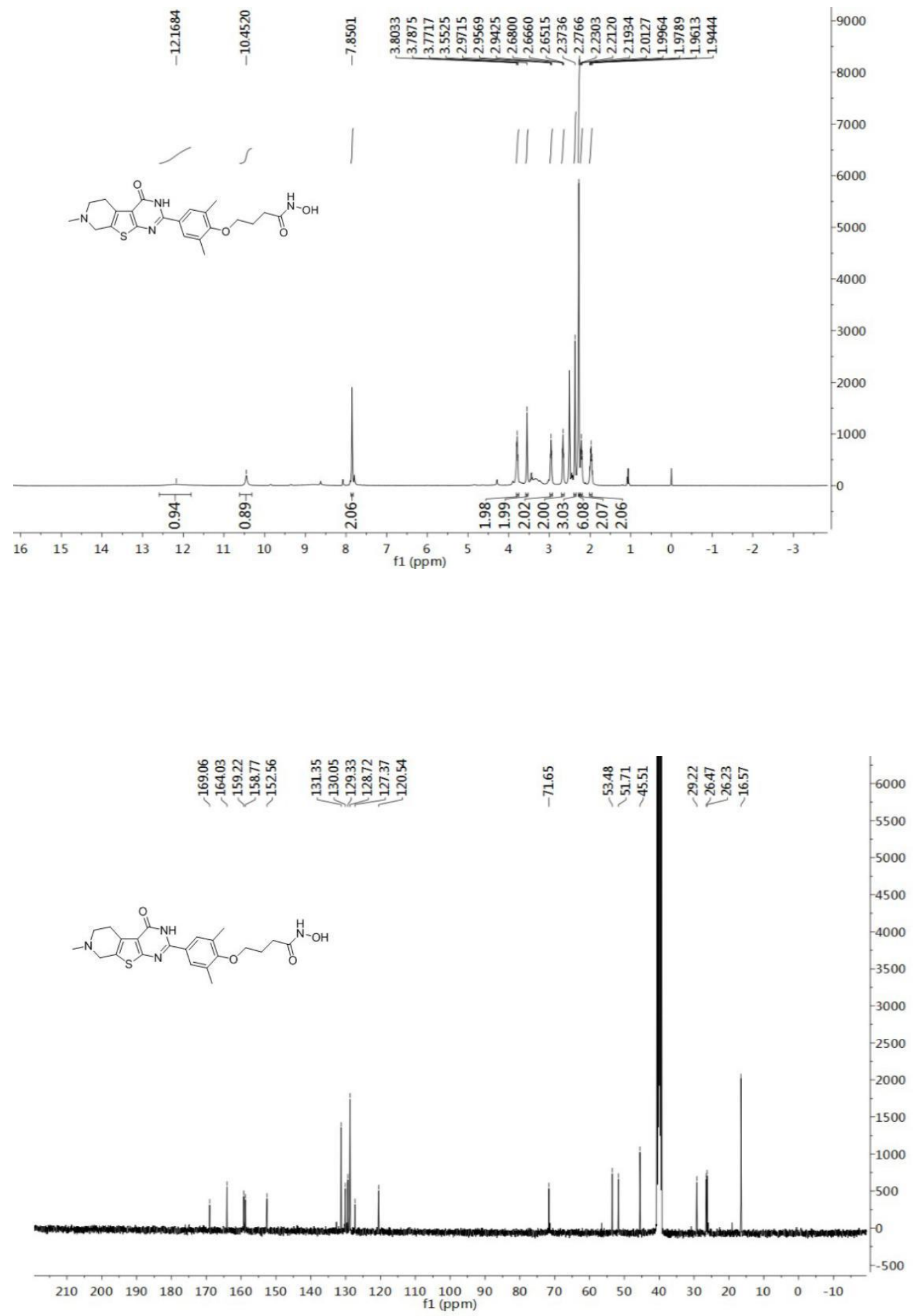
HPLC

Methanol $/$ water $(\mathrm{v} / \mathrm{v})=80: 20,1 \mathrm{ml} / \mathrm{min}$

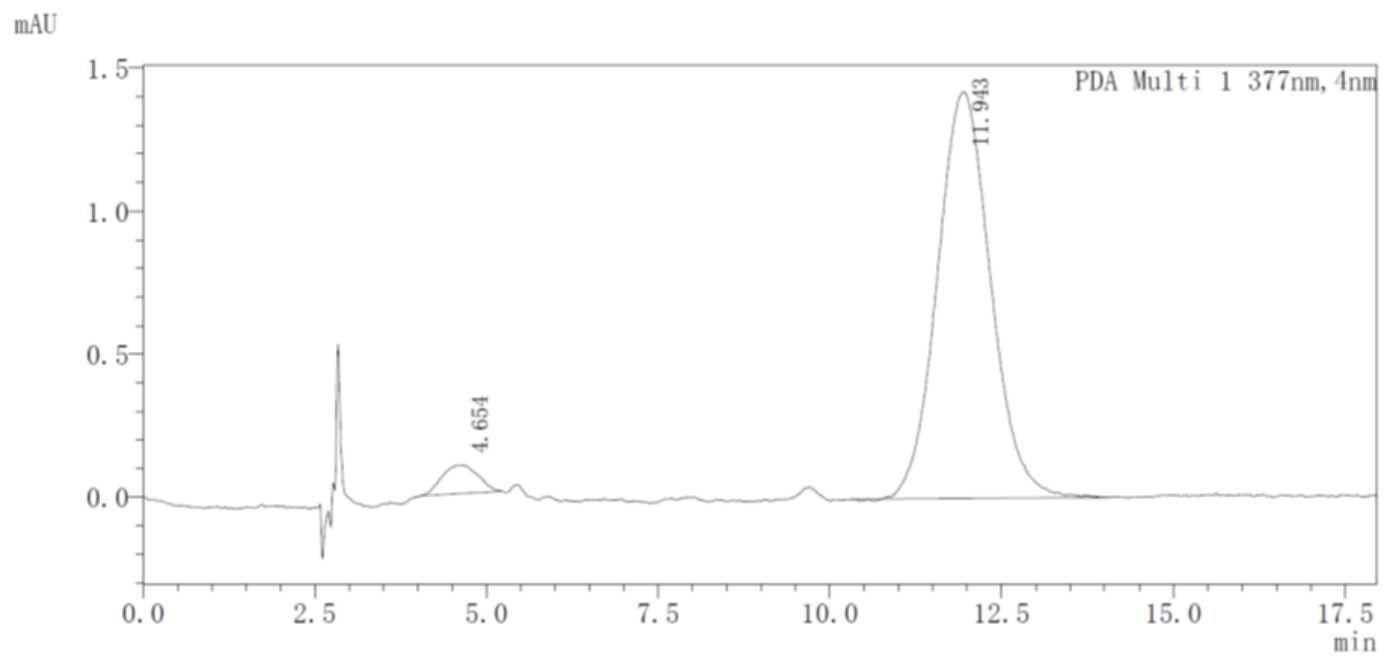

〈峰表〉

PDA Ch1 $377 \mathrm{~nm}$
\begin{tabular}{|r|r|r|r|r|r|r|r|}
\hline 峰号 & 保留时间 & \multicolumn{1}{|c|}{ 面积 } & \multicolumn{1}{c|}{ 高度 } & \multicolumn{1}{|c|}{ 浓度 } & 浓度单位 & 标记 & 化合物名 \\
\hline 1 & 4.654 & 1434 & 138 & 4.639 & & & \\
\hline 2 & 11.943 & 29472 & 1469 & 95.361 & & & \\
\hline 总计 & & 30906 & 1607 & & & & \\
\hline
\end{tabular}

$17 \mathrm{e}$

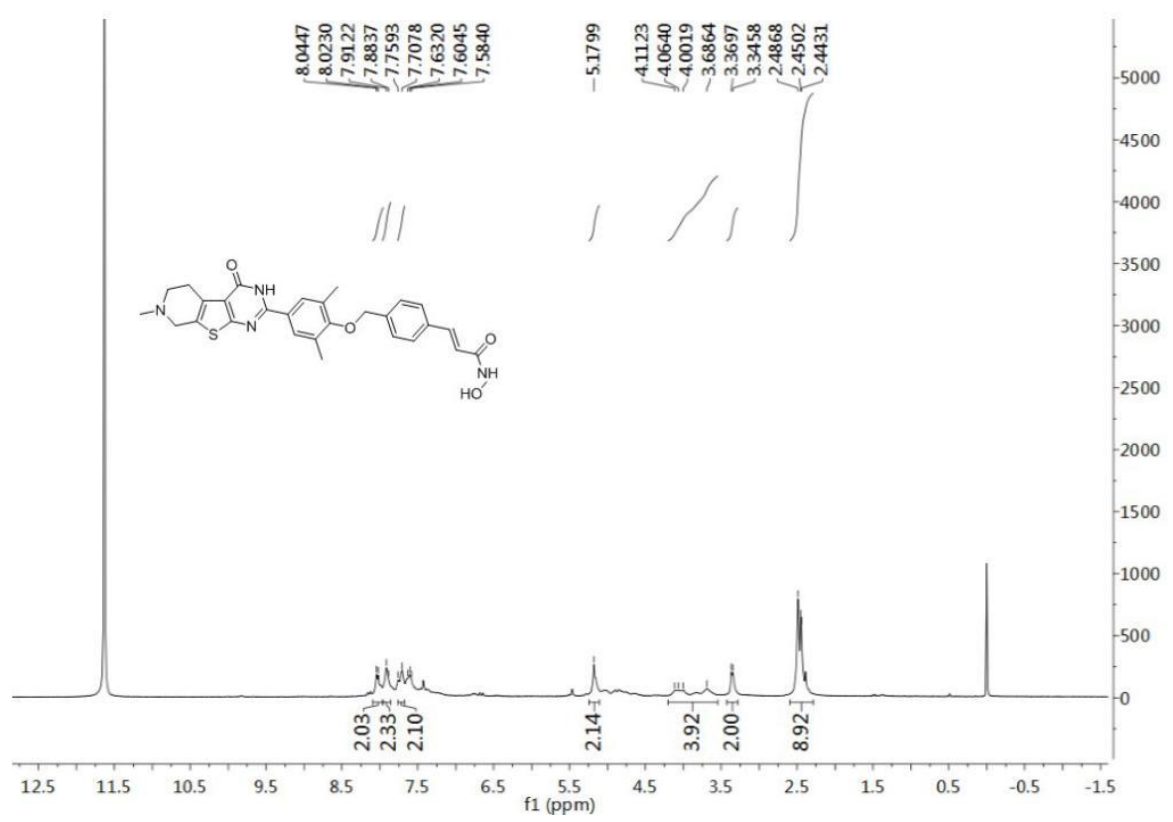




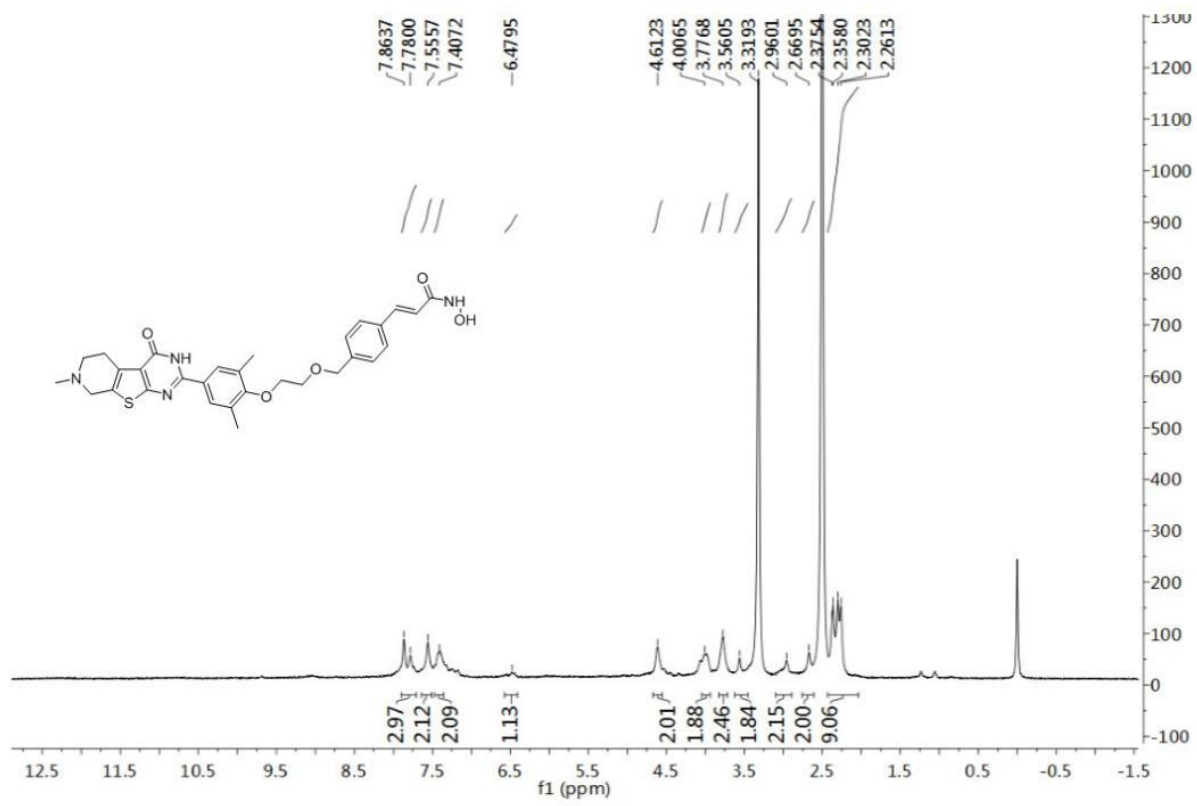

20

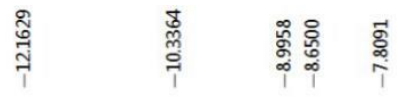

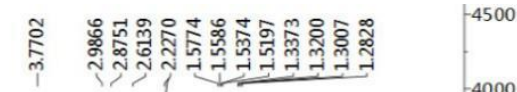

(1)

$-2500$

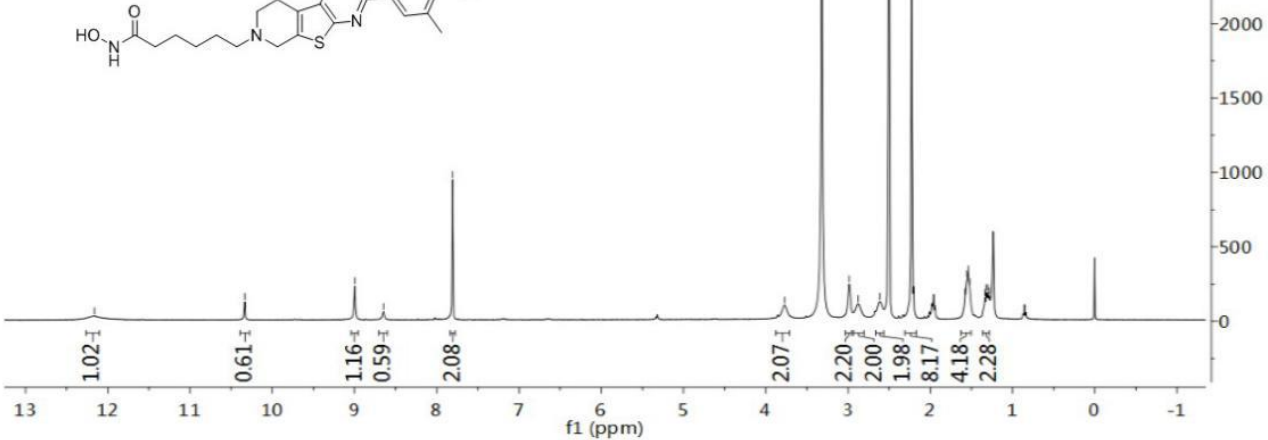




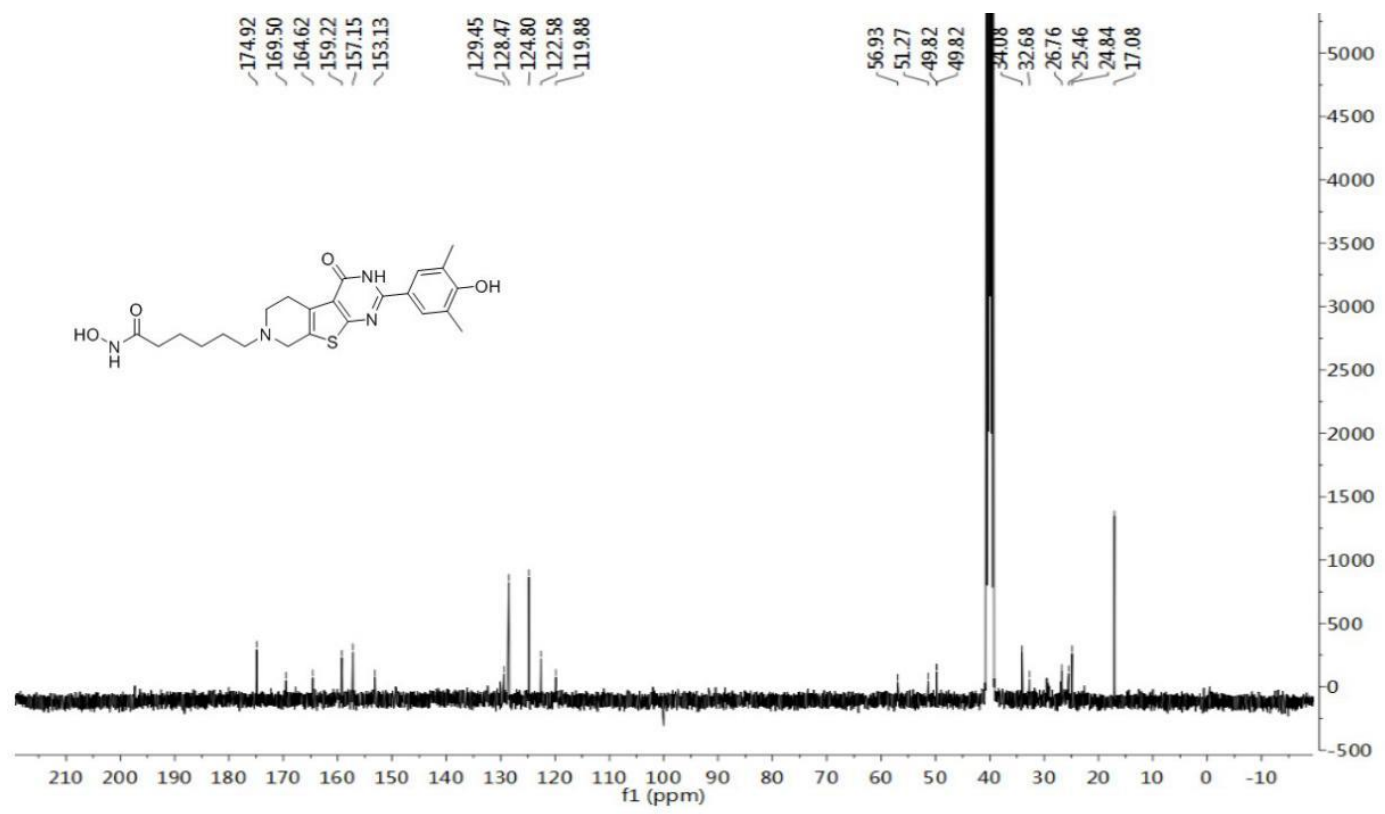

HPLC

Methanol/water(v/v)=10:90 (0.1\% acetic acid), $1 \mathrm{ml} / \mathrm{min}$ mAU

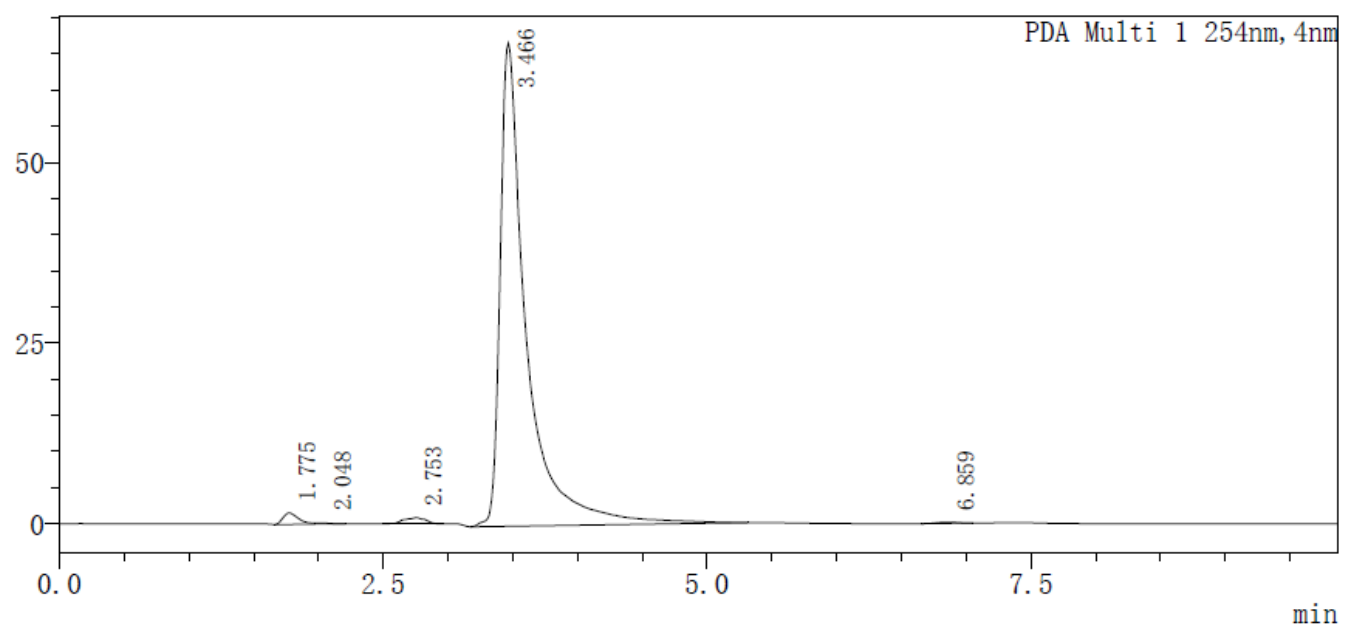

〈峰表〉

PDA Ch1 $254 \mathrm{~nm}$

PDA Ch1 $254 n m$
\begin{tabular}{|r|r|r|r|r|r|r|r|}
\hline 峰号 & 保留时间 & \multicolumn{1}{|c|}{ 面积 } & \multicolumn{1}{c|}{ 高度 } & \multicolumn{1}{c|}{ 浓度 } & 浓度单位 & 标记 & 化合物名 \\
\hline 1 & 1.775 & 13384 & 1588 & 1.377 & & & \\
\hline 2 & 2.048 & 1199 & 140 & 0.123 & & $V$ & \\
\hline 3 & 2.753 & 9625 & 843 & 0.990 & & & \\
\hline 4 & 3.466 & 945876 & 66889 & 97.318 & & & \\
\hline 5 & 6.859 & 1857 & 163 & 0.191 & & & \\
\hline 总计 & & 971941 & 69625 & & & & \\
\hline
\end{tabular}




\section{$21 \mathrm{a}$}<smiles>Cc1noc(C)c1-c1nc2sc3c(c2c(=O)[nH]1)CCN(CC(=O)NO)C3</smiles>

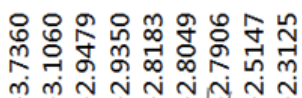

11000

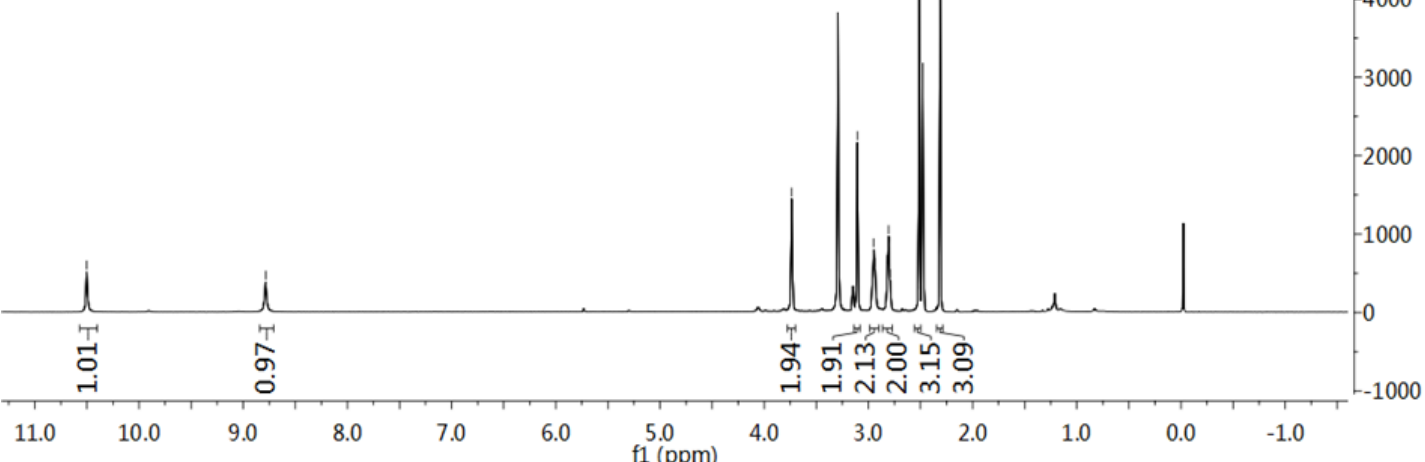

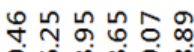

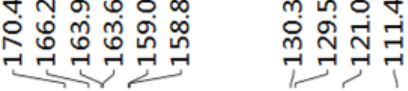

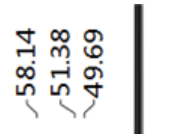

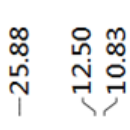

$-500$

50<smiles>Cc1noc(C)c1-c1nc2sc3c(c2c(=O)[nH]1)CCN(CC(=O)NO)C3</smiles>

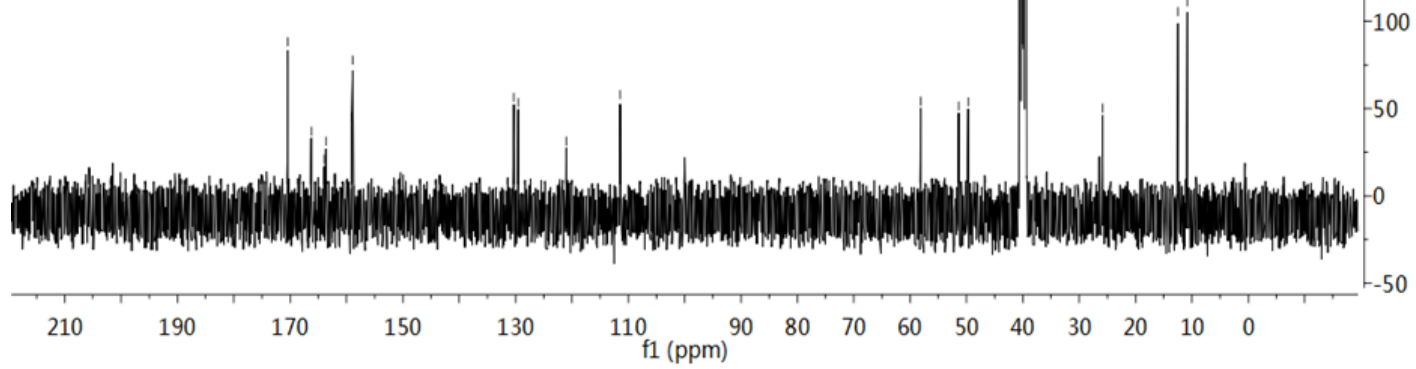


HPLC

Methanol $/$ water $(\mathrm{v} / \mathrm{v})=70: 30,1 \mathrm{ml} / \mathrm{min}$

$\mathrm{mAU}$

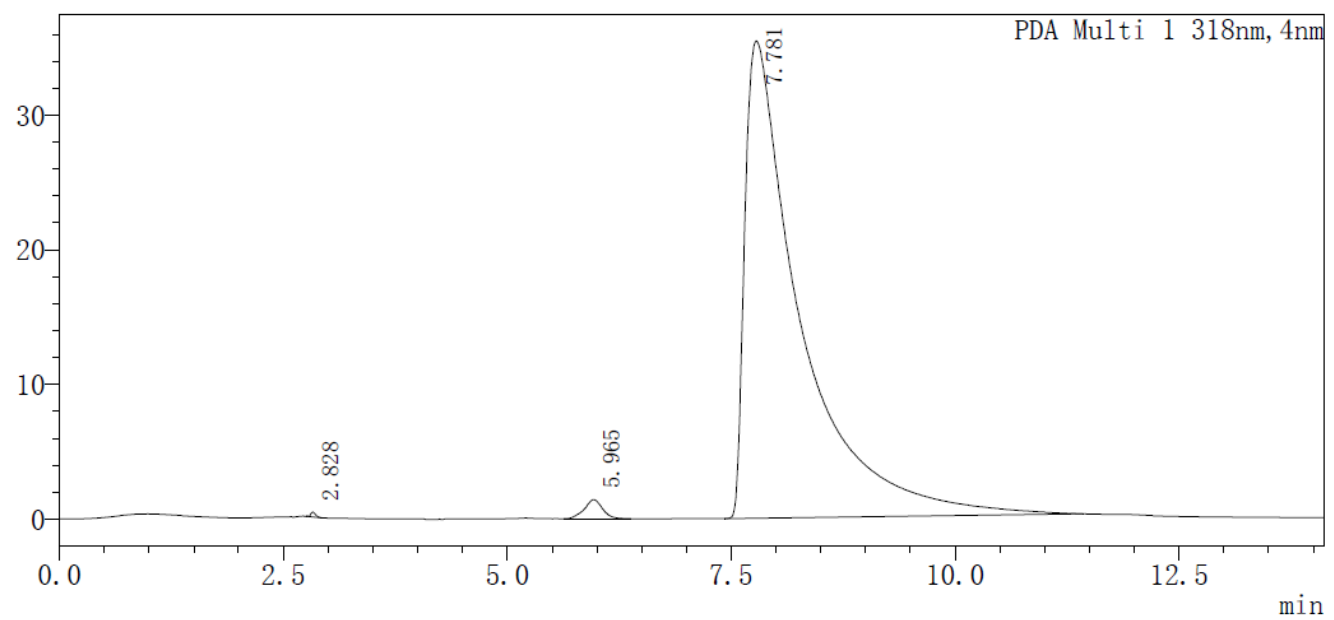

〈峰表〉

PDA Ch1 318nm

\begin{tabular}{|c|c|c|c|c|c|c|c|}
\hline 峰号 & 保留时间 & 面积 & 高度 & 浓度 & 浓度单位 & 标记 & 化合物名 \\
\hline 1 & 2.828 & 1258 & 366 & 0.081 & & & \\
\hline 2 & 5.965 & 20298 & 1421 & 1.306 & & & \\
\hline 3 & 7.781 & 1532084 & 35419 & 98.613 & & & \\
\hline 总计 & & 1553640 & 37206 & & & & \\
\hline
\end{tabular}

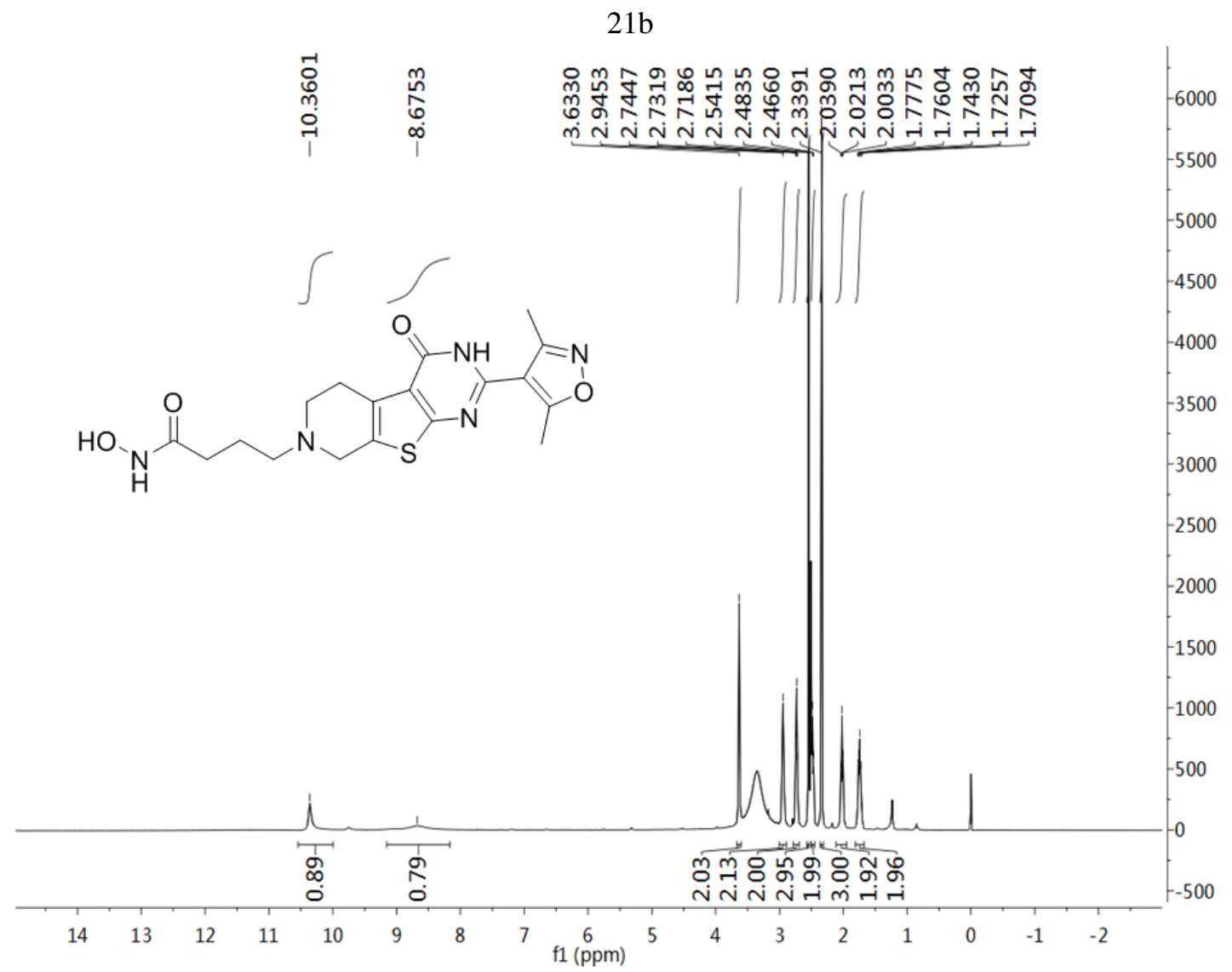




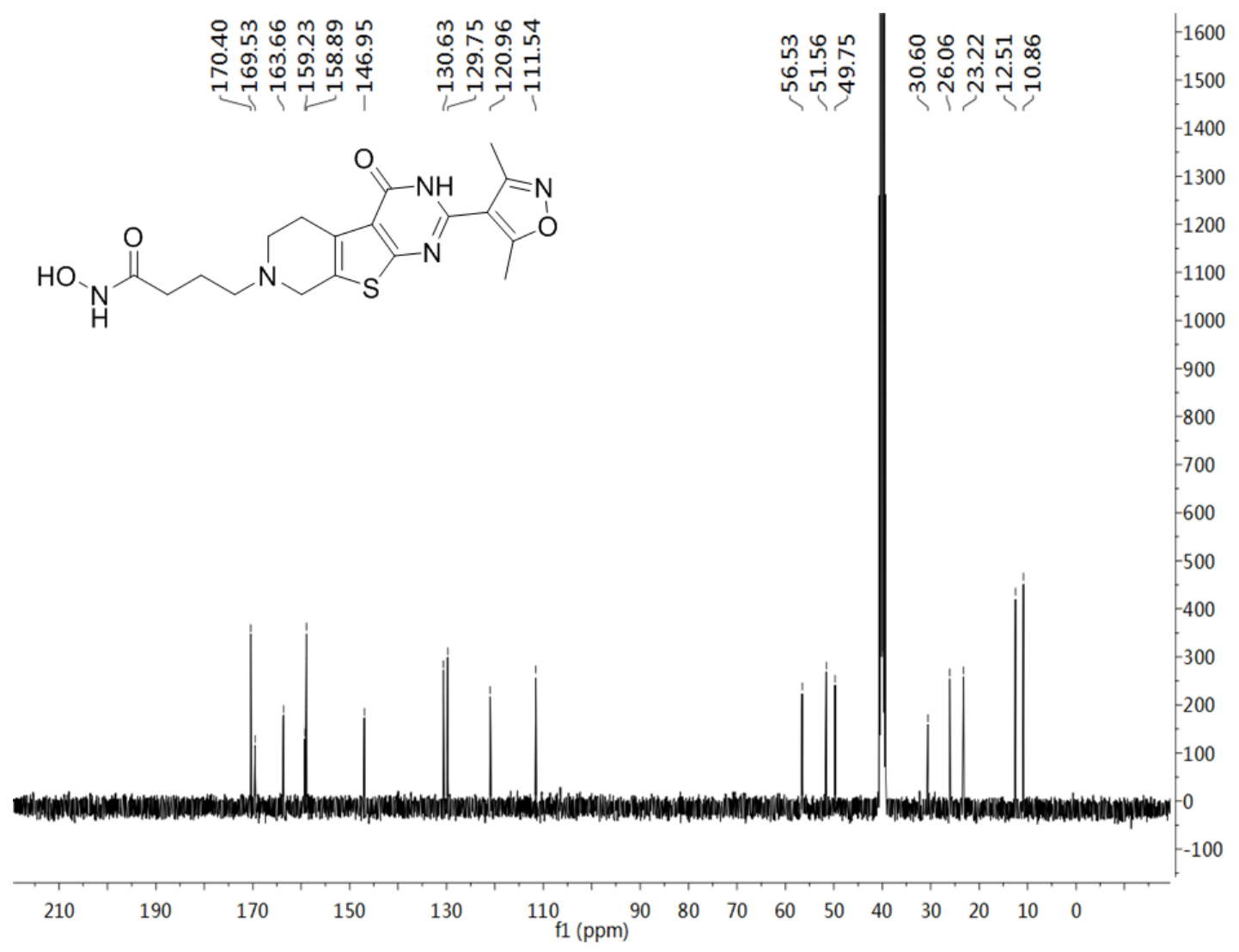

HPLC

Methanol/water(v/v)=70:30, $1 \mathrm{ml} / \mathrm{min}$

$\mathrm{mAU}$

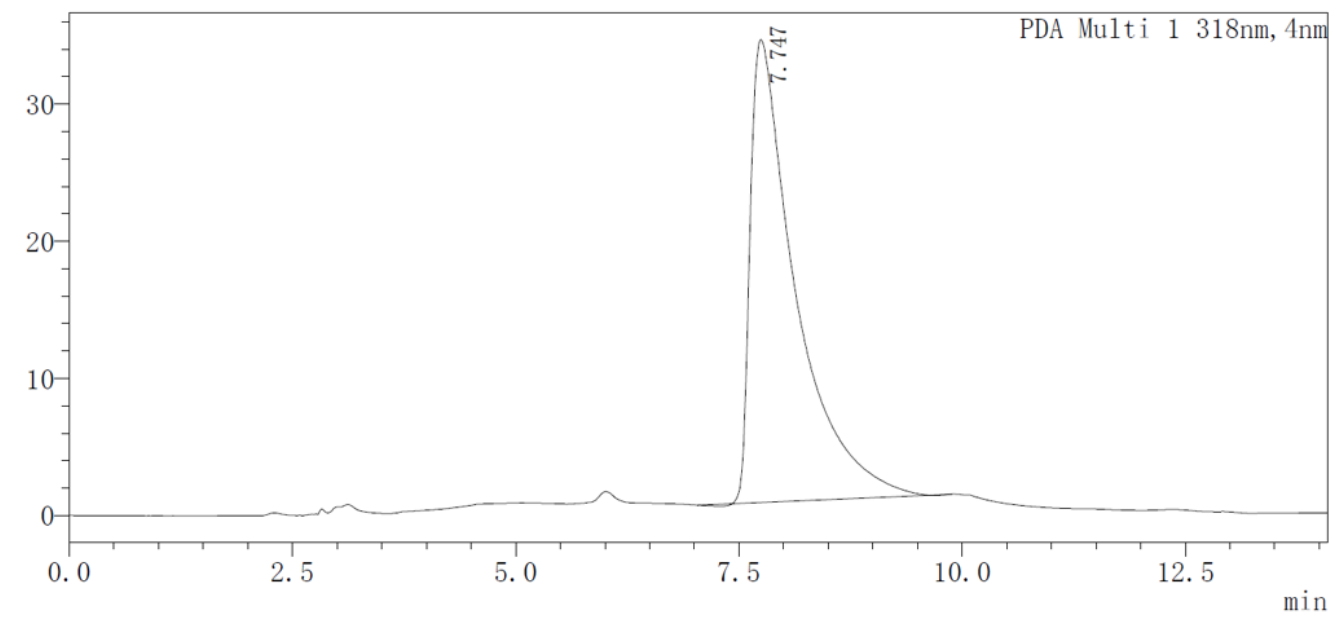

〈峰表〉

PDA Ch1 318nm

\begin{tabular}{|r|r|l|l|l|l|r|r|}
\hline \multicolumn{1}{|c|}{ 峰号 } & 保留时间 & 面积 & 高度 & 浓度 & 浓度单位 & 标记 & 化合物名 \\
\hline 1 & 7.747 & 1191101 & 33755 & 100.00 & & $\mathrm{M}$ & \\
\hline 总计 & & 1191101 & 33755 & & & & \\
\hline
\end{tabular}




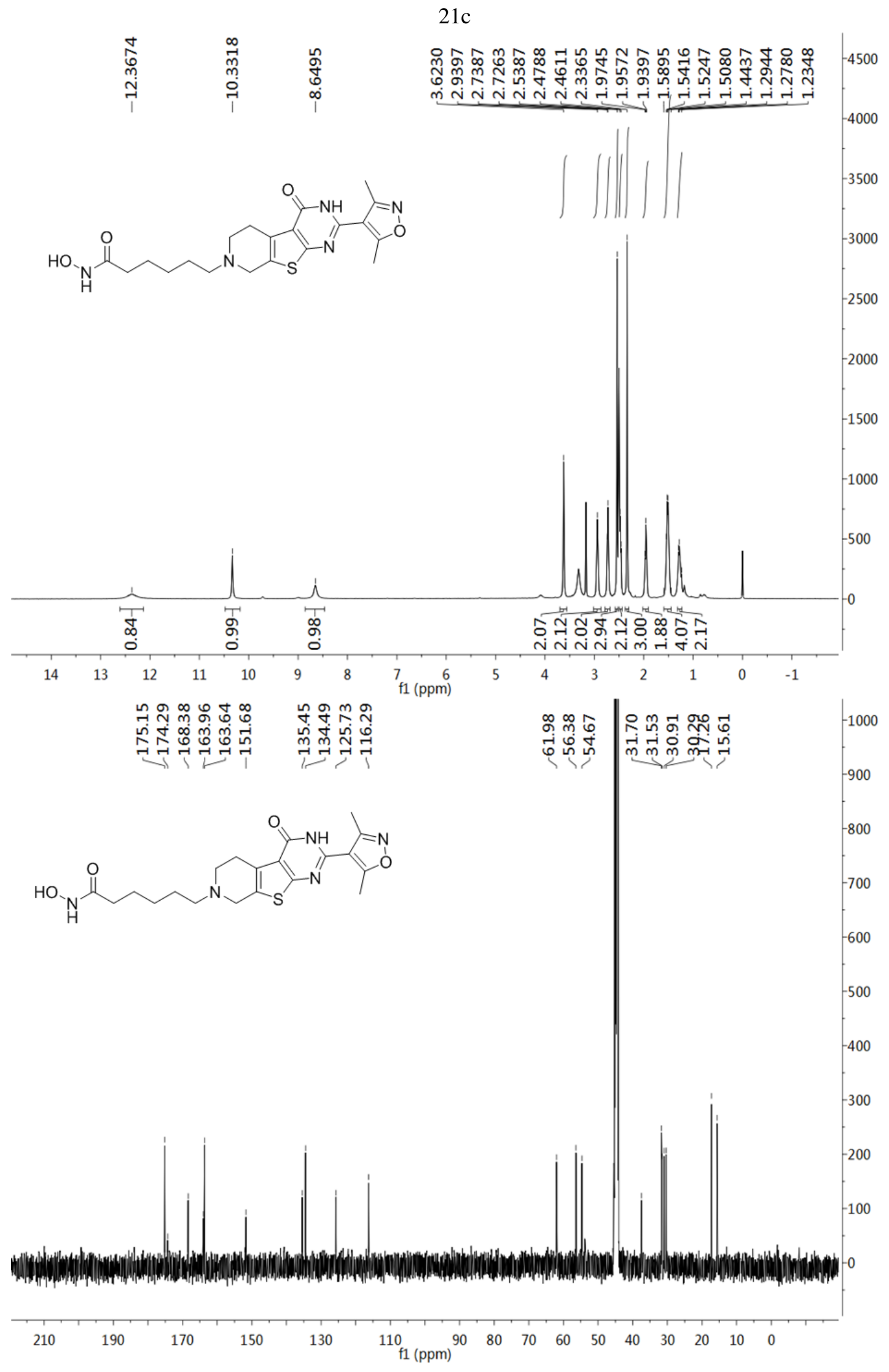


HPLC

Methanol/water(v/v)=80:20, $1 \mathrm{ml} / \mathrm{min}$

$\mathrm{mAU}$

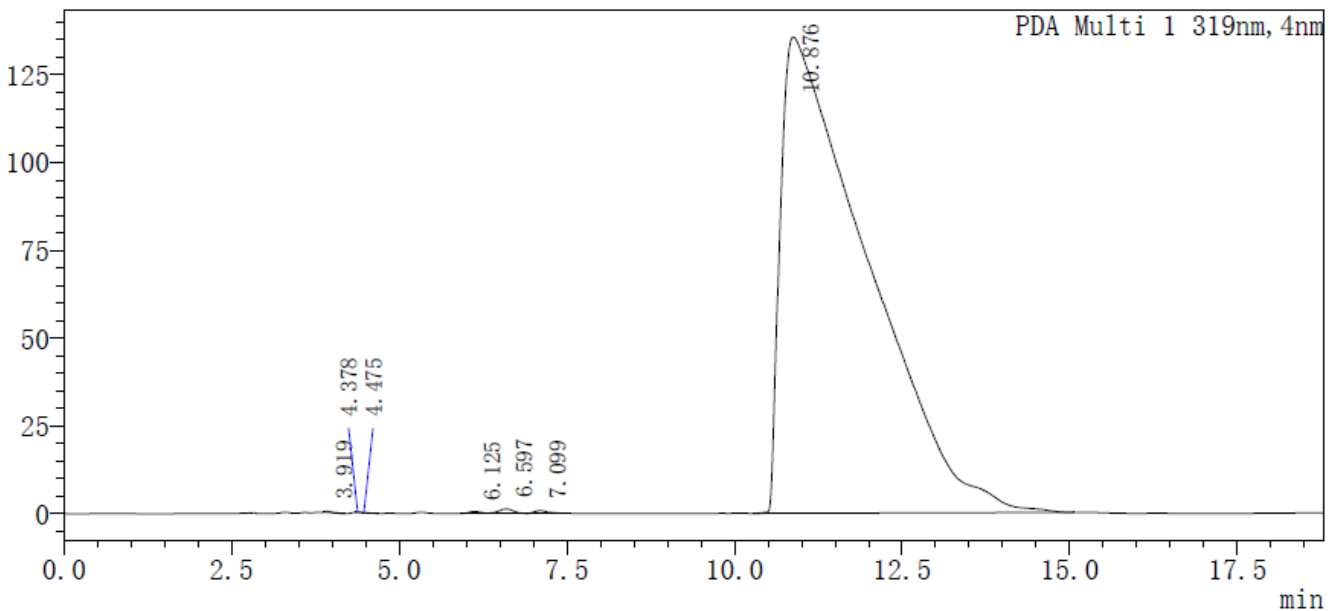

〈峰表〉

PDA Ch1 319nm

\begin{tabular}{|r|r|r|r|r|r|r|r|}
\hline 峰号 & 保留时间 & \multicolumn{1}{|c|}{ 面积 } & \multicolumn{1}{c|}{ 高度 } & \multicolumn{1}{c|}{ 浓度 } & 浓度单位 & 标记 & 化合物名 \\
\hline 1 & 3.919 & 1112 & 257 & 0.009 & & $\mathrm{M}$ & \\
\hline 2 & 4.378 & 325 & 75 & 0.003 & & $\mathrm{M}$ & \\
\hline 3 & 4.475 & -393 & -8 & -0.003 & & $\mathrm{M}$ & \\
\hline 4 & 6.125 & 6353 & 548 & 0.052 & & & \\
\hline 5 & 6.597 & 18403 & 1238 & 0.151 & & $\mathrm{~V}$ & \\
\hline 6 & 7.099 & 9896 & 731 & 0.081 & & $\mathrm{~V}$ & \\
\hline 7 & 10.876 & 12143214 & 135451 & 99.707 & & & \\
\hline 总计 & & 12178910 & 138292 & & & & \\
\hline
\end{tabular}

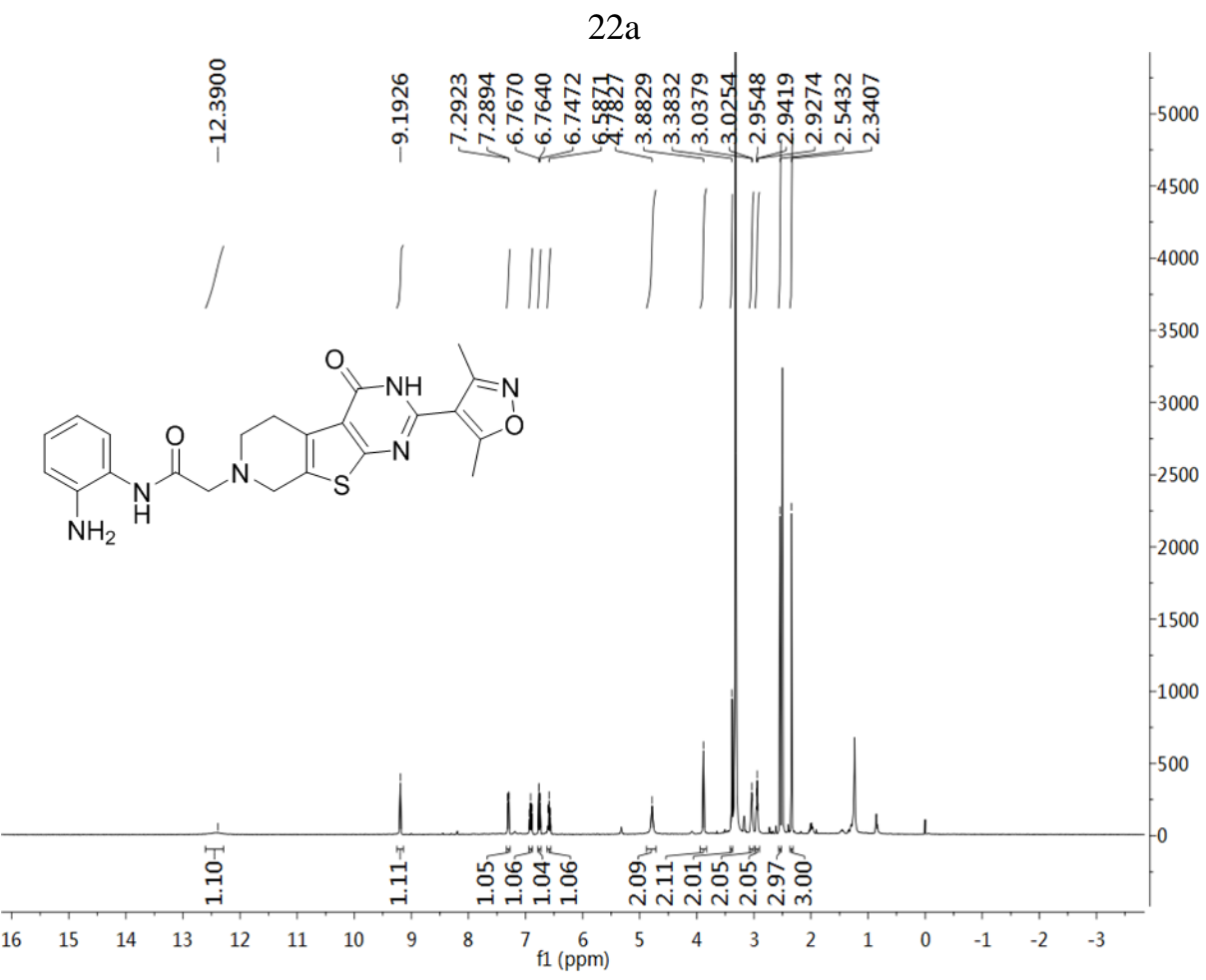




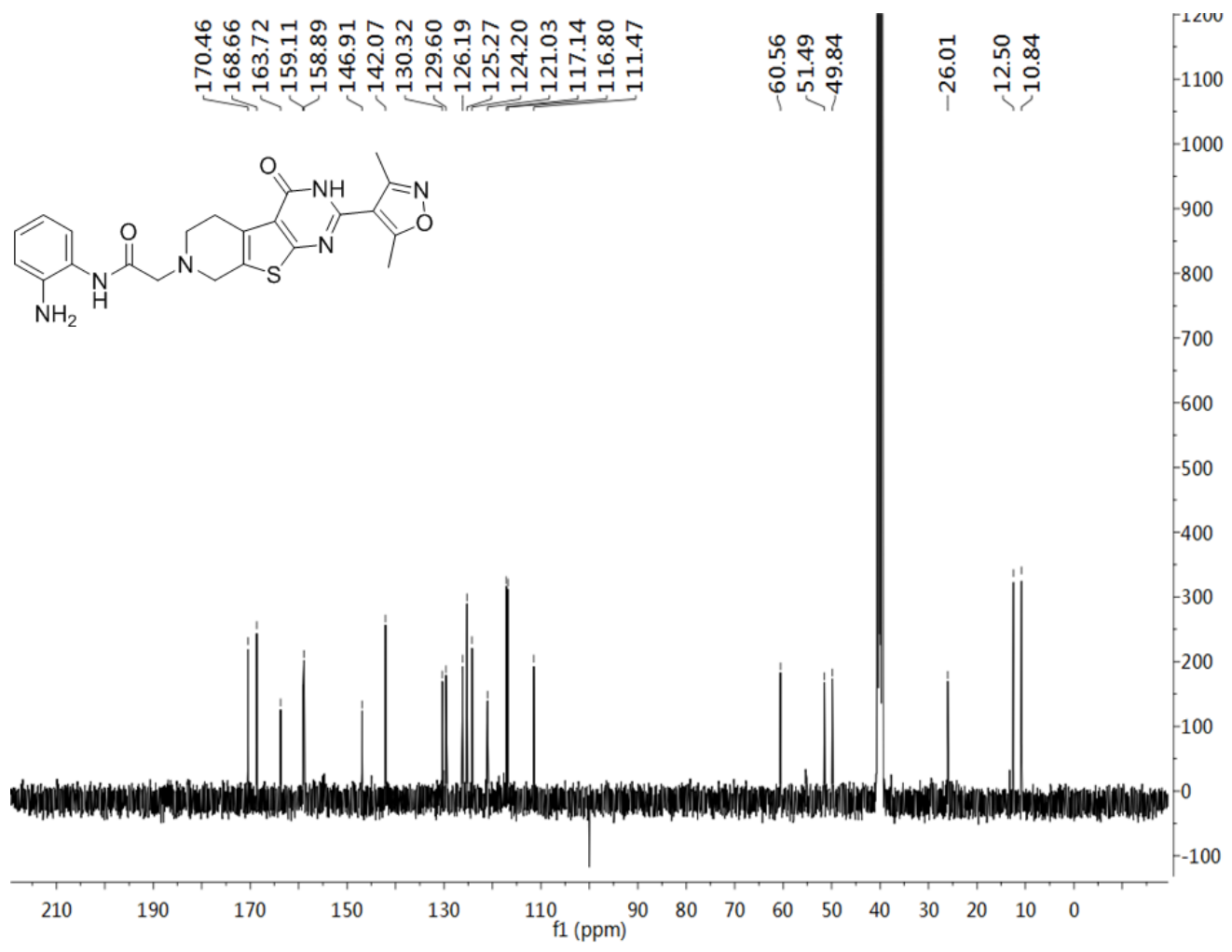

HPLC

Methanol/water $(\mathrm{v} / \mathrm{v})=70: 30,1 \mathrm{ml} / \mathrm{min}$ $\mathrm{mAU}$

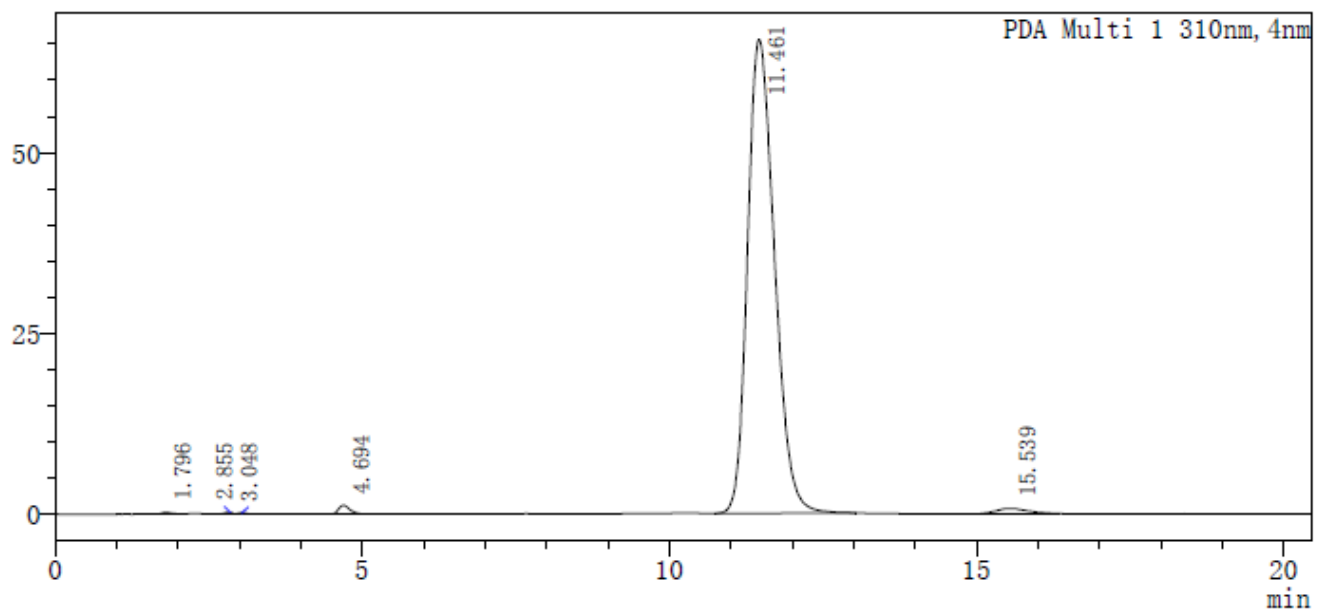

〈峰表〉

PDA Ch1 310nm

\begin{tabular}{|r|r|r|r|r|r|r|l|}
\hline \multicolumn{1}{|r|}{ 峰号 } & 保留时间 & \multicolumn{1}{|c|}{ 面积 } & \multicolumn{1}{c|}{ 高度 } & \multicolumn{1}{c|}{ 浓度 } & 浓度单位 & 标记 & 化合物名 \\
\hline 1 & 1.796 & 2278 & 249 & 0.111 & & & \\
\hline 2 & 2.855 & 1853 & 233 & 0.091 & & & \\
\hline 3 & 3.048 & 1554 & 176 & 0.076 & & $\mathrm{~V}$ & \\
\hline 4 & 4.694 & 15223 & 1221 & 0.744 & & & \\
\hline 5 & 11.461 & 2000472 & 65485 & 97.817 & & & \\
\hline 6 & 15.539 & 23744 & 700 & 1.161 & & & \\
\hline 总计 & & 2045124 & 68063 & & & & \\
\hline
\end{tabular}



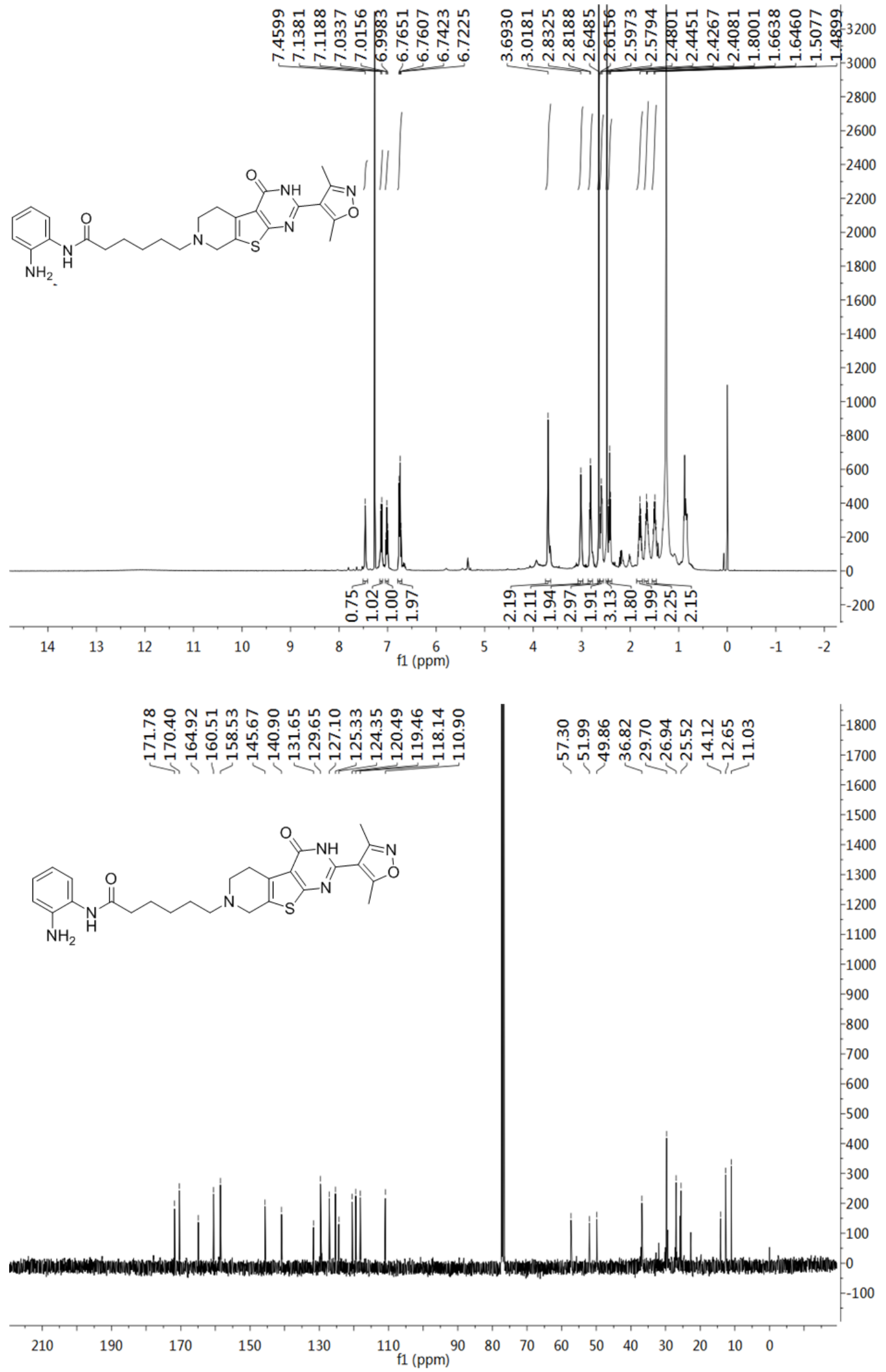
HPLC

Methanol $/$ water $(\mathrm{v} / \mathrm{v})=70: 30,1 \mathrm{ml} / \mathrm{min}$

$\mathrm{mAU}$

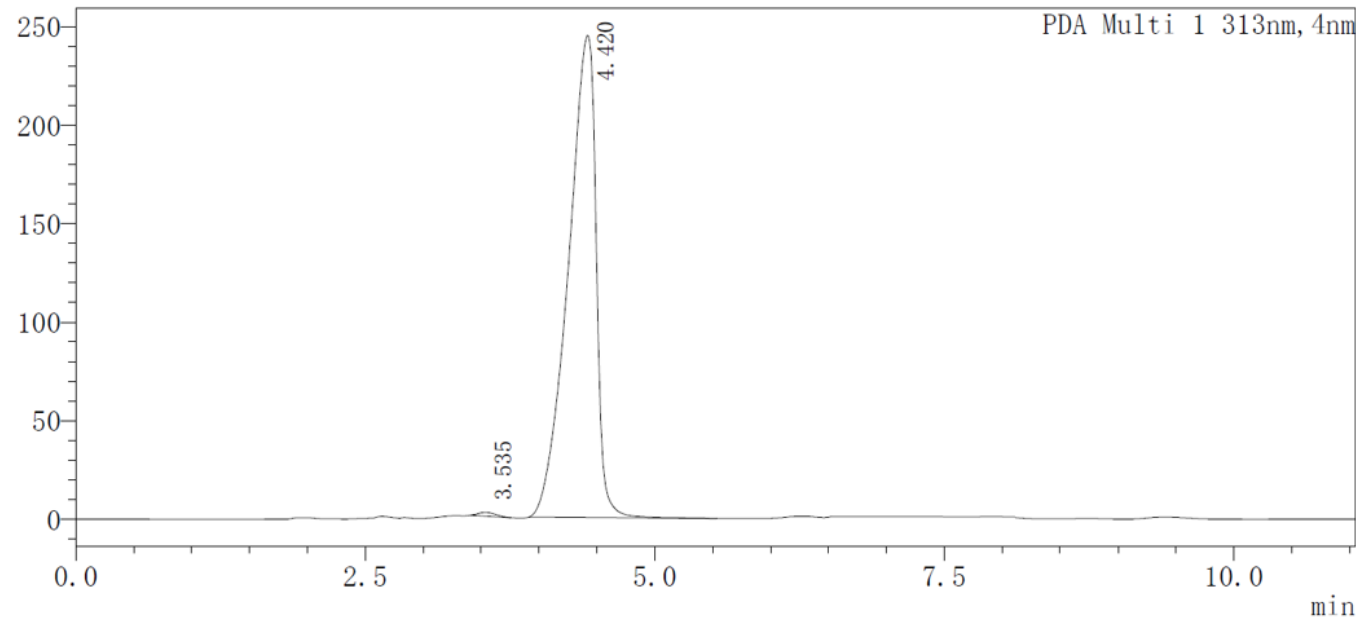

〈峰表〉

PDA Ch1 313nm

\begin{tabular}{|r|r|r|r|r|r|r|r|}
\hline \\
\hline 1 & 3.535 & 19353 & 1841 & \multicolumn{1}{c|}{ 浓度 } & 浓度单位 & 标记 & 化合物名 \\
\hline 2 & 4.420 & 4091958 & 244575 & 99.529 & & $\mathrm{M}$ & \\
\hline 总计 & & 4111311 & 246416 & & & $\mathrm{M}$ & \\
\hline
\end{tabular}

